\author{
UNIVERSIDADE DE SÃO PAULO \\ FACULDADE DE ODONTOLOGIA DE BAURU
}

FRANCISCO JULIHERME PIRES DE ANDRADE

Avaliação do Limiar de Dor a Pressão (LDP) e capacidade mastigatória de pacientes obesos com indicação para cirurgia bariátrica 
FRANCISCO JULIHERME PIRES DE ANDRADE

\section{Avaliação do Limiar de Dor a Pressão (LDP) e capacidade mastigatória de pacientes obesos com indicação para cirurgia bariátrica}

Dissertação apresentada a Faculdade de Odontologia de Bauru da Universidade de São Paulo para obtenção do título de mestre em Ciências Odontológicas Aplicadas.

Área de concentração: Odontologia em Saúde Coletiva

Orientadora: Prof ${ }^{\mathrm{a}}$. $\mathrm{Dr}^{\mathrm{a}}$ Silvia Helena de Carvalho Sales Peres

Versão corrigida 


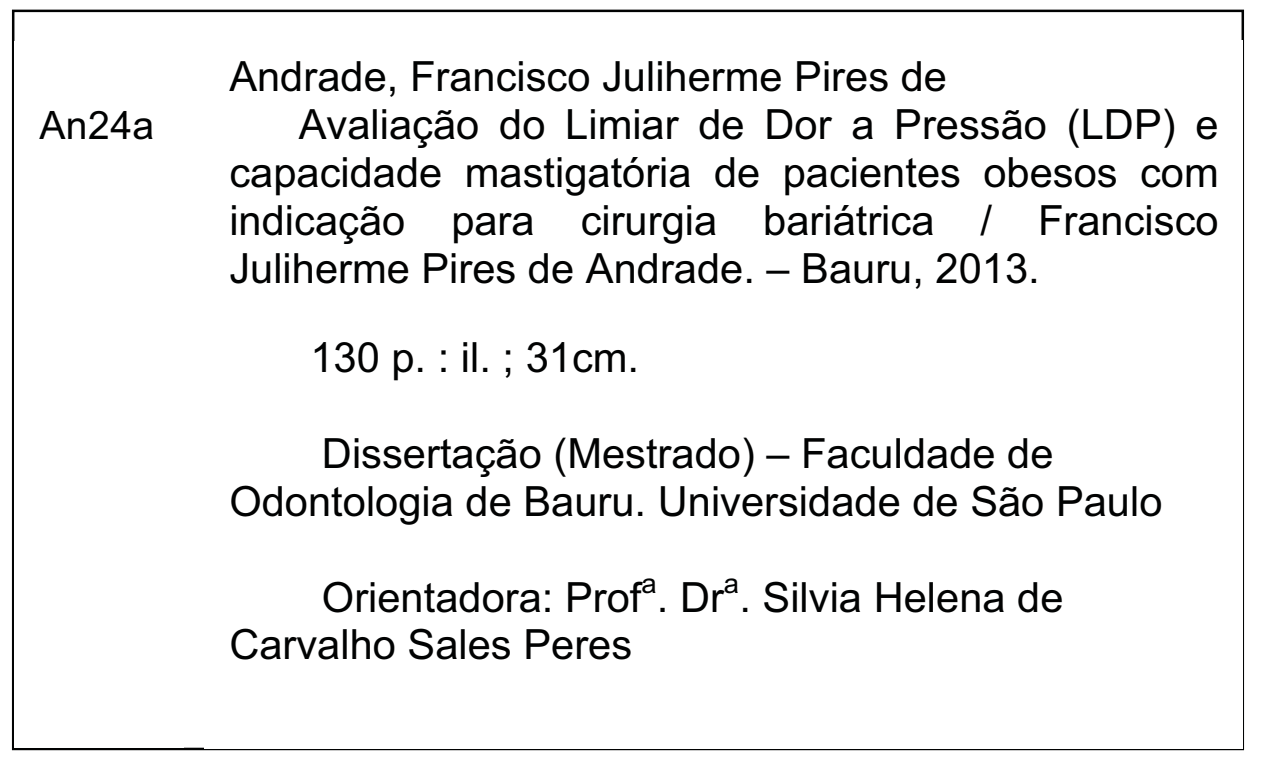

Nota: A versão original desta dissertação/tese encontra-se disponível no Serviço de Biblioteca e Documentação da Faculdade de Odontologia de Bauru - FOB/USP.

Autorizo, exclusivamente para fins acadêmicos e científicos, a reprodução total ou parcial desta dissertação/tese, por processos fotocopiadores e outros meios eletrônicos.

Assinatura:

Data:

Comitê de Ética da FOB-USP

Protocolo n': 014/2011

Data: $30 / 3 / 2011$

Comitê de Ética do HAC

Protocolo $\mathrm{n}^{\mathrm{0}}$ : $111 / 2011$

Data: $17 / 11 / 2011$ 


\section{DEDICATÓRIA}

Aos meus pais, Antonio e llcélia, que sempre acreditaram no meu potencial e nunca desistiram de mim! Com eles, aprendi que o maior bem que se pode ter é a educação. A eles dedico essa vitória.

A minha noiva e companheira Catarina, pelo amor, incentivo e amizade que me fez concluir esse trabalho.

Aos meus irmãos, Julieth, Jonathan, Jonas e Arthur, por serem minha motivação, como primogênito tenho dever de dar exemplos e espero que esse trabalho sirva como espelho para eles, fazendo com que busquem sempre crescer como pessoa e como profissionais.

Aos Tios e primos que me acolheram durante minha vida escolar e acadêmica, este é o fruto de fases preguessas.

Aos meus avós,Luiz Ricardo de Andrade (in memorian) e João Pires de Almeida (in memorian) que não estão mais entre nós fisicamente, mas tenho certeza que estão felizes pela formação do primeiro mestre na família.

Aos amigos que entederam minha ausência para o desenvolvimento deste trabalho.

Aos mestres pelos ensinamentos, atenção e amizade. 


\section{AGRADECIMENTOS}

Agradeço, em especial, a Prof $^{a}$ Dr $^{a}$ Silvia Helena de Carvalho Sales Peres, por tudo que me ensinou, por todo o apoio que sempre me deu e pela confiança depositada em mim para a realização desta pesquisa. Cada dia de convivência só aumentou a minha admiração e respeito pela sua pessoa e pelo seu trabalho. Muito obrigado por sua dedicação a mim e pela amizade. 


\section{AGRADECIMENTOS}

À Deus, pelo dom da vida, por gozar de plena saúde, pela paz no meu dia a dia, pelos livramentos, pela família unida e do bem que tenho, pela companheira especial que colocou na minha vida, só tenho verdadeiramente a agradecer por tudo que sou hoje. Muito Obrigado.

À Família, em especial a meus pais (Antonio e Ilcelia) e irmãos (Julieth, Jonathan, Jonas e Arthur). Espero um dia poder retribuir todo o carinho e dedicação que vocês têem comigo. Sem vocês por trás, me dando opoio, um ouvido e palavras amigas tudo isso seria muito difícil! Amo muito vocês.

A minha noiva Catarina, mulher especial de muita fibra e personalidade. Aprendi que desistir jamais! Sua força interna contradiz sua delicadeza exterior. Ao meu amor, muito obrigado. Amo você.

À tia Célia e Palitot (Tio Nino) e ao Tio Deca e Tia Fátima, por terem me "adotado" como filho e me tratado sempre com muito cuidado e carinho.

Aos amigos e primos Kleber, Geyson e Grace, Marcelo, Gozaga, Marciel e Adriana, que dividiram seu lar comigo, sempre me tratando com muito carinhos e respeito. Meus sinceros agradecimentos.

Ao Prof. Dr. Arsenio Sales Peres por sempre abrir meus olhos para as oportunidades na vida. Lembro do dia que fui até sua sala, no dia de aconselhamento profissional da especialização e ele me perguntar o que eu queria 
fazer da minha vida depois que acabasse a especialização. Esse trabalho nasceu daquela conversa. Muito obrigado!

Ao Prof. Dr. Paulo César Rodrigues Conti, por acreditar no trabalho e na competência da equipe em desenvolvê-lo. Agradeço a atenção e colaboração.

Aos amigos da turma de doutorado e mestrado, Juliane, Marcos Capelari, Bruno, Adriana, Suzana, Águeda, Joselene e Rafaela pela paciência nos dias estressantes e por compartilhar o conhecimento e suas experiências.

Aos amigos especiais, Soraia e Rafael, Dona Rose e "Vó", Gabriel e Ana, Priscila, Gabriela e Nádia minha segunda turma de mestrado! Pelos momentos especiais e divertidos que passamos juntos além das viagens "adventures" que vivemos!

Aos mestres que me ajudaram a desenvolver profissionalmente, $\operatorname{Prof}^{\mathrm{a}} \operatorname{Dr}^{\mathrm{a}}$ Raquel Gomes minha orientadora da graduação, ao Prof Dr. Ricardo Beltrão pelo incentivo e conselhos profissionais, ao Prof Dr. Wellington Bonachela pelos ensinamentos de clínica e de vida.

A faculdade de Odontologia de Bauru, através da pessoa de seu diretor Prof. Dr. José Carlos Pereira, pelo apoio e oportunidade de mais uma conquista nesta casa.

A todos os professores do departamento de Saúde Coletiva pelo carinho e conhecimento transmitido. 
Ao Dr. Celso e ao Dr. Eduardo e sua equipe, pelo apoio fundamental ao desenvolvimento desta pesquisa.

Aos Funcionários da Faculdade de Odontologia de Bauru, principalmente à Rosa ("Rosinha"), Silvia, Marta, Reivanildo, Alcides, pela convivência, amizade e ajuda em tudo o que precisei.

À FAPESP pelo apoio financeiro para a realização desta pesquisa. 
"Julgue seu sucesso pelas coisas que você teve que renunciar para conseguir." 


\section{RESUMO}

\section{Avaliação do Limiar de Dor a Pressão (LDP) e capacidade mastigatória de pacientes obesos com indicação para cirurgia bariátrica}

Este estudo transversal teve como objetivo avaliar o Limiar de Dor a Pressão (LDP) e a capacidade mastigatória de pacientes obesos com indicação para cirurgia bariátrica. Foi composto por 90 pacientes, sendo 60 com perda de elementos dentários que indiquem reabilitação oral (grupo experimental-GE) e 30 totalmente dentados (grupo controle-GC). A coleta de dados foi realizada em dois períodos para o grupo experimental, antes e após a confecção da prótese segundo sua indicação. Já no grupo controle a coleta foi realizada em tempo único. A coleta compreendeu os teste de Limiar de dor a pressão (LDP), escala de análise visual (EAV) para sensação dolorosa, teste de fadiga muscular, capacidade e eficiência mastigatórias e análise da qualidade de vida por meio do Oral Health Impact Profile (OHIP-14). Após verificada a normalidade das variáveis, o teste t de Student foi utilizado para avaliar as diferenças entre os grupos de dentados e desdentados e para avaliação do inicial para o final do grupo experimental. Para avaliar as diferenças entre os períodos dos testes de fadiga mastigatória foi realizada ANOVA para medidas repetidas seguida pelo teste de Tukey. O LDP conservou-se com características de normalidade antes e após a instalação da prótese dentária, apesar da redução do limiar para alguns grupos musculares. Ao se comparar ao grupo controle não houve distinções, com exceção do músculo masseter $(p=0,012)$. Apesar de não haver queixa de dor a EAV obteve uma redução estatística $(p=0,000)$ após a instalação da prótese para o GE, se tornando ainda mais reduzida. $O$ teste de fadiga mastigatória se apresentou similar entre os grupos, entretanto, o LDP e a EAV no decorrer do teste indicaram modificações entre os tempos, porém os aspectos de normalidade foram mantidos. A capacidade e eficiência mastigatória do GE evoluiu após o tratamento protético $(p=0,000)$, embora o grupo controle (dentados) continuasse superior $(p=0,000)$. A análise do OHIP, para ambos os grupos, demonstou que a condição bucal desses pacientes não interfere em sua qualidade de vida. Concluiuse que a análise do limiar de dor a pressão demonstrou que a condição dentária, presença ou ausência de dentes, em pacientes obesos mórbidos obteve níveis considerados normais para pacientes assintomáticos para dor orofacial. A 
capacidade e eficiência mastigatória apresentaram uma melhora significativa após a reabilitação oral, entretanto, não atingiram níveis semelhantes ao do grupo controle. Os pacientes obesos mórbidos indicados à cirurgia bariátrica devem ser submetidos ao tratamento odontológico, especialmente à reabilitação oral, antes e após a cirurgia, colaborando com a nova condição sistêmica do paciente.

Palavras-chave: Prótese Dentária. Obesidade. Cirurgia Bariátrica. 


\section{ABSTRACT \\ Evaluation of Pressure Pain Threshold (LDP) and masticatory capacity of obese patients referred for bariatric surgery}

This cross-sectional study aimed to evaluate the Pain Threshold Pressure (PTP) and masticatory capacity of obese patients referred for bariatric surgery. It was composed of 90 patients, 60 with tooth loss indicating oral rehabilitation (EG-experimental group) and 30 fully dentate (control group-CG. Data collection was conducted in two periods for the experimental group before and after the making of the prosthesis according to his statement. In the control group, the collection was performed in one time. The collection comprised the test pressure pain threshold (PTP), visual analysis scale (VAS) for pain sensation, muscle fatigue test, ability and masticatory efficiency and analysis of quality of life using the Oral Health Impact Profile (OHIP -14). After verified the normality of the variables, the Student's $t$ test was used to assess differences between the groups of toothed and toothless and for evaluating the initial to the end of the experimental group. To evaluate the differences between the periods of masticatory fatigue testing was performed ANOVA for repeated measures followed by the Tukey test. The PTP kept up with normal characteristics before and after installation of dental prosthesis, despite the lowering of the threshold for some muscle groups. Comparied to the control group there were no distinctions, except the masseter $(p=0.012)$. Although there was no complaint of pain VAS scores a statistical reduction $(p=0.000)$ after installation of the prosthesis for $G E$, becoming even smaller. The masticatory fatigue test appeared similar between groups, however, the PTP and the VAS during the test indicated changes between times, but aspects of normality were kept. The ability and masticatory efficiency of GE evolved after prosthetic treatment $(p=0.000)$, although the control group (toothed) remained higher $(p=0.000)$. The analysis of OHIP, for both groups, showed that oral condition of these patients does not interfere with their quality of life. It was concluded that the analysis of the pressure pain threshold showed that the dental status, presence or absence of teeth, in morbidly obese patients achieved normal levels for asymptomatic patients for orofacial pain. The ability and masticatory efficiency showed a significant improvement after oral rehabilitation, however, did not reach levels similar to the control group. The morbidly obese patients referred for bariatric 
surgery should undergo dental treatment, especially oral rehabilitation before and after surgery, collaborating with the new systemic condition of the patient.

Keywords: Dental Prosthesis . Obesity. Bariatric Surgery. 


\section{LISTA DE ILUSTRAÇÕES}

\section{- FIGURAS}

Figura 1 - Esquema da técnica Mista desenvolvida por FobiCapella.

Figura 2 - Algômetro $\operatorname{KRATOS}^{\circledR}$ utilizado para 0 exame de palpação

Figura 3 - Ponta circular chata que entra em contato com a pele do paciente ( $1 \mathrm{~cm}^{2}$ de diâmetro)

Figura 4 - Acionamento, pelo paciente, do dispositivo que registra o LDP

Figura 5 - Palpação realizada no músculo Temporal Médio Direito

Figura 6 - Palpação realizada no Masséter direito 53

Figura 7 - Escala de Análise Visual.

Figura 8 - Forma de resina acrílica autopolimerizável para produção do alimento-teste de Optosil quadrado desenvolvido pelo autor

Figura 9 - Dimensões do alimento-teste de Optosil quadrado

Figura 10- Balança de precisão A\&D 003ND.

Figura 11- Potes e plásticos para armazenamento do alimento teste pesado.

Figura 12- Sistema de tamises (granulação em $\mathrm{mm}$ ) para fracionar o alimento-teste após a mastigação

Figura 13- Produção do alimento teste a base de silicona de condensação, no formato quadrado através de molde fabricado pelo autor e sua pesagem para padronização e armazenagem em pote de plástico. 
Figura 14- Secagem do material colhido no teste de eficiência mastigatória em filtro de papel (Pré pesado) na estufa a $37^{\circ} \mathrm{C}$ por $48 \mathrm{~h}$. Após secagem o material e o filtro é novamente pesado e se tem 0 peso total recolhido até o momento (Peso do filtro - Peso total $=$ peso da amostra).

Figura 15- Peso Total da amostra a ser peneirada (Peso do pote de plástico - Peso Total $=$ peso do material a ser peneirado). 58

Figura 16- Sistema de tamises.

Figura 17- Material recolhido após a mastigação do alimento teste nos tempos $10, \quad 20 \quad 40 \quad$ e $\quad 40$ segundos 59 respectivamente

- QUADROS

Quadro 1- Classificação OHIP-14

\section{- GRÁFICOS}

Gráfico 1- Limiar de dor a pressão em relação ao tempo no teste de fadiga mastigatória para o músculo masséter.

Gráfico 2- Limiar de dor a pressão em relação ao tempo no teste de fadiga mastigatória para o músculo temporal anterior.

Gráfico 3- Limiar de dor a pressão em relação ao tempo no teste de fadiga mastigatória para o músculo temporal médio. 


\section{LISTA DE TABELAS}

Tabela 1- Classificação das cirurgias segundo as

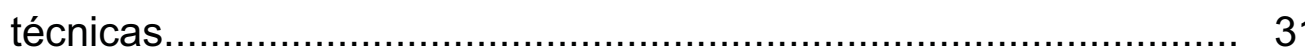

Tabela 2- Limiar de Dor a Pressão (LDP) com diferença significativa nos tempos inicial e final para os músculos da mastigação para o grupo experimental do lado direito $e$

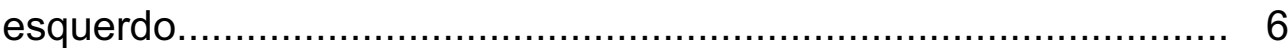

Tabela 3- Média do Limiar de Dor a Pressão (LDP) com diferença significativa nos tempos inicial e final para os músculos da mastigação para o grupo experimental do lado direito e esquerdo

Tabela 4- Comparação do Limiar de Dor a Pressão após reabilitação oral com o LDP do grupo controle para o músculo masseter.

Tabela 5- Escala de Análise Visual do grupo experimental

Tabela 6- Comparação da EAV do grupo experimental após reabilitação oral com o grupo controle

Tabela 7- Análise comparativa entre os GE e GC e nos tempos do teste de fadiga mastigatória para o grupo muscular já descrito

Tabela 8- Teste de Tukey para determinar as diferenças entre os tempos no GE

Tabela 9- Teste de Tukey para determinar as diferenças entre os tempos GC

Tabela 10- Eficiência Mastigatória antes e após a reabilitação oral da amostra do grupo experimental

Tabela 11- Comparação da Eficiência Mastigatória do grupo experimental após reabilitação $\quad$ oral com $\quad 0$ grupo controle.

Tabela 12- Disposição das médias das dimensões avaliadas pelo OHIP segundo os grupos. 
Tabela 13- OHIP do grupo experimental em comparação com o grupo controle.

Tabela 14- Número de dentes perdidos por arcada...................................................................... 73

Tabela 15- Abertura Bucal do grupo experimental antes e após a instalação da prótese dentária.

Tabela 16- Comparação da Abertura Bucal do grupo experimental após $\begin{array}{llll}\text { reabilitação } & \text { oral } & \text { com } & \text { grupo }\end{array}$ controle 


\section{LISTA DE ABREVIATURA E SIGLAS}

\begin{tabular}{|c|c|}
\hline IMC & Índice de Massa Corpórea \\
\hline OMS & Organização Mundial de Saúde \\
\hline IBGE & Instituto Brasileiro de Geografia e Estatística \\
\hline POF & Significante \\
\hline OR & Odds Ratio \\
\hline IC & Intervalo de confiança \\
\hline LDP & Limiar de Dor a Pressão \\
\hline EAV & Escala de Análise Visual \\
\hline OHIP & Oral Health Impact Proflile \\
\hline SISNEP & Sistema Nacional de Ética em Pesquisa \\
\hline CAAE & Certificado de Apresentação para Apreciação Ética \\
\hline DRS & Direção Regional de Saúde \\
\hline HAC & Hospital Amaral Carvalho \\
\hline GE & Grupo Experimental \\
\hline GC & Grupo Controle \\
\hline T1 & Tempo inicial de coleta de dados \\
\hline T2 & Tempo final de coleta de dados \\
\hline PPR & Prótese Parcial Removível \\
\hline PT & Prótese Total \\
\hline $\mathrm{Kg}$ & Kilograma \\
\hline Kgf & Kilograma Força \\
\hline $\mathrm{CM}$ & Capacidade Mastigatória \\
\hline $\mathrm{mm}$ & Milímetros \\
\hline g & Grama \\
\hline FOB & Faculdade de Odontologia de Bauru \\
\hline USP & Universidade de São Paulo \\
\hline h & Hora \\
\hline $\min$ & Minuto \\
\hline Em & Eficiência mastigatória \\
\hline
\end{tabular}




\section{SUMÁRIO}

1 INTRODUÇÃO 25

2 REVISÃO DE LITERATURA 29

$\begin{array}{lll}2.1 & \text { OBESIDADE } & 29\end{array}$

2.2 CIRURGIA BARIÁTRICA 30

2.3 OBESIDADE E SAÚDE BUCAL 33

2.4 PERDA DENTÁRIA E OBESIDADE 34

2.5 PRÓTESE DENTÁRIA E MASTIGAÇÃO 37

3 PROPOSIÇÃO 43

$4 \quad$ MATERIAL E MÉTODOS $\quad 47$

4.1 ASPECTOS ÉTICOS $\quad 47$

4.2 COMPOSIÇÃO DA AMOSTRA 47

4.3 CRITÉRIOS DE EXCLUSÃO PARA O GRUPO EXPERIMENTAL 47

4.4 CRITÉRIOS DE EXCLUSÃO PARA O GRUPO CONTROLE 48

4.5 DELINEAMENTO DO ESTUDO 48

$\begin{array}{lll}4.5 .1 & \text { Calibração do examinador } & 48\end{array}$

$\begin{array}{lll}4.5 .2 & \text { Estudo piloto } & 48\end{array}$

4.5.3 Tempos para coleta de dados 48

4.5.4 Exame intra-oral 49

4.5.5 Exame extra-oral 49

4.5.6 Exame de Palpação - Limiar de Dor a Pressão (LDP) 50

4.5.7 Escala de Análise Visual (EAV) 53

4.5.8 Teste de Fadiga Muscular: Algometria (Limiar de Dor à Pressão 54

4.5.9 Capacidade Mastigatória $\quad 55$

4.5.10 Eficiência Mastigatória $\quad 55$

$\begin{array}{ll}\text { 4.5.11 Qualidade de Vida } & 60\end{array}$

4.6 FORMA DE ANÁLISE DOS RESULTADOS 61

5 RESULTADOS 65

5.1 LIMIAR DE DOR A PRESSÃO (LDP) 65

5.2 ESCALA DE ANÁLISE VISUAL (EAV) 66

$\begin{array}{lll}5.3 & \text { FADIGA MASTIGATÓRIA } & 67\end{array}$ 
5.4 EAV PARA O TESTE DE FADIGA MASTIGATÓRIA 70

5.5 CAPACIDADE MASTIGATÓRIA 71

5.6 EFICIÊNCIA MASTIGATÓRIA

5.7 ORAL HEALTH IMPACT PROFILE (OHIP-14) 72

5.8 PERDAS DE ELEMENTOS DENTÁRIOS POR ARCADA 73

5.9 ABERTURA BUCAL 74

6 DISCUSSÃO 83

7 CONCLUSÕES 97

REFERÊNCIAS 101

APÊNDICES 115

$\begin{array}{ll}\text { ANEXOS } & 129\end{array}$ 

1 Introdução

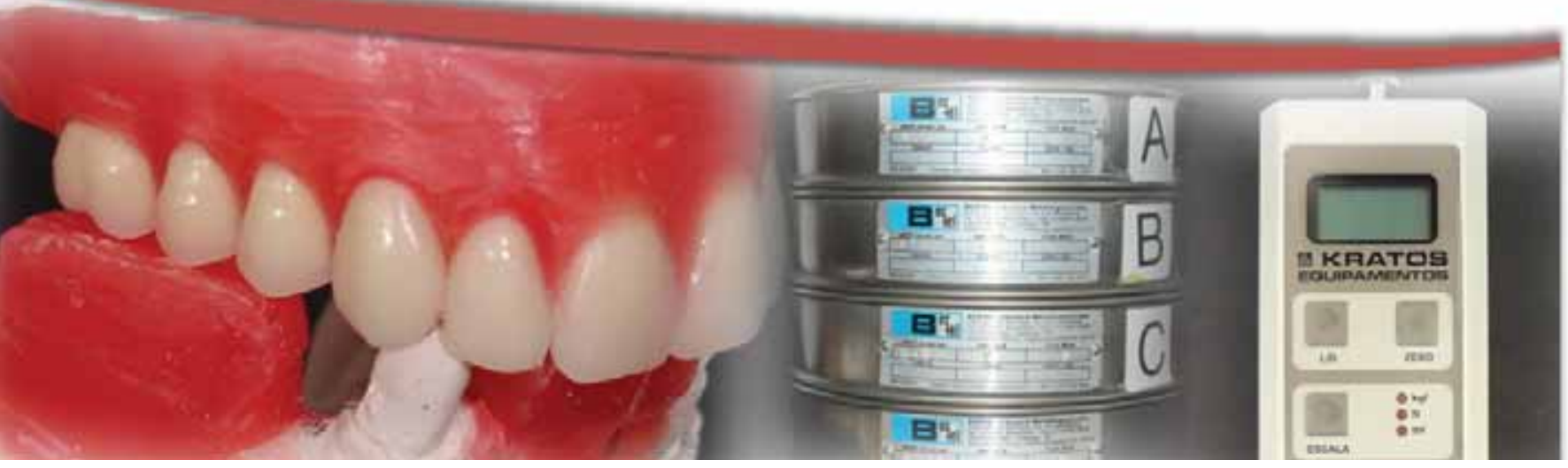



1 INTRODUÇÃO

A obesidade é uma doença crônica que atingiu proporções pandêmicas. Tal condição vem sendo reconhecida como um dos principais desafios de saúde pública enfrentados nos países desenvolvidos e em desenvolvimento (MATHUS-VLIEGEN, 2007), sendo relacionados com importantes problemas socioeconômicos (WHO, 2000). Estima-se que mais da metade da população européia esteja com sobrepeso

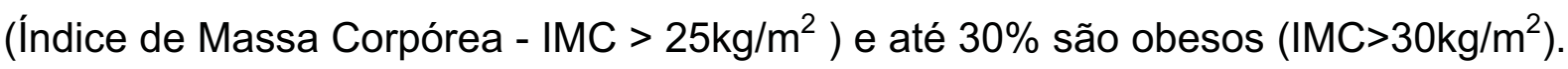
Nos EUA, essa estimativa envolve $64 \%$ da população que se encontra com sobrepeso ou obesidade. No Brasil, a prevalência da obesidade tem aumentado significantemente e estima-se que 38,8 milhões $(40,6 \%)$ de adultos estejam acima do peso (WANG et al., 2007; BARRETO et al., 2004).

Os países em desenvolvimento têm vivenciado a transição nutricional, coexistindo a desnutrição e a obesidade. As implicações dessa situação para a saúde das populações são desastrosas, associando-se a enormes custos econômicos e sociais, visto que a obesidade interfere na qualidade de vida e é uma das responsáveis pela redução na expectativa de duração da vida (FERREIRA, MAGALHÃES, 2011; MONDINI, MONTEIRO, 1998; MONTEIRO et al., 2004; SUTER et al., 2003).

Mathus-Vliegen et al. (2007) acrescentaram que a odontologia tem sua parcela de contribuição na etiologia da obesidade, em se tratando dos diversos problemas bucais, como cárie dentária, doença periodontal, alteração do fluxo salivar, e principalmente a perda de elementos dentários, que podem influenciar no processo de ganho de peso (MOURA-GREC et al., 2012).

Estudos demonstraram que a falta de dentes traz prejuízos consideráveis ao bem estar, uma vez que interfere negativamente na função mastigatória, criando dificuldades para a ingestão de alimentos ricos em nutrientes (TSAKOS et al.,2010; DINSA et al.,2012). A alimentação pobre em nutrientes, por sua vez, pode promover alterações e/ou doenças sistêmicas no indivíduo, comprometendo a saúde deste. Além dos agravos à saúde física do indivíduo, o edentumismo parcial ou total acarreta alterações estéticas e experiências psicológicas negativas, que levam ao desconforto emocional e a perdas econômicas (NOWJACK-RAYMER et al., 1997).

Em uma revisão de literatura evidenciou-se as consequências deletérias da perda dentária sobre a nutrição. Os autores constataram que o consumo de carnes, 
frutas frescas e vegetais por indivíduos totalmente e parcialmente edêntulos é reduzido, tendo em vista que estes dão preferência a uma dieta pastosa, rica em carboidratos, que pode promover carência nutricional ou obesidade (GEISSLER e BATES, 1984). Segundo o National Diet and Nutrition Survey (NDNS), conduzido por Henderson et al. $(2002,2003)$, grandes diferenças no IMC foram encontradas em indivíduos com 1 a 10 dentes e aqueles com mais de 10 dentes naturais. Pesquisas mostraram que, pacientes com menos de 21 dentes apresentaram três vezes mais riscos de tornarem-se obesos do que aqueles com 21 a 32 dentes (JANSSON, 2002).

Frente ao aumento na prevalência da obesidade e a dificuldade na redução de peso, diferentes métodos têm sido propostos para esses pacientes. Entretanto, o tratamento cirúrgico para a obesidade de grau III (cirurgia bariátrica) é o único processo capaz de eliminar o excesso de peso com mínima perda de massa muscular. Sendo proposto tal tratamento aos pacientes com índice de massa corpórea (IMC) maior que $40 \mathrm{~kg} / \mathrm{m}^{2}$ ou maior que $35 \mathrm{~kg} / \mathrm{m}^{2}$ na presença de comorbidades, como hipertensão arterial, dislipidemia, diabetes tipo 2 , apnéia do sono, entre outras. A utilização deste índice é o parâmetro adotado pela Organização Mundial de Saúde (OMS) para pesquisas populacionais (FANDIÑO et al., 2004).

A crescente realização de cirurgias para redução de peso (BUCHWALD et al.,2007; KOPELMAN, 2000; ENCINOSA et al., 2009) e para a melhora nas comorbidades, evidencia a relevância do trabalho multiprofissional na atenção à saúde do indivíduo obeso mórbido. O cirurgião dentista pode contribuir identificando os problemas bucais que mais acometem esse grupo populacional. Além de possibilitar a elaboração de estratégias de intervenção e prevenção, a fim de reduzir os possíveis agravos à saúde bucal e manter os benefícios sistêmicos alcançados com a redução do excesso de peso corporal. Em acréscimo, destaca-se que existe uma lacuna na literatura científica de estudos que abordem este tema, principalmente analisando a repercussão que o edentulismo parcial ou total causa na capacidade e função mastigatória assim como na condição muscular desses pacientes. 


\section{Revisão de Literatura}

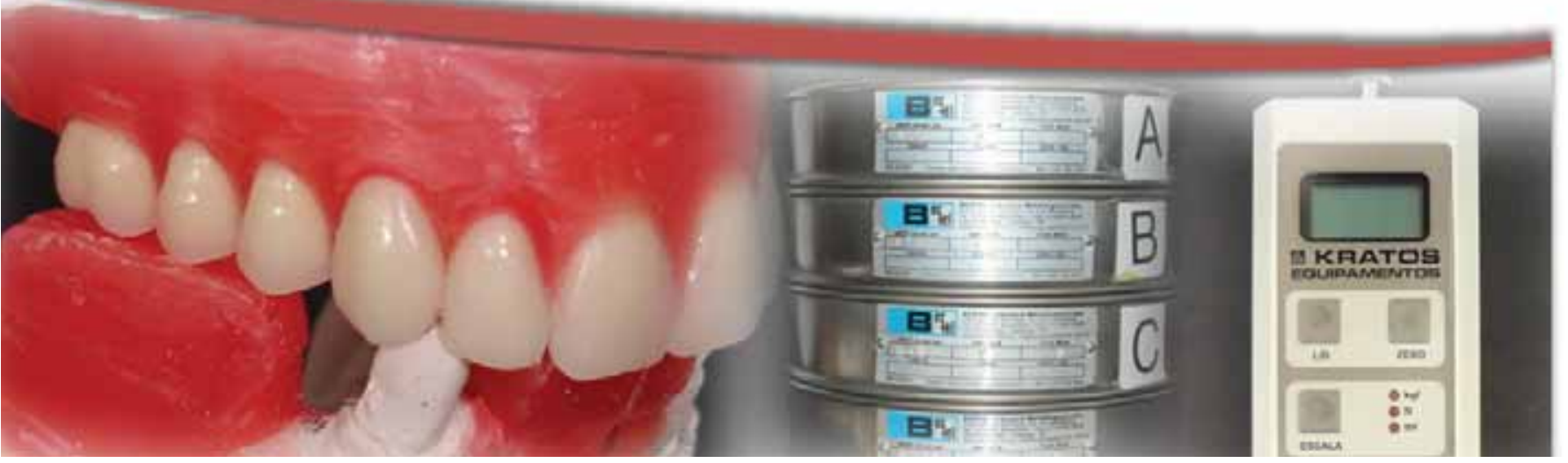





\section{REVISÃO DE LITERATURA}

\subsection{OBESIDADE}

A obesidade é uma doença crônica caracterizada pelo acúmulo excessivo de gordura corporal (WHO,2000). A Organização Mundial da Saúde adotou, após a reunião de 1997, o sistema baseado na medição do Índice de Massa Corporal (IMC) para detectar a obesidade, obtido pelo cálculo da relação entre peso corpóreo $(\mathrm{kg})$ e o quadrado da altura $\left(\mathrm{m}^{2}\right)$. IMC maior ou igual a 25 caracteriza sobrepeso e IMC maior ou igual a 30 caracteriza obesidade (grau I: situa-se entre 30 a 34,99 Kg/m2, grau II: entre 35 a 39,99 Kg/m2, e grau III: acima de $40 \mathrm{Kg} / \mathrm{m} 2)$ (WHO, 2000). A Sociedade Americana de Cirurgia Bariátrica classifica a obesidade em 6 níveis: Obesidade Pequena $(27<30 \mathrm{Kg} / \mathrm{m} 2)$, Obesidade Moderada $(30<35 \mathrm{Kg} / \mathrm{m} 2)$, Obesidade Grave $(35<40 \mathrm{Kg} / \mathrm{m} 2)$, Obesidade Mórbida $(40<50 \mathrm{Kg} / \mathrm{m} 2)$, Super Obesidade $(50<60 \mathrm{Kg} / \mathrm{m} 2)$ e Super-Super Obesidade $(\geq 60 \mathrm{Kg} / \mathrm{m} 2)$ (RENQUIST, 1998).

O crescimento da obesidade tanto em países desenvolvidos quanto em desenvolvimento foi considerado alarmante, sendo um dos problemas contemporâneos de saúde mais negligenciados em todo mundo (KOPELMAN, 2000). Há uma epidemia mundial estimada em 1,7 bilhões de pessoas com sobrepeso e obesidade e 2,5 milhões de mortes por ano atribuídas à obesidade (BUCHWALD; WILLIAMS, 2004). Nos Estados Unidos a prevalência de obesidade em adultos é de 35,5\% em mulheres e 32,2\% em homens (FLEGAL et al., 2010). Já na Europa a obesidade atinge de 10 a $20 \%$ dos homens e de 15 a $25 \%$ das mulheres, sendo que a prevalência de sobrepeso já atinge metade da população (JAMES; RIGBY; LEACH, 2004). O Instituto Brasileiro de Geografia e Estatística (IBGE) divulgou dados sobre a prevalência de excesso de peso e obesidade na população brasileira com 20 anos de idade ou mais no período de 2008/2009. Entre os homens a prevalência de excesso de peso foi de $50,1 \%$ e de obesidade $12,4 \%$. Já entre as mulheres, a proporção de excesso de peso foi de $48 \%$ e de obesidade 16,9\%. Em 30 anos a obesidade cresceu mais de quatro vezes entre os homens e mais de duas vezes entre as mulheres (IBGE, 2010).

A obesidade está associada a algumas das mais prevalentes doenças crônicas e não infecciosas na sociedade moderna. Dentre essas comorbidades 
podem-se citar diabetes mellitus tipo 2, hipertensão arterial, dislipidemia, arteriosclerose, artrite, síndrome de apnéia do sono, refluxo gastresofágico, infertilidade e incontinência urinária em mulheres, disfunções endócrinas, disfunção da vesícula biliar, problemas pulmonares, alguns tipos de câncer, doença periodontal, falta de habilidade para atividades diária, problemas psicossociais e econômicos (FRANCISCHI et al., 2000; KOPELMAN, 2000; RITCHIE, 2007).

\subsection{CIRURGIA BARIÁTRICA}

A cirurgia bariátrica é considerada o tratamento mais radical para a obesidade, porém é o único que resulta em perda de peso expressiva ( $20 \%$ a $40 \%$ do peso inicial) e mantida por, pelo menos, 15 anos, determinando melhora dos parâmetros metabólicos (CARVALHO et al., 2007). O número de cirurgias bariátricas está aumentando nos países ocidentais em decorrência do aumento na prevalência da obesidade e pelo fato de os tratamentos conservadores muitas vezes não apresentarem resultados satisfatórios (SUTER et al., 2003; VALEZl et al., 2004). A seleção de pacientes requer um tempo mínimo de 5 anos de evolução da obesidade e história de falência do tratamento convencional orientado por profissionais qualificados (FANDIÑO et al., 2004).

$\mathrm{O}$ tratamento cirúrgico pode ser proposto para os pacientes com IMC maior que $40 \mathrm{~kg} / \mathrm{m} 2$ ou com IMC maior que $35 \mathrm{~kg} / \mathrm{m} 2$ com comorbidades (hipertensão arterial, dislipidemia, diabetes tipo 2, apnéia do sono, entre outras) (FANDIÑO et al., 2004). Contra-indicações de cirurgia bariátrica relacionam-se ao risco cirúrgico alto, presença de doenças endócrinas (síndrome de Cushing, por exemplo), distúrbios psicóticos, etilismo e/ou dependência a drogas, insuficiência renal e cirrose hepática avançada. Para a seleção dos pacientes, no preparo pré-operatório e no seguimento da evolução pós-operatória, é necessária uma equipe multidisciplinar construída de cirurgião bariátrico, nutrólogo, nutricionista, psicólogo, psicoterapeuta e assistente social (FERRAZ, 2006). Recomenda-se evitar o tratamento cirúrgico para crianças e adolescentes, em pacientes com doenças incapacitantes, como a cirrose hepática, bem como em pacientes acima de 70 anos de idade (FERRAZ, 2006; SANTO; CECCONELLO, 2008). Contudo, o Ministério da Saúde Brasileiro reduziu a idade mínima para as pessoas que tem indicação para cirurgia bariátrica. A idade mínima passou de 18 para 16 anos, em casos em que há risco de morte ao paciente. A iniciativa foi tomada com base em estudos que apontam o aumento crescente da 
obesidade entre os adolescentes, como a Pesquisa de Orçamento Familiar de 2009 (POF), que verificou que na faixa de 10 a 19 anos de idade $21,7 \%$ dos brasileiros apresentam excesso de peso, em 1970, este índice estava em 3,7\%. A decisão consta da consulta pública $\mathrm{n}^{\circ} 12$, de 24 de setembro de 2012. A proposta irá substituir a atual Portaria n 492 e 493, de 31 de agosto de 2007 (CONFEDERAÇÃO NACIONAL DE SAÚDE-BRASIL, 2012).

As cirurgias são classificadas em três grupos: restritivas, disabsortivas e mistas (FANDIÑO et al., 2004) (TABELA 1).

Tabela 1- Classificação das cirurgias segundo as técnicas.

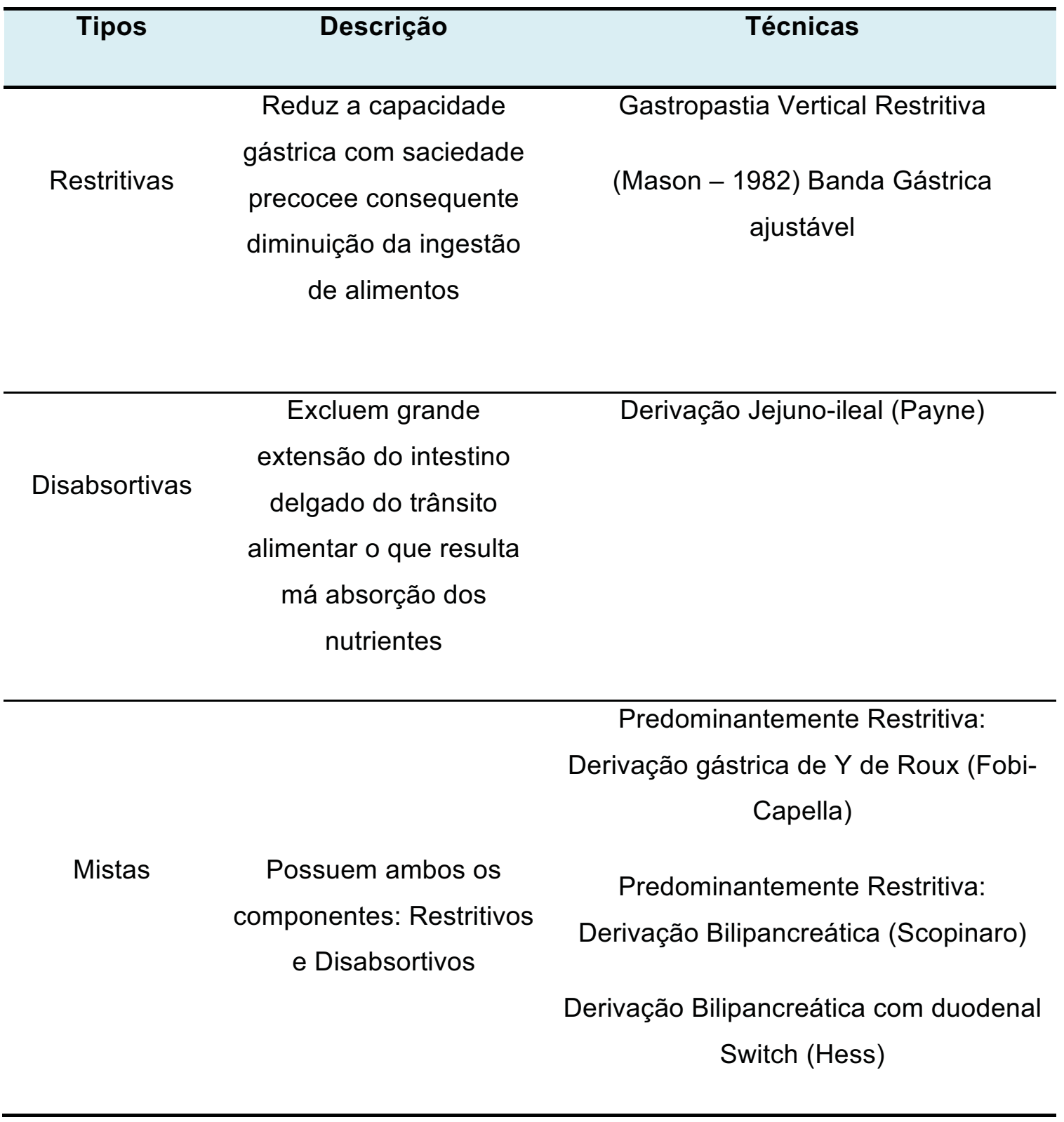

Nos últimos anos, entretanto, vem predominando a terceira técnica que reúne 
restrição e disabsorção, chamada de cirurgia de Fobi-Capella. Nesta técnica a gastroplastia está associada a uma derivação gastrojejunal em formato da letra $Y$ (chamada de $\mathrm{Y}$ de Roux). Este procedimento consiste na restrição do estômago para comportar um volume de cerca de $30 \mathrm{ml}$. O retardo de esvaziamento gástrico é obtido por anel de contenção (orifício de cerca de $1,5 \mathrm{~cm}$ ) colocado a $3 \mathrm{~cm}$ da anostomose gastrojejunal. A exclusão da maior parte do estômago e do duodeno faz com que os alimentos passem do estômago diretamente para o jejuno e a ingestão de carboidratos simples pode, assim, ocasionar a chamada síndrome de "dumping" (náuseas, vômitos, rubor, dor epigástrica, sintomas de hipoglicemia). Esta síndrome faz com que os pacientes passem a evitar a ingestão de doces e pode desempenhar algum papel na manutenção da perda de peso. Com este procedimento, os pacientes obtêm perdas médias na ordem de $35 \%$ em longo prazo. É uma técnica segura e com uma baixa morbidade (ARASAKI et al., 2005; FANDIÑO et al., 2004).

$\mathrm{Na}$ cirurgia Fobi-Capella o pequeno reservatório gástrico restringe a ingestão de alimentos e produz saciedade precoce, enquanto o desvio produz pequeno grau de má-absorção. Nesta cirurgia pode-se usar um anel de silicone ou fita de polipropileno que ajuda restrição da passagem do alimento e produz sensação de saciedade. No entanto, esse anel pode provocar efeitos adversos como vômitos (ARASAKI et al., 2005) (FIGURA 1).

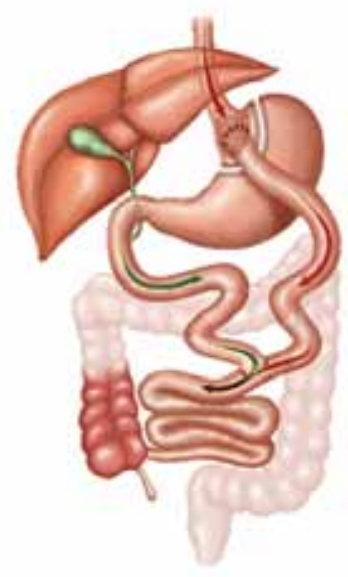

Figura1- Esquema da técnica Mista desenvolvida por Fobi-Capella.

Os resultados esperados com a derivação gastrojejunal em Y-de-Roux incluem: perda e manutenção do peso corporal e melhora das comorbidades associadas e da qualidade de vida (FANDIÑO et al., 2004; SEARS et al., 2008). Por outro lado, há diversas complicações pós-operatórias que merecem especial 
atenção como vômitos frequentes e deficiências nutricionais (ELDER; WOLFE, 2007; FANDIÑO et al., 2004; MALINOWSKI, 2006) que podem refletir tanto na saúde geral como na saúde bucal.

\subsection{OBESIDADE E SAÚDE BUCAL}

A obesidade mórbida está associada a muitos problemas de saúde, tais como desenvolvimento de diabetes mellitus, hipertensão arterial, aumento da incidência de certas formas de câncer, complicações respiratórias (apnéia obstrutiva do sono), entre outras comorbidades (MATHUS-VLIEGEN et al., 2007; KOPELMAN, 2000). A obesidade também está relacionada a vários aspectos de saúde oral, tais como a cárie periodontite, e xerostomia (MATHUS-VLIEGEN et al., 2007; SAITO et al., 2005; MARSICANO et al., 2011).

Estudos demonstraram que a doença periodontal tem sido significativamente associada à obesidade (WOOD, 2003; SAITO, 2007). Desta forma, tem sido sugerido como fator de risco agravante para esta situação o hábito do tabagismo que pode alterar dos tecidos de suporte (NISHIDA et al., 2005). Além disso, a obesidade tem sido associada à maior perda de inserção clínica e à maior profundidade de bolsa periodontal, parâmetros os quais são adotados para avaliar o estado da doença periodontal no indivíduo (MOURA-GREC et al., 2012). Chaffee (2010) em recente meta-análise revelou maior perda de inserção entre pacientes obesos, especialmente os adultos jovens, sendo mais prevalente entre as mulheres, e entre não fumantes. Estudos demonstraram que a razão de chance (Odds Ratio) de a doença periodontal estar associada à obesidade foi de 1,35 vezes (GENCO et al., 2005; PISCHON et al., 2007; YUAN, 2012).

Como consequência mutiladora decorrente da cárie dentária e doença periodontal ocorre a perda de elementos dentários. Os indivíduos obesos estão mais expostos a ter menos dentes do que os indivíduos de peso normal (MEISEL et al., 2012). Em um estudo de coorte foram acompanhados um grupo de obesos e outro de eutróficos, no qual foi demonstrado que os pacientes com maior circunferência abdominal obtiveram menor média de dentes em função $(n=19,7)$ em comparação com indivíduos de peso normal $(n=21,5)$ (YUAN,2012).

Estudos mostraram que indivíduos parcialmente ou completamente edentados que não utilizam prótese dentária são mais propensos a desenvolver obesidade (HILGERT et al.,2009). Como resultado, o edentulismo tem sido associado a uma 
elevação do risco de doenças cardiovasculares e diabetes (CLEARY,1995; LOWE et al.,2003). Tal condição pode contribuir para o consumo dietético pobre, evitando que o indivíduo busque o consumo de alimentos como como vegetais e com menos gordura saturada e colesterol, o que por sua vez podem favorecer o ganho de peso (JOHANSSON et al.,1994; TOUGER-DECKER, 2010; PALACIOS, 2009).

\subsection{PERDA DENTÁRIA E OBESIDADE}

Diretrizes internacionais sugerem que os critérios para cirurgia bariátrica deve em primeiro lugar, incluir o controle do comportamento alimentar, a fim de comer menos e mais lentamente e, em segundo lugar, um estado funcional dentário fornecendo uma adequada função mastigatória (GODLEWSKI et al., 2011). Segundo os mesmos autores, este conjunto de condições foram assumido para reduzir a prevalência de complicações fisiológicas da cirurgia bariátrica, como vômitos, diarréia, dor ou síndrome de "dumping".

Com o aumento da capacidade mastigatória diminui-se o tempo necessário com que o estômago digira as partículas de alimento para um diâmetro suficientemente pequeno para passar através do piloro (PERA et al.,2002). A mastigação também está envolvida na manutenção da correta motilidade no trato digestivo, aumentando o movimento fisiológico gástrico através da ativação da atividade do sistema nervoso parassimpático (MOMOSE et al.,1997; HASEGAWA et al., 2009). Além disso, a mastigação adequada facilita as etapas iniciais de digestão por estimular a produção de salivação e ativação dos controles cefálicos que iniciam a função de assimilação dos alimentos (MATTES,1997).

A capacidade de mastigação em pessoas com obesidade pode afetar as ligações entre nutrição e comportamento alimentar. Estudos prévios de Bellisle (1981) sobre as atitudes da alimentação demonstraram que indivíduos obesos comem mais rápido do que seus pares magros e sugeriu que a falta de estímulos orais pode estar relacionado ao metabolismo energético. Tem sido demonstrado que a baixa atividade do sistema nervoso autônomo, explica uma diminuição na resposta termogênica aos alimentos em indivíduos com obesidade mórbida (DE JONG,1997; GODLEWSKI, 2008). Com ciclos mastigatórios longos estudos mostraram que a palatabilidade da refeição teve um efeito sobre a fase cefálica de termogênese dietética e que este efeito é significativamente diminuído em indivíduos obesos quando comparados com pacientes não obesos (N'GOM,2002). Desta forma, 
pacientes com obesidade mórbida que se submeteram ou possuem indicação à cirurgia bariátrica são encorajados a mastigar lentamente, a fim de diminuir a ingestão de alimentos e otimizar o processo de digestão.

Pesquisas demonstraram que a perda dentária leva a uma função mastigatória (FM) deficiente (CHAUNCEY, et al., 1984). A área somada dos dentes, particularmente nas áreas de contacto entre os dentes superiores e inferiores, são de importância primordial na degradação do alimento e substituir dentes perdidos com próteses dentárias podem melhorar a condição mastigatória. No entanto, essa compensação não pode recuperar a eficiência de um conjunto completo de recursos naturais (SHI,1990). Assim alguma diminuição da FM, principalmente com dentaduras é inevitável (N'GOM,2002). Além da perda dentária, a disfunção das habilidades motoras da língua e falta de tonicidade dos músculos envolvidos nos movimentos de mastigação também podem reduzir a eficiência mastigatória. A língua desempenha um papel importante na captação de informação sensorial e atividade motora. Ela pode esmagar o alimento em seu lado dorsal contra o palato duro, e as partículas de classificação que estão prontas para serem engolidas, são reunidas em um bolo alimentar. Essas partículas são misturadas à saliva e ajudam a limpar a boca e os dentes após as refeições (LIEDBERG,1991). Contudo, xerostomia e outras disfunções relacionadas ao fluxo de saliva podem influenciar negativamente o processo de mastigação, tornando o processo de formação do bolo alimentar incompleto (MARSICANO et al., 2012; N'GOM, 2002; LIEDBERG et al.,1991).

A natureza da relação entre a função mastigatória e a nutrição, não tem sido fatores bem definidos e apresentados na literatura. No entanto, alguns trabalhos sugerem que a FM prejudicada leva a seleção do alimento de forma inadequada (SEBRING et al.,1995; ERNEST,1993; FILLION, 1998). Nas sociedades ocidentais, onde há uma grande variedade de alimentos, aqueles indivíduos que sofrem de disfunção mastigatória podem adaptar a consistência dos alimentos à sua condição dentária. E esta adaptação resulta em um aumento do consumo de refrigerantes e alimentos pastosos e um consumo restrito de alimentos rígidos (N'GOM,2002;JOSHIPURA,1996). A escolha dos alimentos pode ser expressa em três formas diferentes. Segundo Fillion (1998) na primeira, as pessoas com deficiência da FM escolhem comer alimentos industrialmente processados e não alimentos naturais. Algumas formas do resultado do processamento industrial dos 
alimentos os tornam amolecidos e fáceis de serem consumidos. Em indivíduos com FM prejudicada, tal alimento pode favorecer a absorção de quantidades substanciais de gordura saturada e aumentar o nível de colesterol do indivíduo. Na segunda forma, os indivíduos obesos podem evitar alimentos naturais difíceis de mastigar. Essa escolha geralmente envolve a eliminação de alimentos crocantes, como vegetais crus e frutas frescas, alimentos fibrosos, como carne. Frutos vermelhos, tais como framboesas, morangos, uvas e tomates, que usuários de prótese total podem mastigar com facilidade, também podem ser evitados, pois suas sementes, muitas vezes promovem desconforto para alguns usuários de prótese, principalmente as totais. Todos estes alimentos contêm nutrientes importantes. Vegetais crus e frutas são importantes fontes de fibras e muitas vitaminas, além de minerais essenciais, enquanto a carne é uma fonte importante de proteína e ferro. Na terceira forma, as pessoas podem processar os alimentos em casa. Alguns tipos de processamento, tais como os tempos de cozedura longos, alteram o valor nutricional dos alimentos por degradar nutrientes essenciais, como vitamina $C$, tiamina e fosfatos, ocasionando uma redução da biodisponibilidade esperada destes nutrientes (FILLION,1998; YADAV et al.,1995).

Há um consenso na literatura que a digestão humana de alimentos começa na boca, com a mastigação, o que reduz o alimento para partículas menores em que a saliva exerce um fator importante nesse processo. A ação salivar, além dos processos bioquímicos, permite a deglutição sem distorção dos tecidos moles da faringe e do esôfago superior. Experiências com misturas de alimentos sólidos e líquidos em várias proporções demonstraram que a ingestão de limiar mínimo (número de ciclos mastigatórios antes de deglutir) está relacionada ao tamanho das partículas e do grau de aderência salivar (MARSICANO et al., 2012; N'GOM, 2012; CHAUNCEY,1984).

O aumento do risco para desenvolvimento da cárie e periodontite, pode levar à perda prematura de dentes em indivíduos obesos. Um estudo conduzido no Reino Unido mostrou que adultos com mais de 65 anos e com menos de 21 dentes naturais obtiveram, em média, três vezes mais chances de serem obesos do que aqueles que apresentavam de 21-32 dentes (MATHUS-VLIEGEN, 2007; SHEIHAN, 2001; SHEIHAN et al., 2002).

Outros estudos demonstram que homens e mulheres desdentados têm, em média, maior IMC e maior relação cintura-quadril do que os homens e mulheres 
dentados (JOHANSSON et al., 1994). Próteses foram encontradas com maior frequência em indivíduos com sobrepeso (OR = 1,5, IC 1,3-1,7) e obesos $(O R=2,2$, IC 1,9-2,7) em comparação com aqueles com peso normal (WOLK,1996). Diferentes estudos indicaram que quanto maior o IMC menor número de dentes (MATHUSVLIEGEN,2007).

\subsection{PRÓTESE DENTÁRIA E MASTIGAÇÃO}

O objetivo principal de uma reabilitação protética é oferecer saúde, função e estética oral para os pacientes, especialmente para aqueles que são edêntulos totais. Embora o tratamento com implantes osseointegrados seja uma comprovada solução para o edentulismo, próteses totais convencionais permanecem a única opção de tratamento para a grande maioria dos pacientes, especialmente por causa de limitações econômicas (CARLSSON, 2010).

Para alcançar o sucesso da reabilitação com próteses totais, alguns requisitos técnicos devem ser respeitados, tais como a retenção e a estabilidade. No entanto, uma prótese confeccionada com rigor técnico não é necessariamente um indicador de satisfação dos pacientes, considerando que para alguns indivíduos uma prótese em excelentes condições pode resultar em uma falha, enquanto outros estão satisfeitos com sua prótese apesar de sua má qualidade (BERG,1993; DE LUCENA et al., 2011).

Alguns fatores como estética, fala, estabilidade e conforto são freqüentemente relacionadas à expectativas dos pacientes e satisfação geral com dentaduras, mas a possibilidade de ser capaz de mastigar corretamente tem sido apontada como um fator determinante para a boa aceitação à prótese (SMITH, 2004). Indivíduos com uma função mastigatória comprometida podem adaptar-se a estas limitações, porém, deglutindo partículas maiores de alimentos ocasionando um impacto negativo sobre o processo digestivo e podendo afetar a função gastrointestinal (PERA et al., 2002).

A mastigação dos alimentos representa o passo inicial do seu processo para a digestão e absorção pelo trato digestivo. A perda de dentes se apresenta como consequência de patologias orais pregressas, resultando em um dano à função mastigatória, além de outras estruturas tais como músculos e articulações. Acreditase que entre os fatores que afetam a eficiência mastigatória encontram-se a perda sensível de área de contato oclusal e função oro motora (SIERPINSKA et al., 2006; 
HATCH et al., 2000; Van der BILT et al., 1993).

Para Hildebrandt et al. (1995) o melhor preditor de performance mastigatória sem o uso de dispositivos complexos é o número de unidades dentárias funcionais posteriores, que é posteriormente conectado com a força de mastigação. A força principal de esmagamento do alimento é localizada na região posterior dos dentes, enquanto o centro dos contatos oclusais está localizado nas primeiras regiões molares (SUDA et al., 1997). Foi sugerido que a maior força oclusal máxima esteja ligada com a maior performance mastigatória (OKIYAMA et al., 2003). Como a face oclusal, a influência da área de contato na capacidade mastigatória não é unívoca (OLTHOFF et al.,1984).

Como resultado da falta de unidades dentárias funcionais posteriores a superfície da plataforma de oclusão é consideravelmente reduzida. Além disso, a força da mordida é reduzida na mesma proporção, diminuindo assim a FM.

As forças de mastigação necessárias para a preparação do alimento na boca para uma digestão são de $6 \mathrm{~kg}$ para cada dente durante a mastigação, bem como o grau de força pode variar de acordo com as características físicas dos alimentos (YURKSTAS, 1953; SIERPINSKA et al., 2006).

Foi sugerido que a impossibilidade de cominuição do alimento duro foi melhorada por meio do prolongamento dos ciclos mastigatórios (KAYSER,1981; OOSTERHAVEN et al., 1988). Estudos demonstram que a redução acentuada do número de unidades funcionais dentárias posteriores (arco reduzido) causou uma diminuição da capacidade de mastigar. Contudo, prolongamentos dos ciclos de mastigação podem melhorar a cominuição do alimento de consistência mais dura, formando um tipo de compensação em arcos reduzidos (KAYSER,1981; SIERPINSKA et al., 2006).

A restauração da função mastigatória e estética tem se destacado pela sua grande importância na odontologia, principalmente quando os pacientes apresentam perda dentárias extensas (GOIATO et al., 2007). Sendo a mastigação a primeira fase do processo digestivo esta é considerada uma função essencial do sistema estomatognático. Desta forma, devolver a função de mastigar e fragmentar os alimentos, que serão engolidos e digeridos, tornou-se essencial junto com as perspectivas estéticas. Essa função deve estar o mais aproximada possível em relação as estruturas naturais perdidas pois a desagregação mecânica da alimentação ajuda no processo enzimático que depende do bolo alimentar em uma 
forma e granulação que favoreça a ação enzimática e digestiva (FONTIJN-TEKAMP et al., 2004).

Desta forma, mastigar requer coordenação muscular para a realização de movimentos mandibulares e geração de força suficiente para cortar, esmagar e triturar os alimentos mantendo-o na superfície oclusal dos dentes. A atividade dos músculos mandibulares elevadores depende da textura dos alimentos, uma vez que precisa de força para vencer a resistência de alimentos durante a mastigação (FONTIJN-TEKAMP et al.,2004).

Forças musculares exercidas pelos músculos da mastigação podem influenciar no sucesso da reabilitação protética. A ação dos músculos da mandíbula pode gerar forças interoclusais responsáveis pela flexão elástica da mandíbula e modificação clínica significativa de seções posteriores do arco inferior durante funcionamento estomatognático (Van der BILT et al., 1993; CUSTODIO et al., 2011).

A eficiência de mascar pode ser melhorada pela capacidade do paciente de dividir o alimento e pode ser avaliada por um sistema de crivos com malhas diferentes. Em pacientes desdentados, a eficiência mastigatória é reduzida devido à substituição da arcada dentária por dentes artificiais. A perda de dentes naturais provoca alterações como reabsorção óssea, transtornos temporomandibulares e hipotonicidade muscular, que afetam estruturas relacionadas à mastigação e estabilização da mandíbula (WILDING,1993).

Em alguns pacientes, a redução da atividade elétrica do músculo masseter durante a mastigação com novas próteses pode resultar em uma nova condição oclusal (BEYRON,1954). A nova prótese com a posição de cúspides adequadas faz a intercuspidação fácil e requer menos força para trituração de alimentos (GUNNE, 1982; MICHAEL, 1990; OTTENHOFF, 1992). A redução da força ativa proprioceptores em mucosa alveolar e em tendões musculares causam novos padrões de controle de força durante a intercuspidação protética (GIBBS,1981).

De acordo com os estudos, os usuários de novas dentaduras com equilíbrio oclusal apresentaram aumento na eficiência mastigatória, mesmo em um período curto e sem adaptação muscular (FONTIJN-TEKAMP et al., 2004; PIANCINO et al., 2005).

No entanto, usuários de prótese total podem deglutir partículas grandes de alimento depois de mastigar, com aumento e diminuição da atividade elétrica dos músculos masseter e temporal, respectivamente. Este fato pode estar associado à 
ausência de condicionamento físico e capacidade muscular, resultando em inadequado ajuste oclusal com contatos prematuros que desestabilizam e dificultam a mastigação (CHRISTENSEN, 1996).

Muitos autores demonstraram a diminuição da duração média de ciclos de mascar durante o teste de eficiência mastigatória após a inserção de próteses. Esta redução demonstrou um melhor equilíbrio oclusal (WILDING,1993; HONMA, 2005).

No que diz respeito à eficiência e ao número de ciclos mastigatórios, a maioria dos pacientes tem apresentado resultados positivos com nova prótese devido à restauração do equilíbrio oclusal e a presença de cúspides dos dentes artificiais (GOIATO et al, 2008). Além disso, é importante ressaltar que usuários de próteses, totais e/ou parciais removiveis, necessitam trocar periodicamente os aparelhos a cada cinco anos, para que haja uma melhora nas condições musculares e eficiência de mastigação, além de promover uma prevenção de patologias da articulação temporomandibular, além de melhorar a capacidade funcional do sistema mastigatório como um todo.

Até o presente momento, não se tem informação que haja estudos na literatura avaliando pacientes obesos mórbidos quanto ao funcionamento das suas estruturas fisiológicas, alterações na cavidade oral e nos tecidos adjacentes. Desta forma, foram analisados os grupos musculares palpáveis responsáveis pela mastigação em indivíduos obesos mórbidos, dentados e desdentados. 


\section{Proposição}

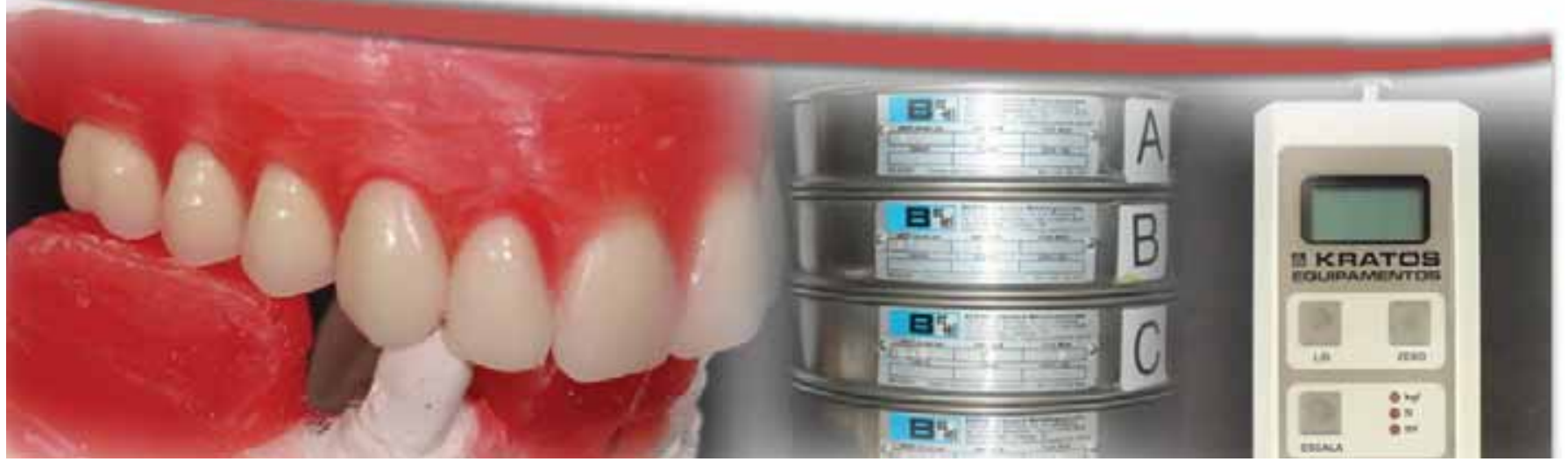



3 PROPOSIÇÃO

O presente trabalho teve por objetivo avaliar o limiar de dor a pressão (LDP) e a fadiga muscular, juntamente com a capacidade e eficiência mastigatórias de pacientes obesos mórbidos com indicação à cirurgia bariátrica no que se refere:

As seguintes hipóteses nulas:

1. Não há diferença no limiar de dor a pressão em pacientes edentulos antes e após a instalação da prótese dentária.

2. Não há diferença no limiar de dor a pressão entre os pacientes usuários de prótese dentária e os totalmente dentados.

3. Não há diferença no limiar de dor a pressão, entre pacientes usuários de prótese dentária e pacientes totalmente dentados, na análise fadiga mastigatória.

4. Não há diferença da sensação dolorosa muscular na análise pela EAV entre os grupos estudados.

5. Não há diferença na capacidade mastigatória em pacientes obesos mórbidos antes e após a instalação da prótese dentária.

6. Não há diferença na capacidade mastigatória em pacientes obesos mórbidos usuários de prótese e pacientes totalmente dentados.

7. Não há diferença na eficiência mastigatória em pacientes obesos mórbidos antes e após a instalação da prótese dentária.

8. Não há diferença na eficiência mastigatória em pacientes obesos mórbidos usuários de prótese e pacientes totalmente dentados.

9. O impacto da saúde bucal na qualidade de vida de pacientes edêntulos parciais ou totais e dentados não difere entre si. 


\section{Materiale Métodos}

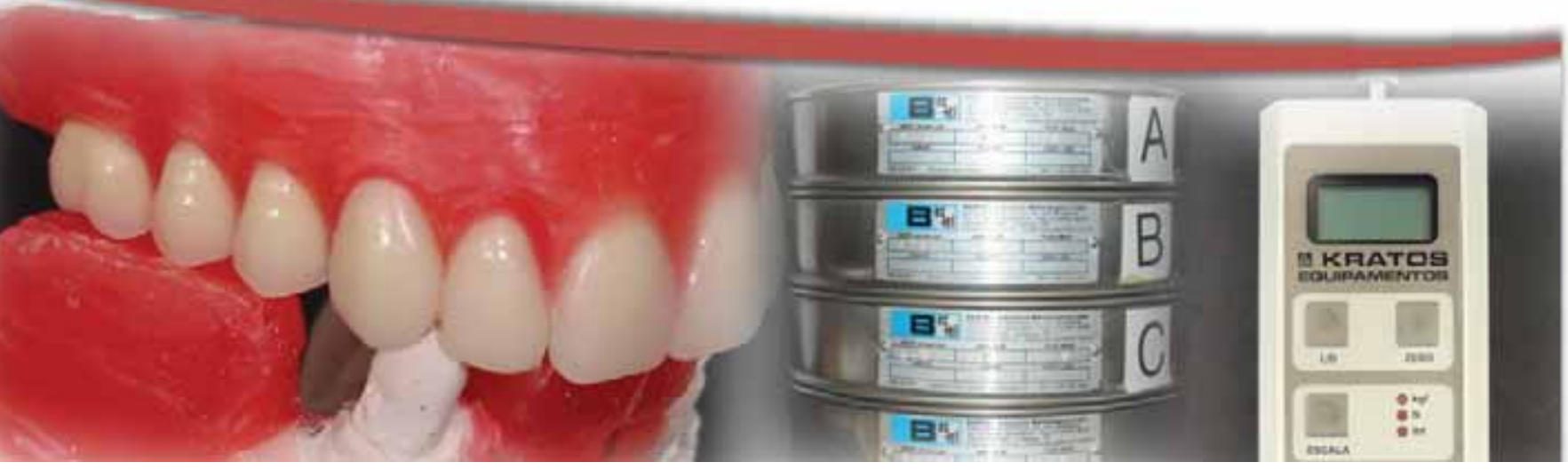





\section{MATERIAL E MÉTODOS}

\subsection{ASPECTOS ÉTICOS}

Em respeito a resolução 196/96 do Conselho Nacional do Ministério da Saúde, este projeto foi aprovado no Comitê de Ética em Pesquisa com Seres Humanos da Faculdade de Odontologia de Bauru, da Universidade de São Paulo (Prot $n^{\circ}$ 014/2011)(ANEXO A) e pelo Comitê e Ética em pesquisa do Hospital Amaral Carvalho (Prot no111/2011) (ANEXO B).

Os pacientes só participaram da pesquisa após uma explicação minuciosa dos objetivos desta e a partir da leitura da carta de orientação ao paciente e, assinatura do Termo de Consentimento Livre e Esclarecido.

\subsection{COMPOSIÇÃO DA AMOSTRA}

Fizeram parte da amostra os pacientes encaminhados pelo Sistema Único de Saúde (SUS), por meio da Direção Regional de Saúde de Bauru (DRS-6), para o ambulatório de Cirurgia Bariátrica do Hospital Amaral Carvalho (HAC), situado no município de Jaú/SP. Após a avaliação médica inicial, os pacientes foram encaminhados para a Faculdade de Odontologia de Bauru para tratamento odontológico preventivo e curativo, como também reabilitação oral quando indicada.

A amostra foi dividida em dois grupos, experimental (GE) e controle (GC), sendo que no GE foram inseridos indivíduos, que tivessem sofrido perdas dentárias que demandassem indicação protética e GC sem perdas dentárias. Em ambos os grupos foram analisados pacientes obesos mórbidos com indicação à cirurgia bariátrica.

O teste de fadiga mastigatória foi realizado apenas nos pacientes que estivessem com a cirurgia agendada pela equipe de cirurgia bariátrica do HAC. Dessa forma, foram totalizados 30 indivíduos ( $G E=15$ e $G C=15$ ) (FARELLA et al., 2001; CONTI et al., 2011).

\subsection{CRITÉRIOS DE EXCLUSÃO PARA O GRUPO EXPERIMENTAL}

Foram excluídos do estudo pacientes que:

1. Se negaram a participar da pesquisa, não concordando em assinar $O$ Termo de Consentimento Livre e esclarecido (APÊNDICE A); 
2. Pacientes que não apresentaram necessidade de reabilitação oral (MOYNIHAN, 2001); e que não tivessem 20 unidades dentárias funcionais segundo padrão da OMS.

\subsection{CRITÉRIOS DE EXCLUSÃO GRUPO CONTROLE}

Foram excluídos do estudo pacientes que:

1. Se negaram a participar da pesquisa, não concordando em assinar o Termo de Consentimento Livre e esclarecido (APÊNDICE B).

\subsection{DELINEAMENTO DO ESTUDO:}

\subsubsection{Calibração do examinador:}

Os testes clínicos desta pesquisa foram realizados por um único examinador previamente calibrado, que foi o próprio autor da pesquisa. O processo de calibração foi conduzido por um examinador padrão, experiente nos testes realizados, de modo que as atividades teórico-práticas envolveram exercícios de treinamento de calibração. Em um primeiro momento, foram ministradas aulas teóricas sobre a padronização inicial de critérios e condutas de exames adotados no estudo. Posteriormente, exercícios práticos para simulação dos testes propostos, bem como de sua correta interpretação foram desenvolvidos. Para a calibração propriamente dita, exames clínicos e os testes de algometria e eficiência mastigatória foram realizados sem qualquer discussão prévia, para que em seguida a tomada de dados, fosse possível a certificação da familiarização do examinador com os procedimentos.

\subsubsection{Estudo piloto:}

Foi realizado um estudo piloto para a verificação das estratégias propostas no Material e Métodos, testando a sua aplicabilidade e avaliando os resultados, viabilizando correções pertinentes no projeto.

\subsubsection{Tempos para coleta de dados:}

A coleta de dados para o grupo experimental foi dividida em dois tempos: 
Tempo 1 Inicial (T1): antes da instalação da prótese dentária segundo sua indicação; Tempo 2 Final (T2): após 45 dias da sua última consulta para ajustes na adaptação da prótese instalada (GARRETT et al.,1996).

Entre os tempos T1 e T2 foram realizados os tratamentos pertinentes ao preparo de boca. Tal preparo envolveu procedimentos restauradores, periodontais e cirúrgicos prévios à confecção da prótese dentária.

Em caso de pacientes desdentados totais esse preparo é inexistente. No qual se configura T1 como antes da instalação da prótese total e T2 após 45 dias da sua última consulta para ajustes na adaptação.

Foram reabilitados aqueles pacientes que obedeciam aos critérios de inclusão. As próteses realizadas foram do tipo Prótese Parcial Removível (PPR) e Próteses Totais (PT). No caso do paciente já possuir algum outro tipo de prótese e esta estivesse apresentando defasagem no seu funcionamento, no caso das próteses totais, e desadaptação no caso de próteses parciais removíveis, estas também foram refeitas de forma a devolver a função das mesmas.

Para o grupo controle houve apenas uma coleta de dados, visto que pacientes totalmente dentados são considerados aptos a cirurgia bariátrica e não necessitam de tratamento protético. Muito embora tenham sido realizados tratamentos restauradores, periodontais e de prevenção sempre que indicados.

Após o consentimento do paciente em participar da pesquisa, iniciou-se o exame propriamente dito.

\subsubsection{Exame intra-oral:}

Mediante uso de uma espátula de madeira, para afastamento de tecidos moles, foi realizado o exame intra oral, no qual foi constatado os elementos dentários ausentes, que foram anotados no odontograma da ficha clínica elaborada para a pesquisa e determinação do diagnóstico, além do plano de tratamento.

\subsubsection{Exame extra-oral:}

Abertura Bucal: Para mensuração da abertura bucal, foi utilizada uma régua flexível, e um compasso de ponta seca envolta em filme plástico PVC trocado a cada paciente, resguardando questões de biossegurança. Foi solicitado ao paciente que executasse sua abertura bucal máxima, sendo esta medida em milímetros. Como parâmetro foi feita a medição da distância entre os bordos incisais dos incisivos centrais superiores e inferiores 
do paciente. Na ausência de uma ou ambas unidades dentárias, a medição foi realizada pelos incisivos laterais. Quando o paciente se apresentava edêntulo, a medida foi tomada pelos bordos dos lábios superior e inferior. Este procedimento foi registrado no momento inicial da coleta de dados, após a reabilitação protética.

\subsubsection{Exame de Palpação - Limiar de Dor a Pressão(LDP):}

O limiar de dor à pressão foi mensurado por meio do exame de palpação, o qual foi realizado com o auxílio de um algômetro da marca KRATOS ${ }^{\circledR}$ (FIGURA 2).

Esse algômetro é capaz de medir tração e pressão em Kgf e possui uma haste em uma das extremidades com ponta em forma circular chata (FIGURA 3). A parte plana dessa ponta é a porção do aparelho que entra em contato com a face do indivíduo. Possui uma área de $1 \mathrm{~cm}^{2}$, similar à da ponta do dedo indicador, que normalmente é o dedo utilizado no exame de palpação digital.

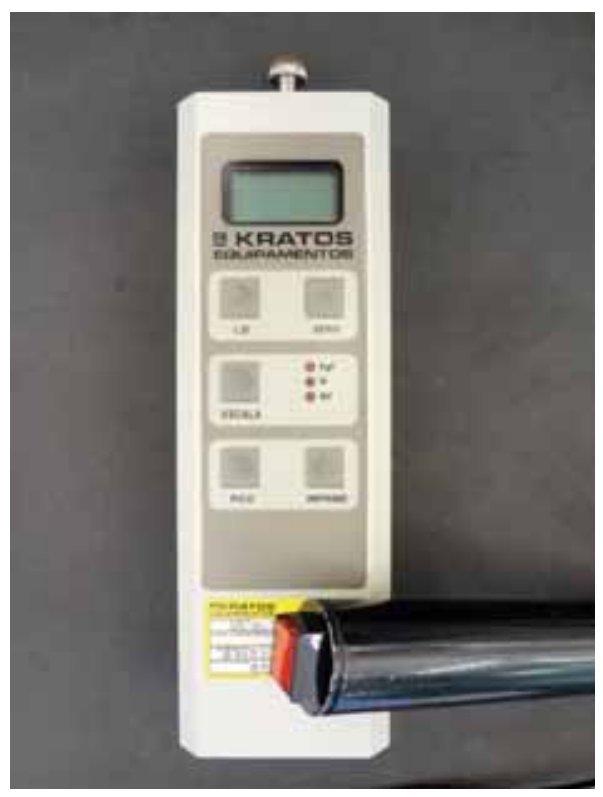

Figura 2 - Algômetro KRATOS ${ }^{\circledR}$ utilizado para o exame de palpação. 


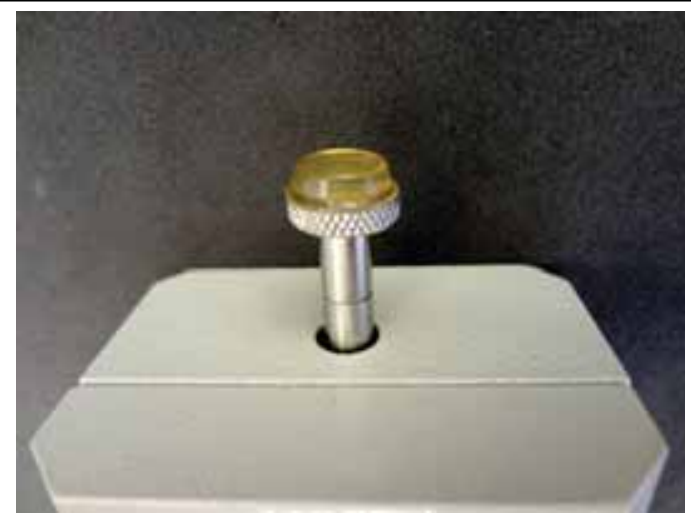

Figura 3 - Ponta circular chata que entra em contato com a pele do paciente $(1 \mathrm{~cm}$ de diâmetro).

Os músculos escolhidos para a realização do exame de palpação foram o masséter (corpo) e o temporal (anterior, médio e posterior), em ambos os lados.

Para o músculo temporal anterior, o ponto a ser palpado está a $30 \mathrm{~mm}$ para posterior do ponto mais lateral da órbita e $15 \mathrm{~mm}$ acima da extremidade superior do arco zigomático. Para o temporal médio, o ponto de palpação se localiza $60 \mathrm{~mm}$ ao longo de uma linha vertical imaginária perpendicular à outra linha do canto do tragus ao meio do meato auditivo externo. O ponto de palpação para o temporal posterior localiza-se a $40 \mathrm{~mm}$ para posterior do ponto anteriormente marcado para o temporal médio. Para a palpação do corpo do masséter, solicitou-se ao indivíduo que apertasse os dentes para que se pudesse localizar todo o corpo do músculo. Em seguida, localizou-se o ponto médio entre a origem e a inserção.

Cada indivíduo foi orientado pelo examinador em relação à palpação, de forma a avisá-lo, de maneira clara, acionando o dispositivo em sua mão (FIGURA 4). o momento exato em que o estímulo crescente exercido na sua face deixava de ser de pressão e passava a ser doloroso. Foram orientados a não ficar suportando a dor, e sim registrar o instante em que esta se iniciou. 


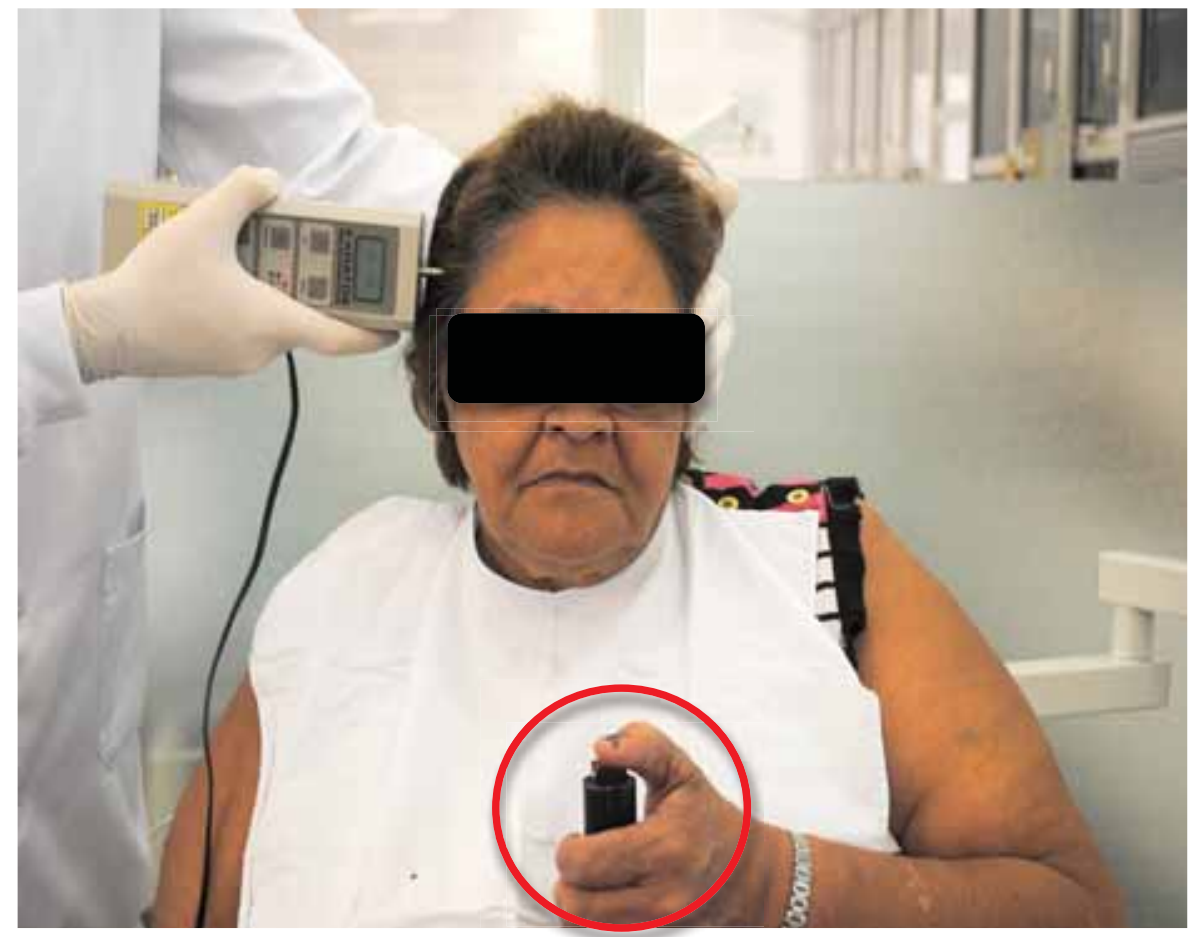

Figura 4 - Acionamento, pelo paciente, do dispositivo que registra o LDP.

A palpação foi realizada com o algômetro perpendicular ao ponto a ser examinado exercendo uma pressão crescente e constante de aproximadamente $0,5 \mathrm{~kg} / \mathrm{cm}^{2} / \mathrm{s}$ em cada ponto pré-determinado, até que o paciente relatasse a dor.

Nesse momento, a pressão deixou de ser aplicada e o algômetro registrou o valor, que foi anotado. Enquanto a palpação era realizada com uma mão, a outra servia de anteparo para que o paciente não movimentasse a cabeça e prejudicasse a obtenção dos dados. Durante o exame, além do anteparo com a mão, o paciente se manteve sentado com a face voltada ao horizonte, em linha reta (FIGURA 5; FIGURA 6). 


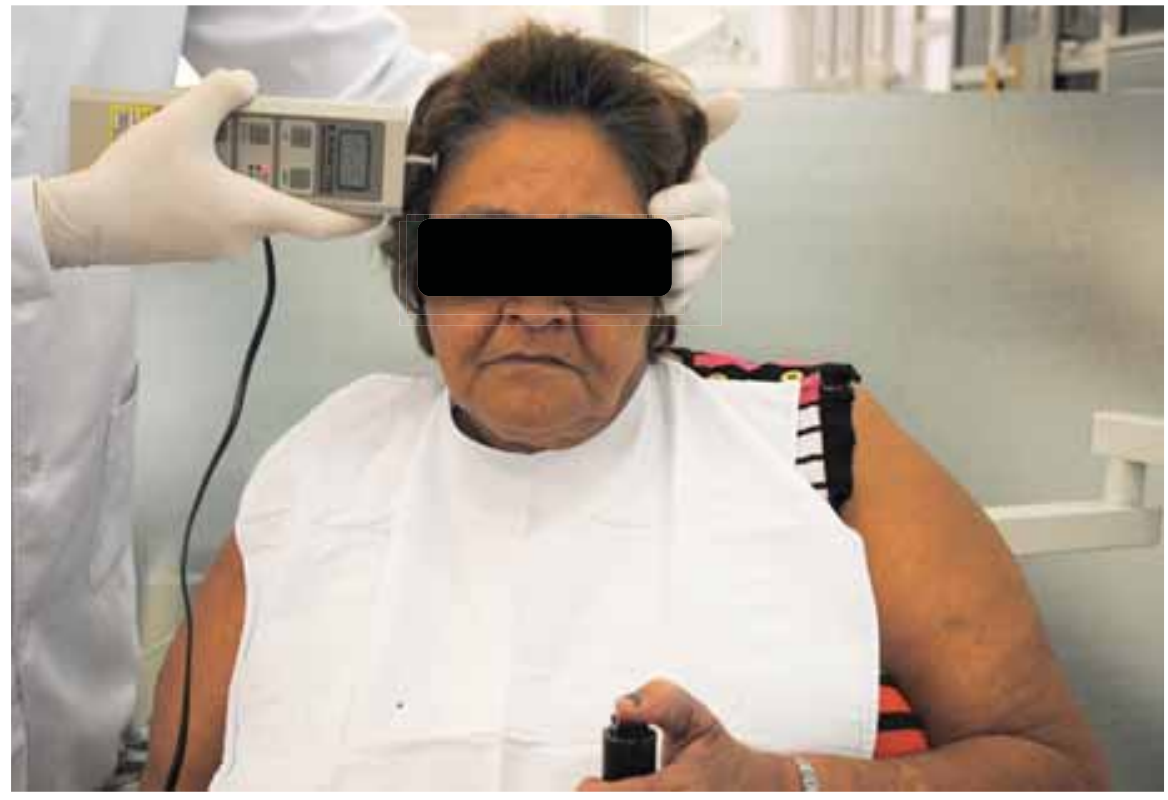

Figura 5 - Palpação realizada no músculo Temporal Médio Direito.

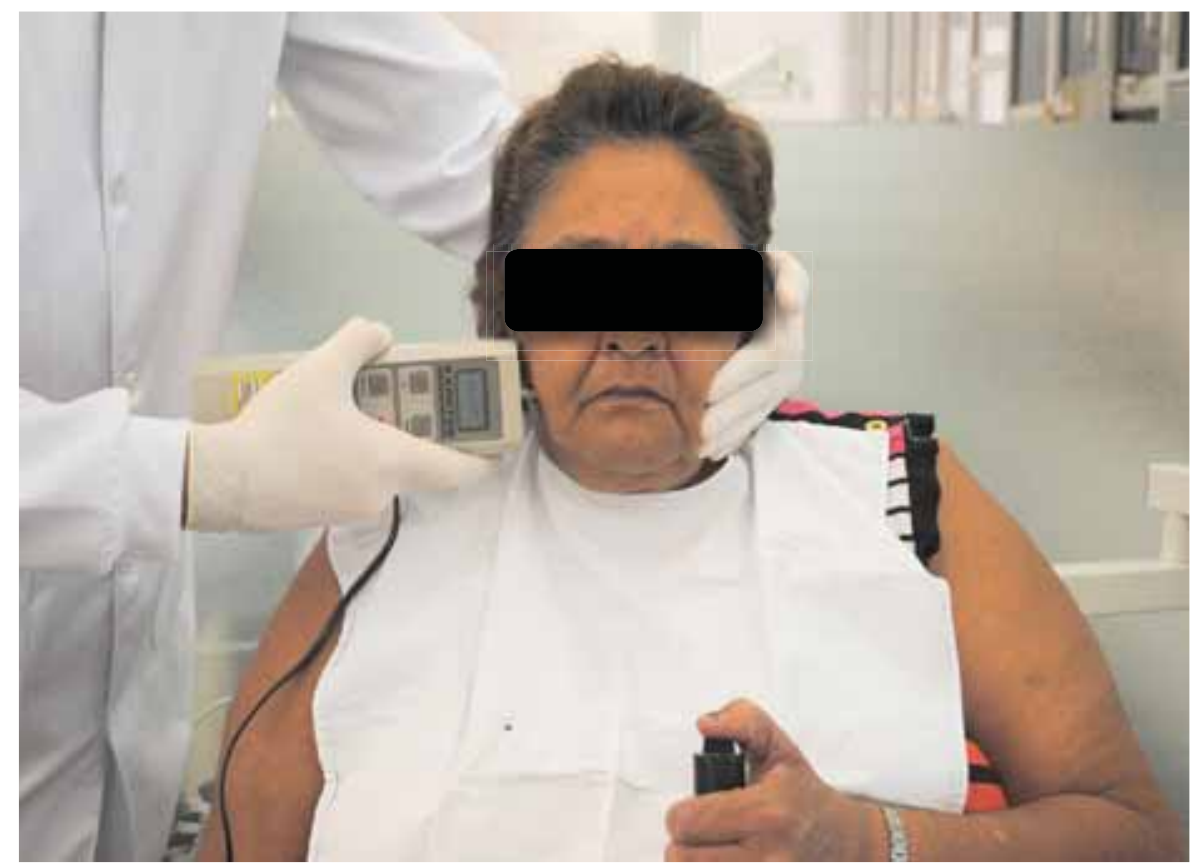

Figura 6 - Palpação realizada no músculo Masséter direito.

\subsubsection{Escala de Análise Visual (EAV):}

Esta escala é representada por uma reta de $100 \mathrm{~mm}$ onde na extremidade esquerda lê-se "sem dor" e na direita lê-se "pior dor imaginável". Antes do teste de mastigação, os participantes foram solicitados a indicar a intensidade da sua dor naquele momento inicial, antes do teste, através da escala de análise visual 
analógica (EAV), variando de 0mm ("sem dor") a 100mm ("pior dor imaginável"). Cada EAV foi preenchido em uma parte separada de papel, a fim de evitar viés de registros anteriores. O paciente marcou com um traço vertical, cortando essa reta, onde acreditava que a sua dor estivesse localizada no momento do exame (FIGURA 7) (CONTI et al.,2001).

\section{Escala de Análise Visual / LDP}

Sem dor

Pior Dor Imaginável

Indique a média de seu nível de dor neste momento, marcando com uma linha vertical a escala abaixo, a extremidade esquerda indica a ausência total de dor e a direita indica a pior dor

Figura 7 - Escala de Análise Visual

\subsubsection{Teste de Fadiga Muscular: Algometria (Limiar de Dor à Pressão - LDP):}

O exame para análise do LDP no teste de fadiga mastigatória foi realizado com o auxílio de um algômetro da marca $\operatorname{KRATOS}{ }^{\circ}$.

Durante as sessões dos testes mastigatórios os sujeitos foram acomodados em uma cadeira odontológica confortável, na posição vertical com a cabeça inclinada para trás sobre o encosto da cadeira.

Os músculos selecionados para a realização do exame de LDP foram o masseter (corpo), masseter profundo e temporal (anterior, médio e posterior) de ambos os lados. Foram obedecidos os mesmos critérios da avaliação da LDP registrado normalmente.

Após o registro inicial das quantificações de (EVA e LDP), os sujeitos foram instruídos a começar a mastigar uma goma de mascar (Trident Total ${ }^{\circ}$ ) por 9 minutos, do lado preferido. Depois, os indivíduos foram instruídos a manter suas mandíbulas em posição de repouso (lábios e dentes separados). Mantendo-se nessa posição por 9 minutos, completando o período total de teste de 18 minutos. A EVA foi registrada novamente após 3,6 e 9 minutos (P3, P6 e P9, respectivamente) após o início do experimento e durante o período de repouso a 12, 15 e 18 minutos (P12, P15 e P18 minutos). Enquanto que as medições da LDP foram avaliadas inicialmente (P0) após os 9 minutos do estresse mastigatório (P9) e no final do repouso (P18). Todos os dados foram devidamente registrados em uma ficha 
específica (APÊNDICE D).

\subsubsection{Capacidade Mastigatória:}

A capacidade mastigatória $(\mathrm{CM})$ foi obtida por resposta direta do paciente às perguntas realizadas sobre a capacidade que seu aparelho mastigatório (ou próteses) tem ao fragmentar alimentos, seja ela com ou sem dificuldades, por meio de respostas sim e não (APÊNDICE C).

Os fatores físicos e funcionais de cada paciente podem interferir diretamente na qualidade da mastigação de alimentos, como o tamanho funcional disponível das superfícies oclusais, a forma das cúspides, a quantidade de dentes antagonistas e a qualidade do contato dessas quando em oclusão, a ação da língua, dos lábios e das bochechas, bem como dos músculos responsáveis pela mastigação.

Essa análise é um panorama subjetivo do paciente a respeito da sua condição mastigatória.

\subsubsection{Eficiência Mastigatória:}

Para esta avaliação foi utilizado como alimento-teste um material de moldagem à base de silicona de condensação - Optosil囚 (Heraeus Kulzer, South America, Ltda.). O material de moldagem foi manipulado segundo instruções do fabricante e colocado em formas de resina acrílica para obter as formas quadradas com estrutura similar (FIGURA 8). Essas formas não são encontradas no mercado para venda, desta forma o pesquisador teve que desenvolver esse molde para a confecção dos alimentos-teste.

As amostras de Optosil[ foram preparadas em um formato quadrado, padronizado de $18 \mathrm{~mm} \times 18 \mathrm{~mm} \times 5 \mathrm{~mm}$ e com peso médio de $2,24 \mathrm{~g}$ (FIGURA 9).

Figura 8 - Forma de resina acrílica autopolimerizável para produção do alimento- 
teste de Optosil quadrado desenvolvido pelo pesquisador.

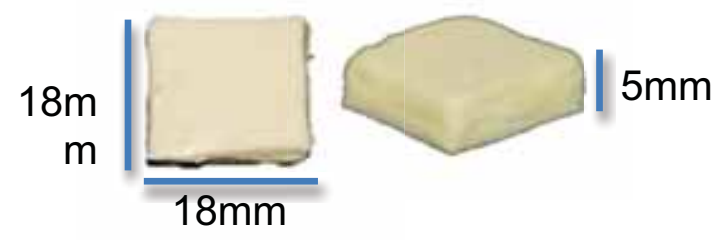

Figura 9 - Dimensões do alimento-teste de Optosil quadrado

Todas as amostram foram pesadas em balança de precisão (A\&D 003ND Departamento de Materiais Dentários - FOB USP) e separadas em potes plásticos (FIGURA 10; FIGURA 11).

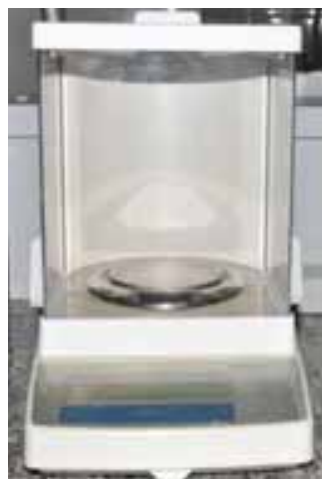

Figura 10 - Balança de precisão A\&D 003ND.

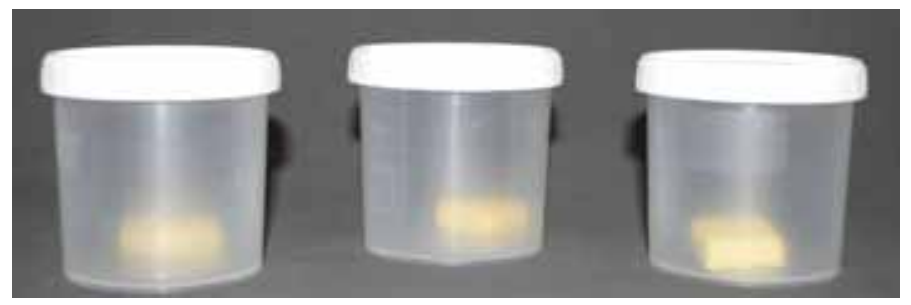

Figura 11 - Potes e plásticos para armazenamento do alimento teste pesado.

Para a análise do material colhido após a mastigação foi utilizado o sistema de tamises composto por peneiras com telas de $4,75 \mathrm{~mm} / 4,00 \mathrm{~mm} / 2,80 \mathrm{~mm} / 1,18 \mathrm{~mm}$ (FIGURA 12). Todas as tamises adquiridas junto a Bertel (Indústria Metalúrgica,Caieiras,São Paulo,LTDA®) e com granulação conforme padrão da ABNT. 


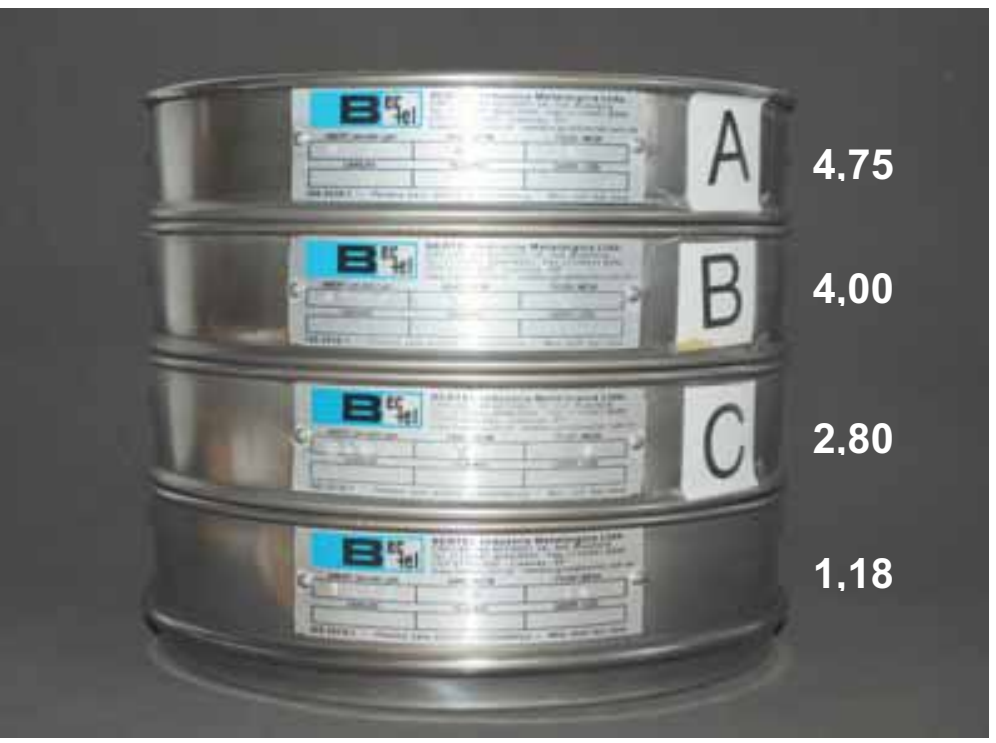

Figura 12 - Sistema de tamises(granulação em $\mathrm{mm}$ ) para fracionar o alimento-teste após a mastigação

A sequência do teste realizada da seguinte forma:

O alimento-teste usado foi o Optosil@ (Heraeus Kulzer South America Ltda.). As amostram tinham o formato quadrado com dimensões de $18 \times 18 \times 5 \mathrm{~mm}$ (FIGURA 13).

O indivíduo foi instruído a mastigar cada amostra de forma habitual, sem restrições quanto ao lado de mastigação. As amostras eram mastigadas por 10, 20 e 40 segundos, marcados pelo examinador, com um cronômetro. Cada amostra mastigada era colocada de volta ao seu pote de plástico original, onde se tinha o registro inicial do peso da amostra. Nesse momento, era escrito no pote o nome do indivíduo e por quanto tempo aquele alimento-teste havia sido mastigado. $\mathrm{O}$ conteúdo era dispensado no pote de plástico pelo indivíduo. Na sequência, o examinador conferia se pequenos pedaços ainda restavam dentro da boca. Caso houvesse, o indivíduo fazia bochechos com água até que todas as partículas fossem recolhidas para o pote. Todo o conteúdo do pote era dispensado em um filtro de papel e colocado para secar em estufa à $37^{\circ} \mathrm{C}$ por $48 \mathrm{~h}$ (Departamento de Materiais Dentários - FOB USP) (FIGURA 14). Após esse tempo, a amostra era transferida para um pote plástico, pré pesado na balança de precisão. A amostra mastigada era então pesada para ser conferida o quanto de material foi perdido durante a mastigação (FIGURA 15). 
I
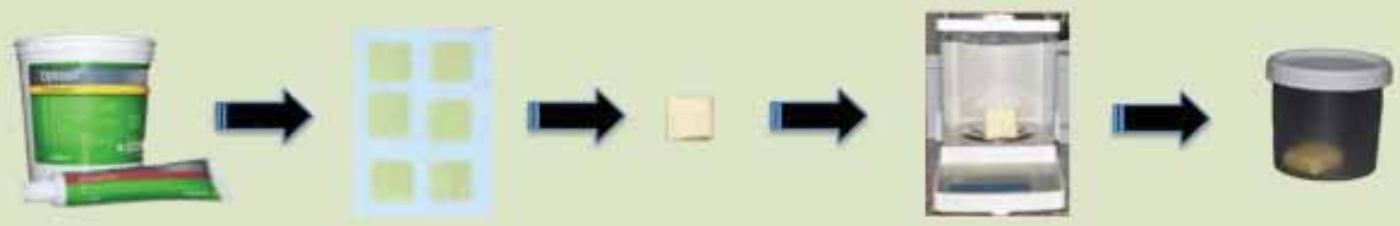

Figura 13 - Produção do alimento teste a base de silicona de condensação, no formato quadrado através de molde fabricado pelo autor e sua pesagem para padronização e armazenagem em pote de plástico.

II
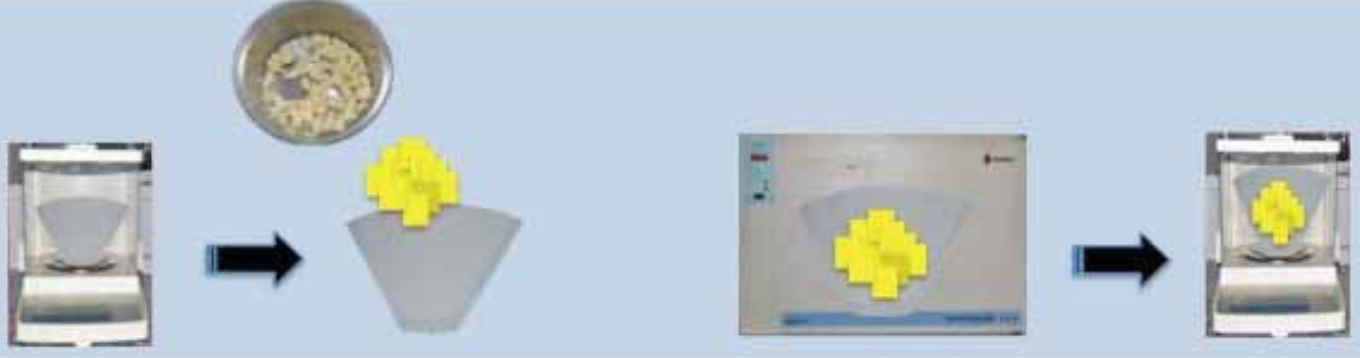

Figura 14 - Secagem do material colhido no teste de eficiência mastigatória em filtro de papel(Pré pesado) na estufa a $37^{\circ} \mathrm{C}$ por $48 \mathrm{~h}$. Após secagem o material e o filtro é novamente pesado e se tem o peso total recolhido até o momento( Peso do filtro Peso total $=$ peso da amostra).

III
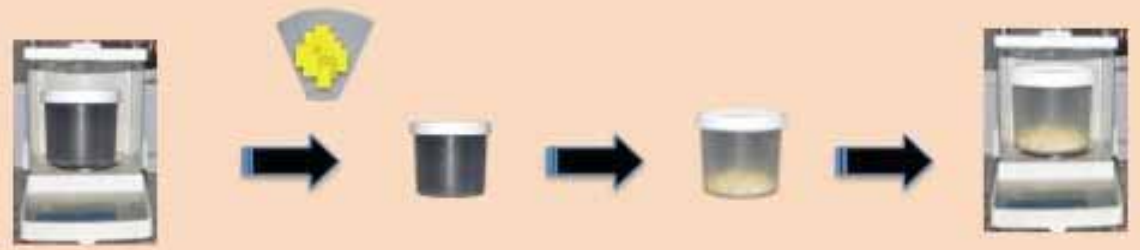

Figura 15 - Peso Total da amostra a ser peneirada ( Peso do pote de plástico Peso Total $=$ peso do material a ser peneirado)

A amostra foi dispensada em um sistema de tamises composto das seguintes peneiras de cima para baixo: $4,75 \mathrm{~mm} / 4,00 \mathrm{~mm} / 2,78 \mathrm{~mm} / 1,18 \mathrm{~mm}$. Esse sistema ficava sobre um suporte para filtro de papel,de forma que as partículas que 
passassem pela última peneira, de $1,18 \mathrm{~mm}$ fossem recolhidas pelo filtro. As partículas retidas em cada peneira eram contadas obedecendo a classificação para análise do teste (FIGURA 16).
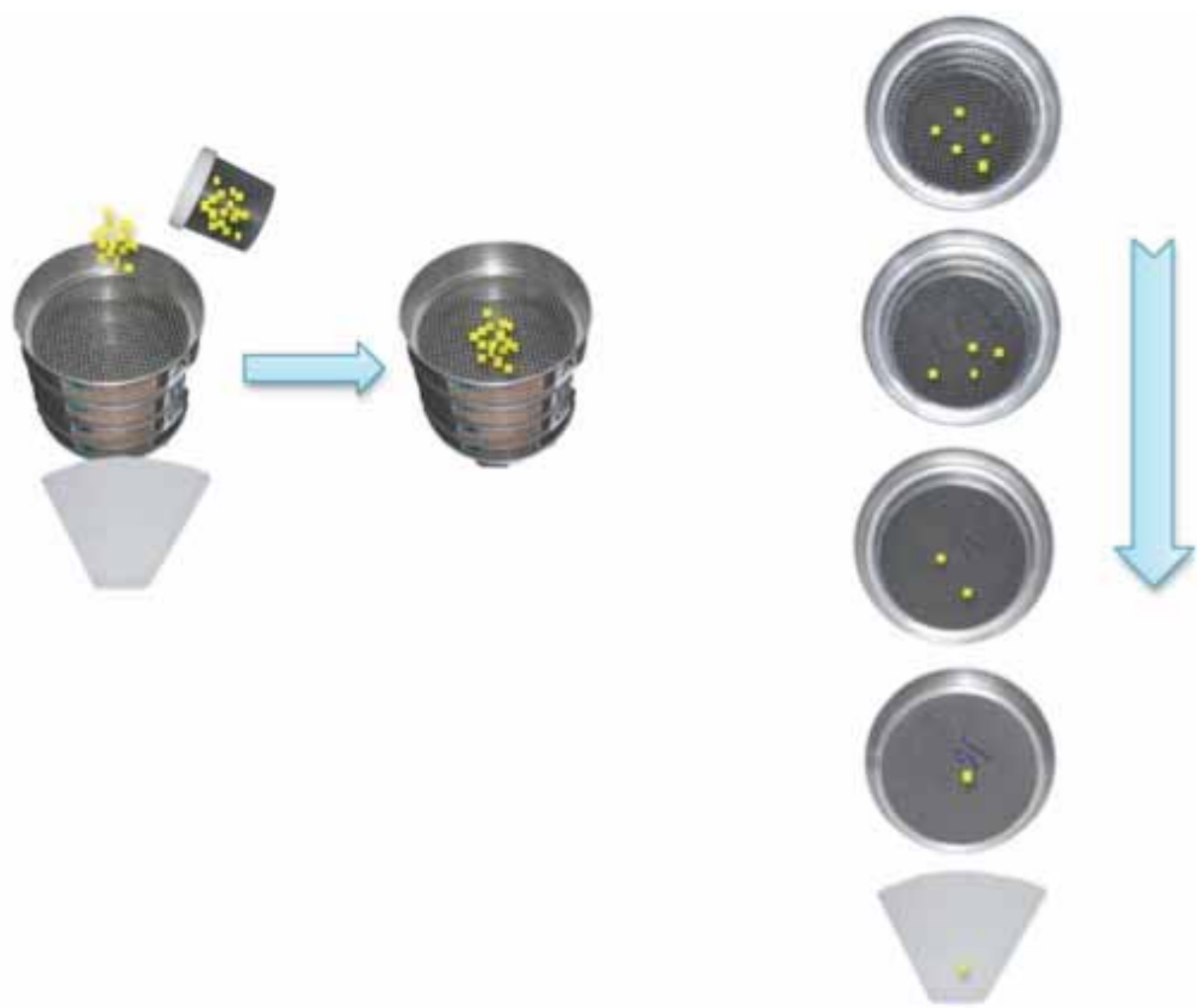

Figura 16 - Sistema de tamises.

Os resultados para cada tempo de mastigação 10, 20 e 40s foram anotados de forma distinta (FIGURA 17).
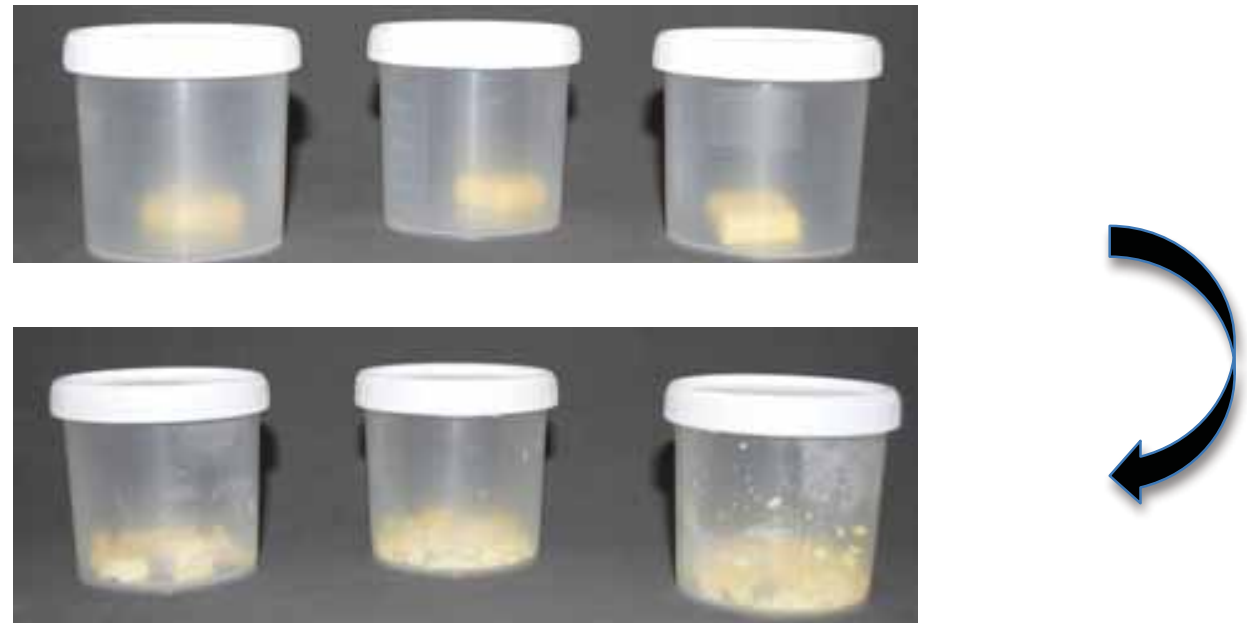

Figura 17- Material recolhido após a mastigação do alimento teste nos tempos 10,20 e 40 segundos respectivamente. 
A eficiência mastigatória foi classificada em 5 categorias (HELKIMO,CARLSSON ; HELKIMO, 1978):

1. Eficiência Mastigatória Ótima (Em1): ausência de partículas maiores que 4,75 $\mathrm{mm}$ e presença de poucas partículas maiores que $4 \mathrm{~mm}$ após a fragmentação do alimento-teste por 10 segundos.

2. Eficiência Mastigatória Boa (Em2): ausência de partículas maiores que 4,75 $\mathrm{mm}$ e presença de poucas partículas maiores que $4 \mathrm{~mm}$ após a fragmentação do alimento-teste por 20 segundos.

3. Eficiência Mastigatória Regular (Em3): presença de poucas partículas maiores que $4,75 \mathrm{~mm}$ e $4 \mathrm{~mm}$ após a fragmentação do alimento-teste por 20 segundos.

4. Eficiência Mastigatória Ruim (Em4): paciente não se enquadra nas classificações EM1, EM2, EM3; entretanto, não há presença de partículas de $4,75 \mathrm{~mm}$ após a fragmentação do alimento-teste por 40 segundos.

5. Eficiência Mastigatória Péssima (Em5): presença de partículas de 4,75 mm após a fragmentação do alimento-teste por 40 segundos

\subsubsection{Qualidade de vida}

Foi utilizado um questionário de avaliação sócio-funcional, OHIP-14 (Oral Health Impact Profile), para a verificação das dimensões de impacto na qualidade de vida nas experiências vividas nos últimos 12 meses. As dimensões mensuradas por esse questionário são: limitação funcional, dor física, desconforto psicológico, incapacidade física, incapacidade psicológica, incapacidade social e deficiência. As respostas foram feitas numa escala em que o código escolhido foi multiplicado pelo respectivo peso da questão. Os códigos são: $0=$ nunca; 1 = dificilmente; 2 = às vezes; 3 = quase sempre; 4 = sempre. Desta forma o valor máximo que cada dimensão pôde alcançar foi 4 e o impacto de cada dimensão foi classificado em fraco, médio e forte. A escala alcançou a variação geral de 0 a 28 e foi considerado de fraco impacto quando o índice esteve classificado entre zero e nove. Entre $10 \mathrm{e}$ 18 foi considerado de médio impacto e entre 19 e 28 de forte impacto da saúde bucal sobre a qualidade de vida. 
Segundo Slade (1997) cada reposta possui um peso a ser descrito no quadro a seguir (QUADRO 1):

\begin{tabular}{|c|c|c|}
\hline Dimensäo & Perguntas & Peso \\
\hline \multirow[t]{2}{*}{$\begin{array}{l}\text { Limitação } \\
\text { funcional }\end{array}$} & $\begin{array}{l}\text { Você tem problemas para pronunciar palavras por causa de } \\
\text { problemas com seus dentes ou sua boca? }\end{array}$ & 0.51 \\
\hline & $\begin{array}{l}\text { Vocé ja sentiu mudança no sabor dos alimentos por causa } \\
\text { de problemas com seus dentes ou a boca? }\end{array}$ & 0.49 \\
\hline \multirow[t]{2}{*}{ Dor fisica } & Vocé já sentiu dor na sua boca? & 0,34 \\
\hline & $\begin{array}{l}\text { Você ja teve desconforto para comer qualquer alimento por } \\
\text { causa de problemas com seus dentes ou a boca? }\end{array}$ & 0,66 \\
\hline \multirow[t]{2}{*}{$\begin{array}{l}\text { Desconforto } \\
\text { psicologico }\end{array}$} & $\begin{array}{l}\text { Vocé já ficou inibido por causa dos seus dentes ou sua } \\
\text { boca? }\end{array}$ & 0,45 \\
\hline & $\begin{array}{l}\text { Você já se sentiu estressado por causa de seus dentes ou } \\
\text { sua boca? }\end{array}$ & 0.55 \\
\hline \multirow[t]{2}{*}{$\begin{array}{l}\text { Incapacidade } \\
\text { fisica }\end{array}$} & $\begin{array}{l}\text { A sua alimentação tem sido ruim por causa de problemas } \\
\text { com seus dentes ou boca? }\end{array}$ & 0,52 \\
\hline & $\begin{array}{l}\text { Vocé já teve que interromper alguma refeição por causa dos } \\
\text { seus dentes ou sua boca? }\end{array}$ & 0,48 \\
\hline \multirow[t]{2}{*}{$\begin{array}{l}\text { Incapacidade } \\
\text { psicologica }\end{array}$} & $\begin{array}{l}\text { Voce ja teve dificuldade para descansar por causa de } \\
\text { problemas com seus dentes ou sua boca? }\end{array}$ & 0.60 \\
\hline & $\begin{array}{l}\text { Você já se sentiu um pouco envergonhado por causa de } \\
\text { seus dentes e sua boca? }\end{array}$ & 0,40 \\
\hline \multirow[t]{2}{*}{$\begin{array}{l}\text { Incapacidade } \\
\text { social }\end{array}$} & $\begin{array}{l}\text { Vocé já ficou um pouco irritado com outras pessoas por } \\
\text { causa de problemas com sua boca ou dentes? }\end{array}$ & 0,62 \\
\hline & $\begin{array}{l}\text { Você tem dificuldades para fazer suas atividades diárias por } \\
\text { causa de seus dentes ou sua boca? }\end{array}$ & 0,38 \\
\hline \multirow[t]{2}{*}{ Deficiêncla } & $\begin{array}{l}\text { Vocé já sentiu que de maneira geral a vida te satisfaz } \\
\text { menos por causa de problemas com seus dentes ou sua } \\
\text { boca? }\end{array}$ & 0,59 \\
\hline & $\begin{array}{l}\text { Vocé já esteve totalmente incapaz de agir por causa de } \\
\text { problemas com seus dentes ou sua boca? }\end{array}$ & 0.41 \\
\hline
\end{tabular}

Quadro 1 - Classificação OHIP-14

\subsection{FORMA DE ANÁLISE DOS RESULTADOS}

Os dados coletados e anotados foram organizados com dupla entrada, em arquivos do programa Excel para Mac 2011, para posterior análise descritiva (média,desvio-padrão, frequências absolutas e relativas) e analítica utilizando o programa estatístico Statistica 10.0 para Windows, adotando-se nível de significância de $5 \%$.

Após, foi verificada a normalidade das variáveis, o teste $\mathrm{t}$ de Student foi utilizado para avaliar as diferenças entre os grupos de dentados e desdentados e para avaliação do inicial para o final do grupo experimental. Para avaliar as diferenças entre os períodos dos testes de fadiga mastigatória foi realizada ANOVA para medidas repetidas seguida pelo teste de Tukey. 


\section{Resultados}

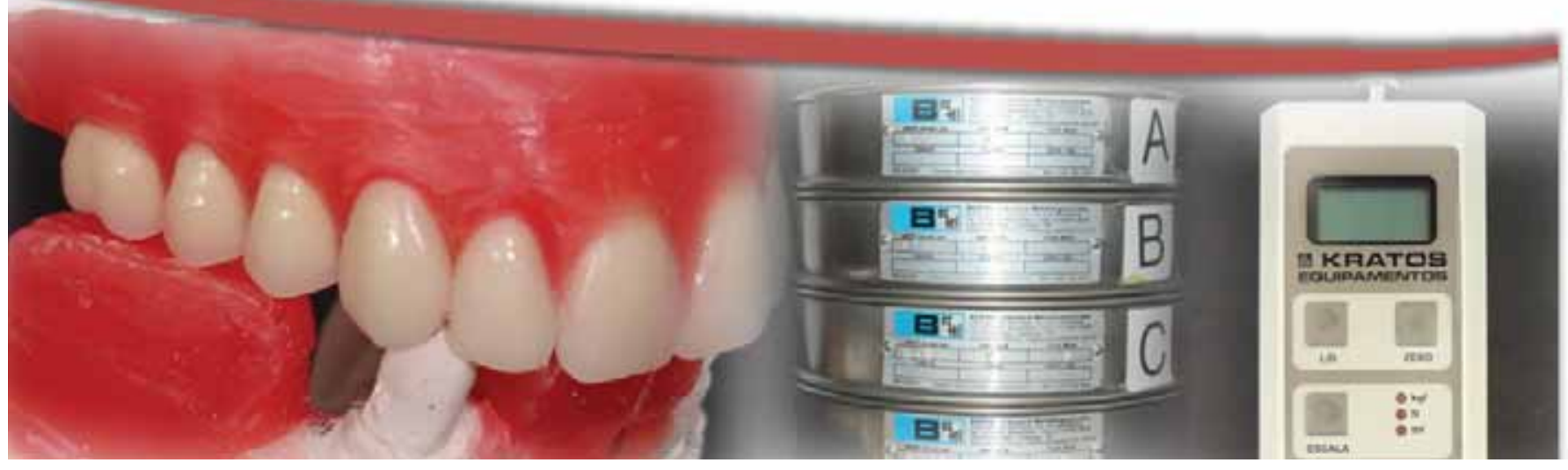





\section{RESULTADOS}

O total de indivíduos da amostra (90) foi dividido em dois grupos. O grupo experimental (GE), composto por 60 sujeitos (47 mulheres e 13 homens) com idade média de 44,6 anos, variando de 26 a 71 anos. O Grupo Controle (GC), indivíduos dentados sem necessidade de prótese dentária, foi composto por 30 indivíduos (19 mulheres e 11 homens) com idade média de 39,2 anos variando de 27 a 51 anos.

\subsection{LIMIAR DE DOR A PRESSÃO (LDP)}

O teste de Limiar de Dor a Pressão é feito por grupo muscular para ambos os lados (direito e esquerdo). Denomina-se "1" o lado direito do paciente e consequentemente "2" o lado esquerdo. Os Músculos envolvidos foram os denominados no material e métodos (Masseter-corpo; Feixe anterior, médio e posterior do Músculo Temporal). Tal avaliação foi realizada em duplicata de cada medida e registrada sua média de cada grupo muscular (APÊNDICE E e F). Foi analisada sua evolução para cada músculo. Obteve-se resultados diferentes do inicial no Músculo Temporal no seu feixe anterior, médio do lado direito e anterior e posterior do lado esquerdo. Ao se calcular a média do músculo (soma da LDP do lado 1 e 2$)$ obteve diferença significante $(p<0,05)$ para os músculos masseter e feixe anterior do músculo temporal (TABELA 2,3).

Tabela 2. Limiar de Dor a Pressão (LDP) com diferença significativa nos tempos inicial e final para os músculos da mastigação para o grupo experimental do lado direito e esquerdo.

\begin{tabular}{|c|c|c|c|c|c|c|}
\hline Músculo & Tempo & \multicolumn{2}{|c|}{ Padrão) } & $\mathbf{n}$ & $\mathbf{p}$ & IC (95\%) \\
\hline (1)Temporal & Inicial & 2,85 & $( \pm 0,86)$ & & & \\
\hline Anterior & Final & 2,54 & $( \pm 0,56)$ & 60 & $0,005^{*}$ & $(0,95-5,22)$ \\
\hline (1)Temporal & Inicial & 3,60 & $( \pm 1,20)$ & & & \\
\hline Médio & Final & 3,25 & $( \pm 0,97)$ & 60 & $0,004^{*}$ & $(1,21-5,82)$ \\
\hline (2)Temporal & Inicial & 2,94 & $( \pm 0,88)$ & & & \\
\hline Anterior & Final & 2,59 & $( \pm 0,64)$ & 60 & $0,002^{*}$ & $(1,28-5,63)$ \\
\hline (2)Temporal & Inicial & 3,97 & $( \pm 1,30)$ & & & \\
\hline Posterior & Final & 3,55 & $( \pm 1,03)$ & 60 & $0,009^{*}$ & $(1,21-5,82)$ \\
\hline \multirow{2}{*}{ (2) Masséter } & Inicial & 1,96 & $( \pm 0,81)$ & & & \\
\hline & Final & 2,18 & $( \pm 0,83)$ & 60 & $0,001^{*}$ & {$[-3,60-(-0,65)]$} \\
\hline
\end{tabular}


Tabela 3. Média do Limiar de Dor a Pressão (LDP) com diferença significativa nos tempos inicial e final para os músculos da mastigação para o grupo experimental do lado direito e esquerdo.

\begin{tabular}{|c|c|c|c|c|c|c|}
\hline $\begin{array}{l}\text { Média do LDP } \\
\text { dos Músculos }\end{array}$ & Tempo & Média & $\begin{array}{l}\text { (Desvio } \\
\text { Padrão) }\end{array}$ & $\mathbf{n}$ & $\mathbf{p}$ & IC $(95 \%)$ \\
\hline Temporal & Inicial & 2,90 & $( \pm 0,81)$ & & & \\
\hline Anterior & Final & 2,57 & $( \pm 0,58)$ & 60 & $0,001^{*}$ & $(1,34-5,19)$ \\
\hline Temporal & Inicial & 3,70 & $( \pm 1,11)$ & & & \\
\hline Posterior & Final & 3,47 & $( \pm 1,01)$ & 60 & $0,037^{*}$ & $(0,14-4,35)$ \\
\hline
\end{tabular}

Ao se comparar o grupo experimental na situação final (pós reabilitação) com o grupo controle, encontrou-se diferenças significativas apenas no músculo masseter em ambos os lados (TABELA 4).

Tabela 4. Comparação do Limiar de Dor a Pressão após reabilitação oral com o LDP do grupo controle para o músculo masseter.

\begin{tabular}{cccccc}
\hline $\begin{array}{c}\text { LDP dos } \\
\text { Músculos }\end{array}$ & Média GE & Média GC & $\mathbf{p}$ & $\mathbf{n}(\mathbf{G E})$ & $\mathbf{n ( G C )}$ \\
$\begin{array}{c}\text { (1) Masséter GE x } \\
\text { (1) Masséter GC }\end{array}$ & 2,11 & 2,79 & $0,002^{*}$ & 60 & 30 \\
$\begin{array}{c}\text { (2) Masséter GE x } \\
\text { (2) Masséter GC } \\
\text { Média Masséter }\end{array}$ & 2,18 & 2,79 & $0,043^{*}$ & 60 & 30 \\
$\quad$ GE & & & & & \\
X & 2,14 & 2,77 & $0,012^{*}$ & 60 & \\
Média Masséter & & & & & \\
GC & & & & &
\end{tabular}

\subsection{ESCALA DE ANÁLISE VISUAL (EAV)}

A escala de análise visual auto reportada pelo paciente se refere a dor orofacial. No grupo experimental antes e após a reabilitação oral obteve uma diferença significante $(p=0,000)$ (TABELA 5). Mesmo com a melhora na condição final do grupo composto por obesos mórbidos reabilitado com prótese dentária, ainda houve uma diferença para com o grupo controle $(p=0,035)$ (TABELA 6). 
Tabela 5. Escala de Análise Visual do grupo experimental.

\begin{tabular}{lccccccc}
\hline EAV & Média & Desvio Padrão & $\mathbf{n}$ & $\mathbf{d f}$ & $\mathbf{p}$ & $\mathbf{C l}-$ & $\mathbf{C l +}$ \\
\hline EAV Inicial & 3,13 & $\pm 2,96$ & 60 & 29 & 0,000 & 1,51 & 3,15 \\
EAV final & 0,80 & $\pm 1,37$ & & & & & \\
\hline
\end{tabular}

Tabela 6. Comparação da EAV do grupo experimental após reabilitação oral com o grupo controle.

\begin{tabular}{lllllllll}
\hline Variável 1 vs Variável2 & & $\begin{array}{c}\text { Média } \\
\text { V1 }\end{array}$ & $\begin{array}{c}\text { Média } \\
\text { V2 }\end{array}$ & t & df & $\mathbf{p}$ & $\mathbf{n}(\mathrm{V} 1)$ & $\mathbf{n}(\mathbf{V 2})$ \\
\hline $\begin{array}{l}\text { EAV final experimental } \\
\text { controle }\end{array}$ & X EAV & 0,80 & 0,00 & 2,16 & 42 & 0,03 & 60 & 30 \\
\hline
\end{tabular}

\subsection{FADIGA MASTIGATÓRIA}

Para o teste e fadiga mastigatória foi realizado o teste ANOVA para medidas repetidas seguidas de Tukey para cada grupo muscular.

Para o grupo do músculo masseter houve apenas diferença estatística significante na condição inicial entre os grupos, porém ocorreu modificação nas condições no decorrer dos tempos do teste (TABELA 7)

A análise estatística utilizada foi Anova medidas repetidas, seguidas de Tukey para demonstrar as diferenças entre as condições.

Tabela 7. Análise comparativa entre os GE e GC e nos tempos do teste de fadiga mastigatória para o grupo muscular já descrito.

\begin{tabular}{|c|c|c|c|c|}
\hline $\begin{array}{c}\text { Variável LDP } \\
(\mathrm{KgF} / \mathrm{cm})\end{array}$ & Grupo & 0 (Inicial) & 9(Minutos) & 18(Minutos) \\
\hline \multirow{2}{*}{$\begin{array}{l}\text { LDP Masseter } \\
\text { Direito }\end{array}$} & Experimental & $1,600^{\mathrm{Aa}}$ & $1,590^{\text {Aab }}$ & $1,730^{\mathrm{AD}}$ \\
\hline & Controle & $2,77^{\mathrm{Ba}}$ & $1,988^{A D}$ & $2,230^{A D}$ \\
\hline \multirow{2}{*}{$\begin{array}{l}\text { LDP Masseter } \\
\text { Esquerdo }\end{array}$} & Experimental & $1,560^{\mathrm{Aa}}$ & $1,920^{\mathrm{Aa}}$ & $1,921^{\mathrm{Aa}}$ \\
\hline & Controle & $2,74^{\mathrm{Ba}}$ & $2.002^{A D}$ & $2.182^{\mathrm{Ab}}$ \\
\hline \multirow{2}{*}{$\begin{array}{l}\text { LDP Temporal } \\
\text { Anterior Direito }\end{array}$} & Experimental & $2,040^{\text {Aa }}$ & $2,060^{A D}$ & $2,970^{\text {Aab }}$ \\
\hline & Controle & $2,68^{\text {Aa }}$ & $1,823^{\mathrm{AD}}$ & $2,160^{\text {Aab }}$ \\
\hline \multirow{2}{*}{$\begin{array}{l}\text { LDP Temporal } \\
\text { Anterior } \\
\text { Esquerdo }\end{array}$} & Experimental & $2,135^{\text {Aa }}$ & $2,470^{A a}$ & $2,283^{\text {Aa }}$ \\
\hline & Controle & $2,974^{\mathrm{Aa}}$ & $2,231^{\text {Aab }}$ & $2,522^{A b}$ \\
\hline
\end{tabular}




\begin{tabular}{ccccc}
\hline \hline \multirow{2}{*}{$\begin{array}{c}\text { LDP Temporal } \\
\text { Médio Direito }\end{array}$} & Experimental & $2,592^{\mathrm{Aa}}$ & $3,329^{\mathrm{Ab}}$ & $2,350^{\mathrm{Ab}}$ \\
\cline { 2 - 5 } & Controle & $3,674^{\mathrm{Aa}}$ & $2,921^{\mathrm{Ab}}$ & $3,122^{\mathrm{AD}}$ \\
\hline $\begin{array}{c}\text { LDP Temporal } \\
\text { Médio Esquerdo }\end{array}$ & Experimental & $2,541^{\mathrm{Aa}}$ & $2,854^{\mathrm{Aa}}$ & $2,870^{\mathrm{Aa}}$ \\
\cline { 2 - 5 } & Controle & $3,866^{\mathrm{Aa}}$ & $3,101^{\mathrm{Ab}}$ & $3,321^{\mathrm{Ab}}$ \\
\hline LDP Temporal & Experimental & $2,546^{\mathrm{Aa}}$ & $2,972^{\mathrm{Aa}}$ & $3,950^{\mathrm{Aa}}$ \\
\cline { 2 - 5 } Posterior Direito & Controle & $3,717^{\mathrm{Aa}}$ & $3.236^{\mathrm{Aa}}$ & $3,541^{\mathrm{Aa}}$ \\
\hline $\begin{array}{c}\text { LDP Temporal } \\
\text { Posterior }\end{array}$ & Experimental & $2,905^{\mathrm{Aa}}$ & $3,128^{\mathrm{Aab}}$ & $3,073^{\mathrm{Ab}}$ \\
\cline { 2 - 5 } Esquerdo & Controle & $3,982^{\mathrm{Aa}}$ & $2,876^{\mathrm{Ab}}$ & $3,219^{\mathrm{Ab}}$ \\
\hline
\end{tabular}

Letras maiúsculas diferentes indicam diferença significante entre os grupos Experimental (GE) e Controle (GC). Letras minúsculas diferentes indicam diferença significante entre os tempos avaliados.

O músculo masseter no grupo controle se apresentou semelhante em ambos os lados no decorrer do teste, contudo o grupo experimental apresentou uma pequena alteração ao final do esforço mastigatório. Não houve diferença estatística significante na comparação entre os grupos (GRÁFICO 1).

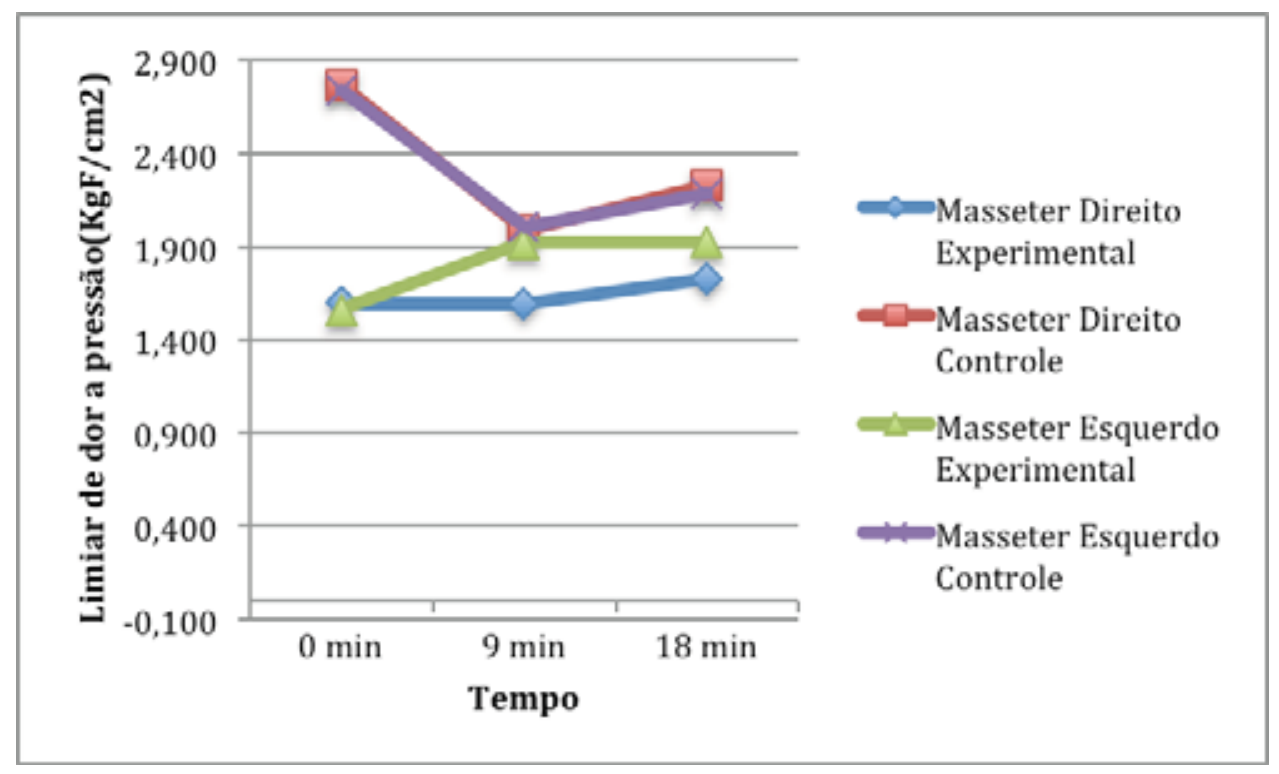

Gráfico 1. Limiar de dor a pressão em relação ao tempo no teste de fadiga mastigatória para o músculo masséter.

Para o músculo Temporal, a análise mostrou que não houve diferença entre as LDP's do GE e GC. Porém foi demostrado diferença no decorrer dos tempos (GRÁFICO 2). 


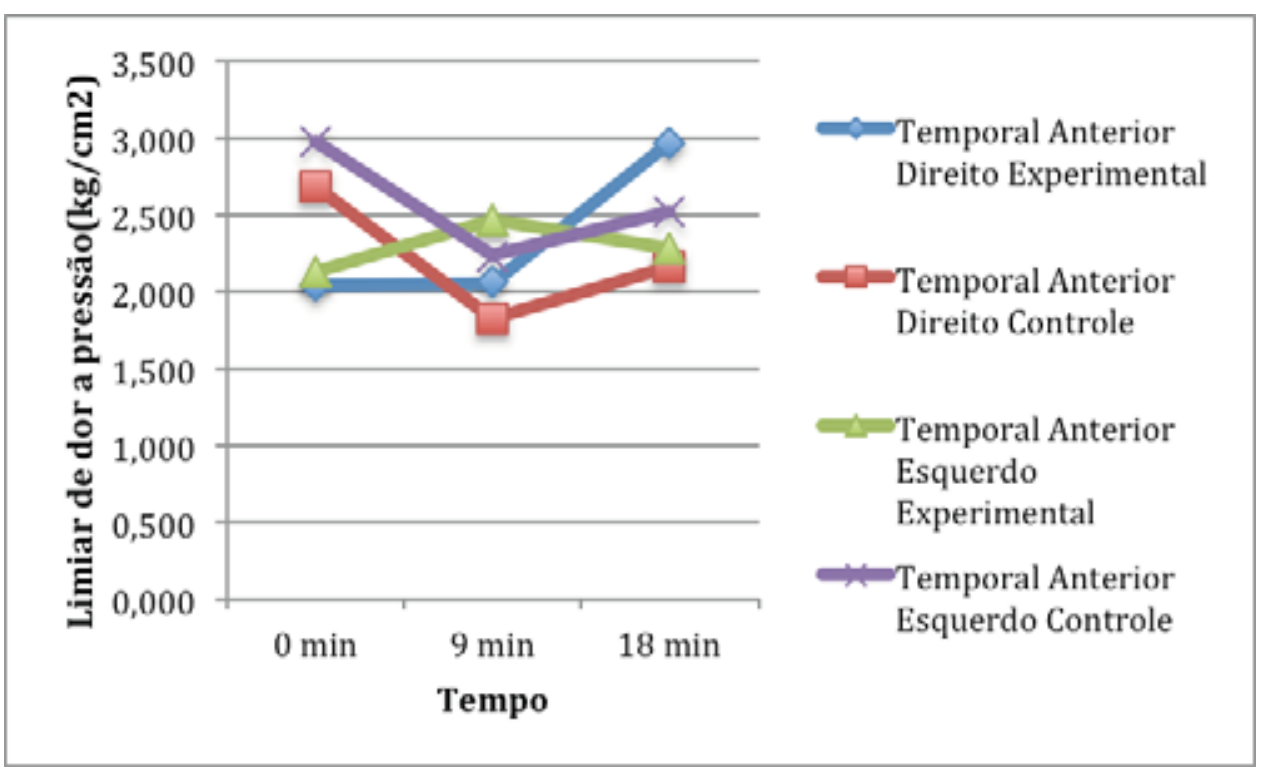

Gráfico 2. Limiar de dor a pressão em relação ao tempo no teste de fadiga mastigatória para o músculo temporal anterior.

O músculo temporal Médio apresentou dados no qual não houve diferença estatística significante entre os grupos e tempos (0, 9 e 18 minutos) referente ao teste de fadiga (GRÁFICO 3).

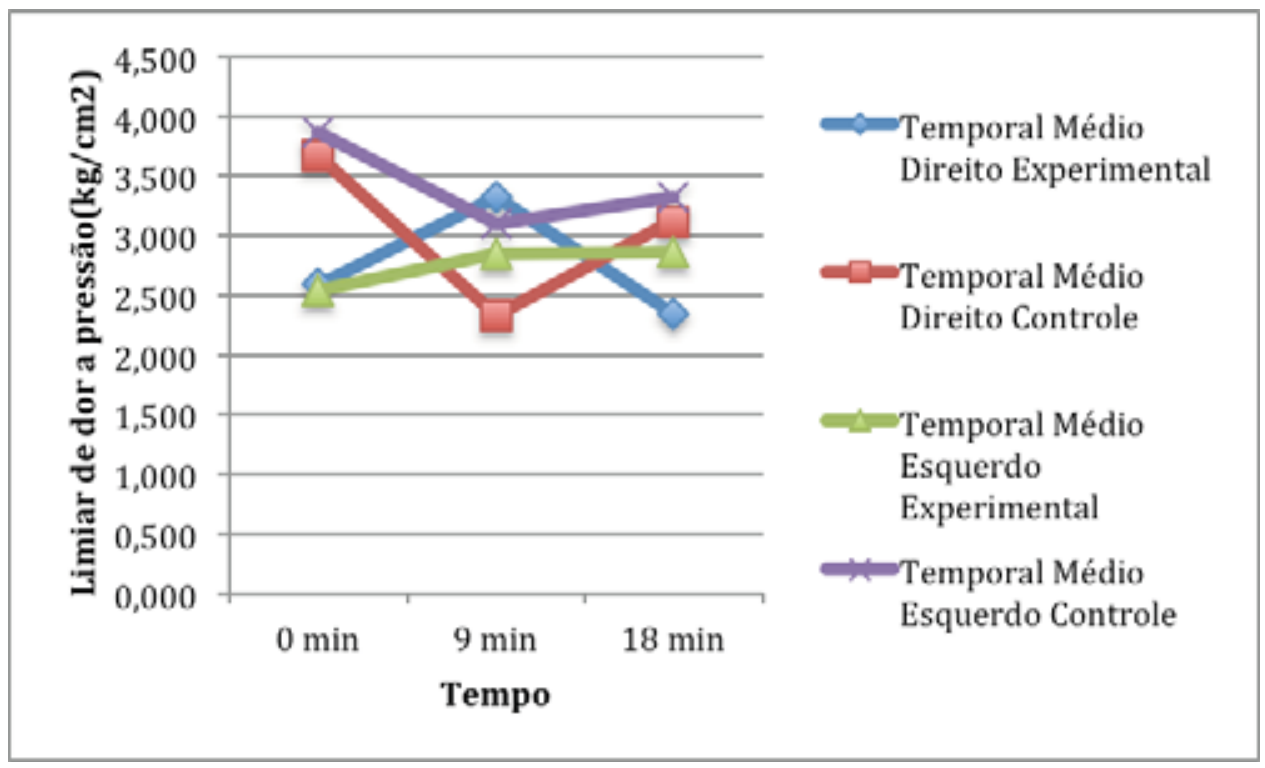

Gráfico 3. Limiar de dor a pressão em relação ao tempo no teste de fadiga mastigatória para o músculo temporal médio. 
O músculo temporal posterior após estimulado na mastigação pelo teste de fadiga não apresentou LDP diferente entre os GE e GC. Entre os tempos foi mostrado que essa diferença inexistiu $(p>0,05)$ (GRÁFICO 4).

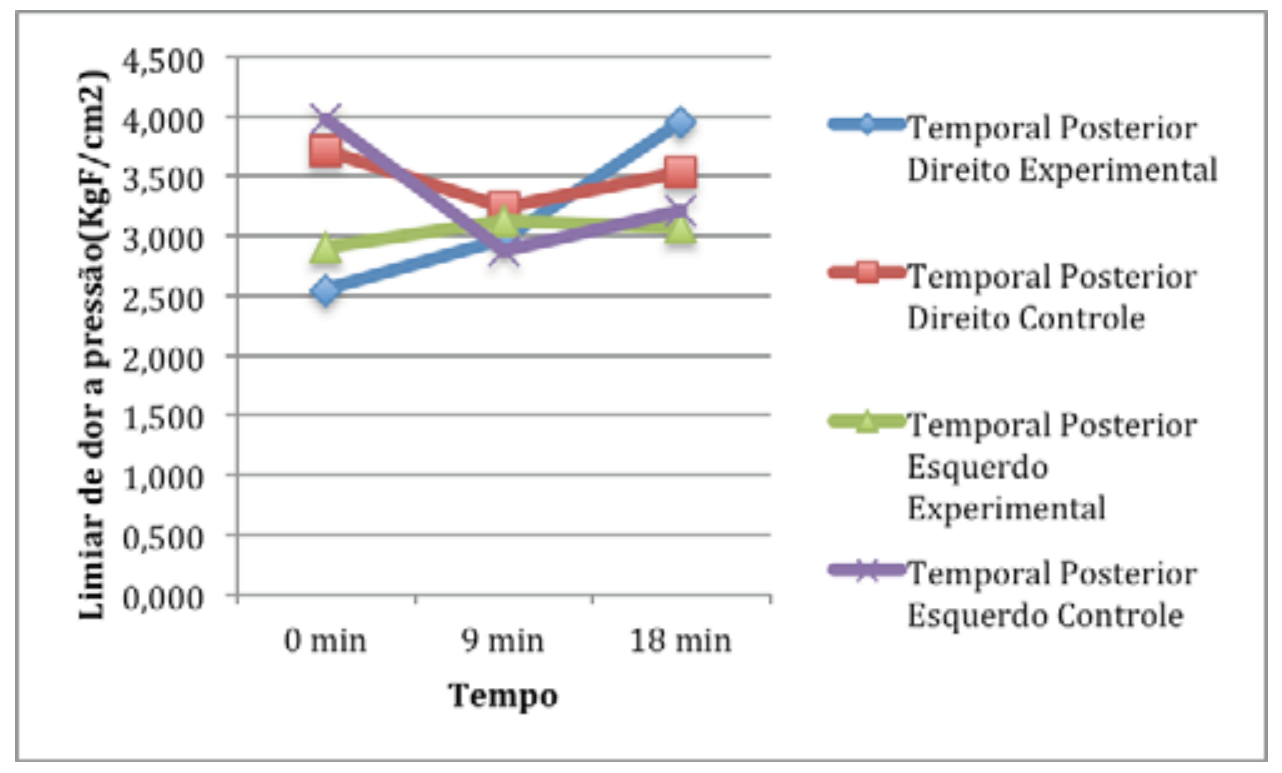

Gráfico 4. Limiar de dor a pressão em relação ao tempo no teste de fadiga mastigatória para o músculo temporal posterior.

\subsection{EAV PARA O TESTE DE FADIGA MASTIGATÓRIA}

Foi realizado um teste estatístico para verificar a diferença na sensação dolorosa durante o teste de fadiga (estímulo mastigatório) e no repouso pós teste para ambos os grupos (GE e GC). Para essa inferência, utilizou-se ANOVA medidas repetidas para os grupos, seguidas de Tukey para os tempos.

Segundo o teste, não houve diferença significante entre os grupos experimental e controle $(p=0,128)$ em relação a sensação dolorosa. Porém foi verificado a existência de diferentes níveis de dor estatisticamente significante para os tempos da coleta (TABELA 8,9).

Tabela 8. Teste de Tukey para determinar as diferenças entre os tempos no GE.

\begin{tabular}{llllccccc}
\hline Variáveis & Grupo & 0 min & 3 min & $\begin{array}{c}6 \\
\text { min }\end{array}$ & $\begin{array}{c}9 \\
\min \end{array}$ & $\begin{array}{c}12 \\
\min \end{array}$ & $\begin{array}{c}15 \\
\min \end{array}$ & $\begin{array}{c}18 \\
\min \end{array}$ \\
\hline EAV & Experimental & $0,6^{\mathrm{a}}$ & $9,8^{\mathrm{b}}$ & $12^{\mathrm{b}}$ & $15,6^{\mathrm{b}}$ & $10,2^{\mathrm{bd}}$ & $5,4^{\text {abde }}$ & $1,8^{\text {ace }}$ \\
\hline
\end{tabular}

Letras minúsculas diferentes indicam diferença significante entre os tempos avaliados. 
Tabela 9 . Teste de Tukey para determinar as diferenças entre os tempos GC.

\begin{tabular}{lllllllll}
\hline Variáveis & Grupo & 0 min & 3 min & 6 min & $\begin{array}{c}9 \\
\text { min }\end{array}$ & $\begin{array}{c}12 \\
\min \end{array}$ & $\begin{array}{c}15 \\
\min \end{array}$ & $\begin{array}{c}18 \\
\text { min }\end{array}$ \\
\hline EAV & Controle & $0,4^{\mathrm{a}}$ & $9,2^{\mathrm{b}}$ & $18^{\mathrm{bc}}$ & $27^{\text {bcd }}$ & $9,5^{\text {bde }}$ & $5,7^{\text {adeg }}$ & $2,0^{\text {acdefg }}$ \\
\hline
\end{tabular}

Letras minúsculas diferentes indicam diferença significante entre os tempos avaliados.

\subsection{CAPACIDADE MASTIGATÓRIA}

A capacidade mastigatória foi avaliada de acordo com as respostas do questionário para avaliação da capacidade de mastigação (APÊNDICE C).

As respostas dadas pelos indivíduos do GE foram comparadas entes e após a reabilitação protética (APÊNDICE F) e entre a situação final do GE com o GC . Para análise foi utilizado o Teste T para comprar o antes e depois do GE e esse com o GC.

As respostas que questionava algo subjetivo como que alimentos oferecia maior dificuldade para mastigar, $88,6 \%$ do grupo experimental responderam carne vermelha. Quando questionado o porquê, eles relatavam a falta de dentes $(91,3 \%)$ no período pré reabilitação(Q2).

Ao se questionar sobre a satisfação com o tempo que o paciente leva para mastigar durante as refeições $96,1 \%$ afirmavam satisfação. Como justificativa apontavam uma indicação da equipe de nutricionistas para aumentar o tempo que levaria para deglutir o alimento (APÊNCIDE G) .

Houve uma evolução da auto percepção da capacidade mastigatória em todos os quesitos relacionados a este item, mas ao se comparar com o grupo controle houve diferença significativa apenas para questões como facilidade em ingerir legumes frescos e padrões de mastigação unilateral ou bilateral.

\subsection{EFICIÊNCIA MASTIGATÓRIA}

A análise de pacientes desdentados e após a reabilitação mostrou uma melhora estatisticamente significativa $(p=0,000)$ (TABELA 10). A amostra controle (pacientes dentados) apresentou melhor condição em relação ao grupo experimental $(p=0,000)($ TABELA 11). 
Tabela 10. Eficiência Mastigatória antes e após a reabilitação oral da amostra do grupo experimental

\begin{tabular}{cccccccc}
\hline Variável & Média & Desvio Padrão & $\mathbf{n}$ & df & $\mathbf{p}$ & $\mathbf{C l}$ - & $\mathbf{C l +}$ \\
\hline $\begin{array}{c}\text { Eficiência } \\
\text { Mastigatória } \\
\text { Inicial }\end{array}$ & 4,46 & $\pm 0,68$ & & & & & \\
$\begin{array}{c}\text { Eficiência } \\
\text { Mastigatória } \\
\text { Final }\end{array}$ & 2,96 & $\pm 0,55$ & 60 & 29 & 0,000 & 1,31 & 1,68 \\
\hline
\end{tabular}

Tabela 11. Comparação da Eficiência Mastigatória do grupo experimental após reabilitação oral com o grupo controle

\begin{tabular}{clllllll}
\hline Eficiência Mastigatória & $\begin{array}{l}\text { Média } \\
\text { V1 }\end{array}$ & $\begin{array}{l}\text { Média } \\
\text { V2 }\end{array}$ & $\mathbf{t}$ & df & $\mathbf{p}$ & $\mathbf{n}(\mathbf{V 1})$ & $\mathbf{n}$ (V2) \\
\hline $\begin{array}{c}\text { Eficiência Mastigatória final } \\
\text { experimental(V1) }\end{array}$ & 2,96 & 1,00 & 13,15 & 42 & 0,000 & 60 & 30 \\
$\mathbf{X}$ & & & & & & & \\
$\begin{array}{c}\text { Eficiência Mastigatória } \\
\text { controle(V2) }\end{array}$ & & & & & & & \\
\hline
\end{tabular}

\subsection{ORAL HEALTH IMPACT PROFILE (OHIP-14)}

Para análise da qualidade de vida foi utilizado o OHIP-14 (Oral Health Impact Profile). O Mann-Whitney foi utilizado para verificar diferença estatística entre os grupos, de acordo com suas dimensões (TABELA 12). Segundo tal teste houve diferença estatística entre as dimensões, limitação funcional, dor física, desconforto psicológico, incapacidade física, incapacidade psicológica, incapacidade social e deficiência.

ANOVA para medidas repetidas também foi realizado para comprar os grupos (TABELA 13). 
Tabela 12. Disposição das médias das dimensões avaliadas pelo OHIP segundo os grupos.

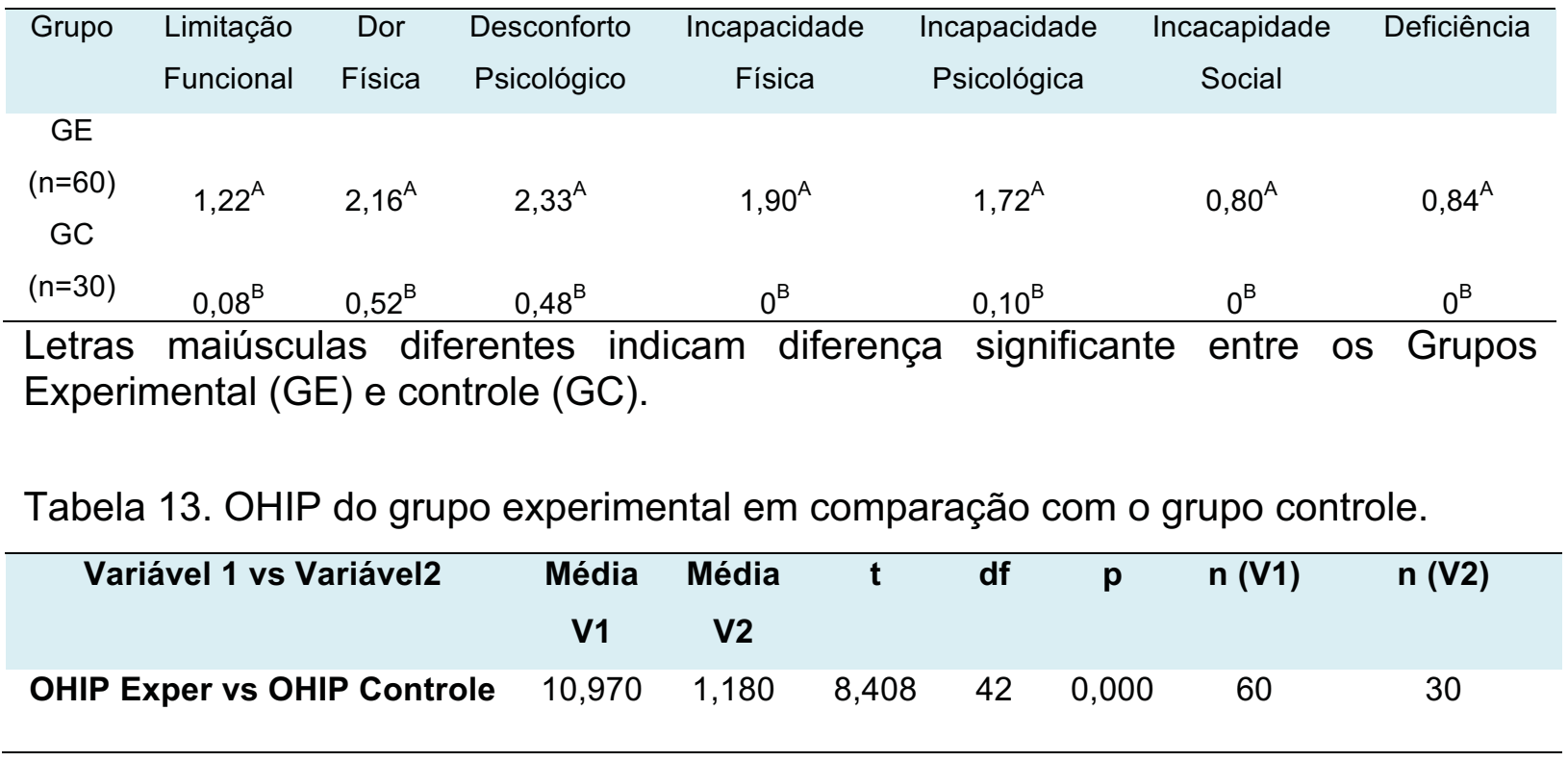

\subsection{PERDAS DE ELEMENTOS DENTÁRIOS POR ARCADA}

Foi calculado o número de dentes perdidos por arcada no grupo experimental $(n=60)$ (TABELA 14).

Tabela 14. Número de dentes perdidos por arcada

\begin{tabular}{ccc}
\hline Sujeitos(n) & Dentes Perdidos(n) & $\begin{array}{c}\text { Média de Dentes Perdidos } \\
\text { por arcada }\end{array}$ \\
60 & $\mathbf{1 . 0 5 7}$ & $\mathbf{8 , 8 0}$ \\
\hline
\end{tabular}

\subsection{ABERTURA BUCAL}

A abertura Bucal foi mensurada segundo critérios descritos do material e métodos sobre o grupo experimental e grupo controle. Na TABELA 15 foi analisada pelo teste t pareado a diferença entre a abertura bucal inicial e final $(p=0,003)$ onde houve uma diferença estatisticamente significante. Porém ao se comparar a situação final do grupo experimental $(n=60)$ com o grupo controle, não houve diferença entre os grupos (TABELA 16). 
Tabela 15. Abertura Bucal do grupo experimental antes e após a instalação da prótese dentária.

\begin{tabular}{|c|c|c|c|c|c|c|c|}
\hline \multirow[t]{2}{*}{ Variável } & \multirow[t]{2}{*}{ Média } & Desvio & \multirow[t]{2}{*}{$\mathrm{n}$} & \multirow[t]{2}{*}{ df } & \multirow[t]{2}{*}{$p$} & \multirow[t]{2}{*}{$\mathrm{Cl}$ - } & \multirow[t]{2}{*}{$\mathrm{Cl}+$} \\
\hline & & Padrão & & & & & \\
\hline AB Inicial & 50,33 & $\pm 3,345$ & \multirow{2}{*}{60} & \multirow{2}{*}{29} & \multirow{2}{*}{0,003} & \multirow{2}{*}{$-1,809$} & \multirow{2}{*}{$-0,390$} \\
\hline AB final & 51,43 & $\pm 3,420$ & & & & & \\
\hline
\end{tabular}

Tabela 16. Comparação da Abertura Bucal do grupo experimental após reabilitação oral com o grupo controle

\begin{tabular}{|c|c|c|c|c|c|c|c|}
\hline Variável 1 vs Variável2 & $\begin{array}{l}\text { Média } \\
\text { V1 }\end{array}$ & $\begin{array}{l}\text { Média } \\
\text { V2 }\end{array}$ & $\mathbf{t}$ & df & p & n (V1) & $\mathrm{n}(\mathrm{V} 2)$ \\
\hline $\begin{array}{c}\text { Abertura bucal final } \\
\text { experimental } \\
\mathrm{X}\end{array}$ & 51,43 & 50,35 & 0,662 & 42 & 0,511 & 60 & 30 \\
\hline Abertura bucal controle & & & & & & & \\
\hline
\end{tabular}


6 Discussão

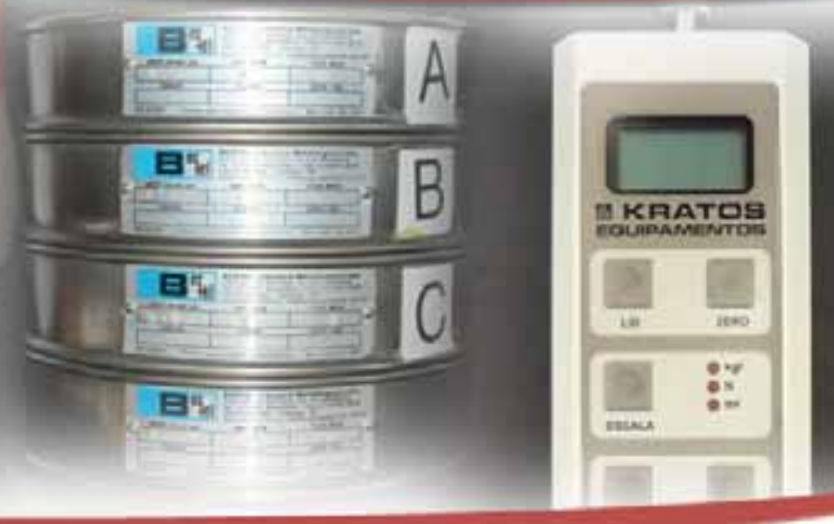





\section{DISCUSSÃO}

A amostra do presente estudo foi composta em sua maioria por mulheres (73,3\%), embora a distribuição da obesidade não difira entre os gêneros no Brasil (IBGE, 2010). Em estudo conduzido por Harris e Barger (2010) 83\% dos indivíduos submetidos à cirurgia bariátrica eram mulheres. $\mathrm{O}$ excesso de peso está associado à redução da qualidade de vida, uma vez que o ideal de corpo feminino se relaciona a imagem de magreza como símbolo da atratividade, beleza e sucesso na vida (BACEVICIENE; REKLAITIENE; TAMOSIUNAS, 2009).

Em se tratando das perdas dentárias, o levantamento epidemiológico brasileiro (BRASIL, 2010) para a faixa etária de $35-44$ anos evidenciou que $7,3 \%$ dos indivíduos apresentavam elementos dentários ausentes. Já a necessidade de prótese na população nessa faixa etária foi de $68,8 \%$. Para o presente estudo, os indivíduos foram divididos em dois grupos de acordo com presença ou ausência de dentes, sendo que os primeiros foram incluídos no grupo controle e aqueles com ausência fizeram parte do grupo experimental e foram reabilitados em suas necessidades.

A ausência de dentes pode desencadear algum grau de disfunção (RIBEIRO et al., 2002) e que a reabilitação é capaz de atuar positivamente na diminuição da severidade destes distúrbios nesses pacientes (GIL; NAKAME, 1999).

Para o diagnóstico adequado dos distúrbios que envolvem $\mathrm{O}$ aparato mastigatório, especificamente, são utilizados diferentes métodos, ferramentas e testes diagnósticos. Entre os testes diagnósticos apresentados na literatura o Limiar de Dor à Pressão (LDP) é um deles (MURPHY et al.,1992; FREDRIKSSON; ALSTERGREN; KOPP, 2000; ISSELEE et al., 2002). Por meio da palpação detectase esse Limiar de Dor a Pressão (LDP) dos indivíduos, porém, quando realizada sem treinamento nem calibração, pode resultar em um teste diagnóstico de pouca sensibilidade e especificidade, devido à presença de resultados falso-positivos (presença de dor em indivíduos saudáveis) e falso-negativos (ausência de dor em pessoas doentes) (GOMES et al., 2008; LUND; WIDMER; FEINE, 1995; VISSCHER et al., 2000), já que é difícil, durante a avaliação, quantificar e padronizar a pressão exercida nos músculos (BENDTSEN et al., 1994).

No presente estudo para reduzir os vieses utilizou-se o algômetro, para a medição quantitativa do LDP dos pacientes, garantindo maior confiabilidade ao 
exame de palpação. A determinação do LDP com o auxílio de um algômetro pode ser influenciada por alguns fatores, como a taxa de aplicação da pressão (pressão/segundo), o tempo de reação do paciente e do examinador à medida que a dor é detectada, a área da ponta do aparelho e o próprio aspecto subjetivo do relato de dor (GOULET et al., 1998; ISSELEE et al., 2002; OHRBACH; CROW; KAMER, 1998).

O consenso que existe sobre a taxa de aplicação é que ela deve ser constante e rápida o suficiente para evitar uma pressão prolongada aos tecidos e fadiga do examinador; e lenta o suficiente para permitir que o indivíduo examinado reaja no real momento em que sentiu a dor, evitando que haja superestimação devido ao tempo de reação (CHUNG et al.,1992; CHUNG et al.,1993; LIST et al., 1989; MENSE et al., 2001; MURPHY et al.,1992).

No grupo experimental foram avaliados os músculos masseter e temporal, sendo que neste foram mensurados anterior, médio e posterior, de ambos os lados.

O músculo masséter obteve valores do LDP que variaram de 2,08 - 2,14 após a reabilitação oral. Houve um aumento de seu valor em relação ao inicial, apesar de não haver diferença significativa para essa análise. No entanto, os valores se conservaram dentro de padrões aceitáveis para a condição de normalidade, que pode variar de 1,4 a $2,73 \mathrm{KgF} / \mathrm{cm}^{2}$ (LIST; HELKIMO,1987; LIST et al., 1989; MURPHY et al., 1992; ISSELÉE et al., 1997; OHRBACH; GALE,1989; FUJISAWA et al.,1999).

A porção anterior do músculo temporal junto ao masséter é a porção mais utilizada para o teste do LDP, devido a sua alta confiabilidade de dados, já que são músculos de fácil localização. A literatura aponta uma variação entre 1,49 - 2,87 (LIST; HELKIMO,1987; LIST et al.; 1989; CHUNG; UM; KIM, 1992; MURPHY et al., 1992; ISSELÉE et al., 1997) para o músculo temporal em indivíduos assintomáticos para dor. Os resultados encontrados nesta pesquisa mostraram uma diferença estatística que variou de 2,90 para 2,57. Apesar da redução no valor de LDP, os valores encontrados nos pacientes obesos após a reabilitação oral apresentam-se normais para pacientes sem sintomatologia dolorosa.

A análise do LDP para os músculos temporal médio e posterior apresentou redução em relação ao inicial, porém só houve diferença significativa para o temporal posterior. O LDP do músculo temporal médio apresentou um valor de 3,36 na sua condição final, valor que se assemelha a testes como o de Chung, Um e Kim 
(1992) que relatou um valor de 3,57 para pacientes assintomáticos. O mesmo autor em seu trabalho avaliou o músculo temporal posterior encontrando o valor de 3,54 $\mathrm{KgF} / \mathrm{cm}^{2}$ para pacientes sem relato de dor. $\mathrm{Na}$ presente pesquisa, o dado encontrado para o mesmo músculo foi de $3,47 \mathrm{KgF} / \mathrm{cm}^{2}$ em indivíduos obesos desdentados após a instalação da prótese.

No grupo controle foram avaliados os mesmos músculos, adotando-se os mesmos referencias que no grupo experimental.

Da mesma forma que o grupo experimental, os resultados obtidos com a mensuração do LDP no grupo de pacientes dentados obteve valores que são considerados normais, visto que são pacientes que não relataram queixa de dor ou sintomas de disfunção.

No grupo controle, para o músculo masséter foi encontrado o valor médio de 2,77, valor acima do limite de normalidade para esse grupo muscular, que é de 1,4 a 2,73 KgF/cm² (LIST; HELKIMO,1987; LIST et al., 1989; MURPHY et al., 1992; ISSELÉE et al., 1997; OHRBACH; GALE, 1989; FUJISAWA et al., 1999).

A variação entre 1,49 - 2,87 (LIST; HELKIMO, 1987; LIST et al., 1989; CHUNG; UM; KIM, 1992; MURPHY et al., 1992; ISSELÉE et al., 1997) é considerada normal para o músculo temporal no seu feixe anterior em pacientes sem sintomatologia dolorosa. Para o grupo controle, dentado, foi encontrado o valor de 2,81, semelhante aos estudos que utilizaram a mesma metodologia e mesmo feixe muscular. O feixe médio do músculo temporal apresentou nesta pesquisa valor médio de 3,73, valor maior do que demonstrado por Chung, Um e Kim (1992), que encontraram um valor de 3,57. Para o feixe posterior a literatura indica um valor de normalidade de $3,54 \mathrm{KgF} / \mathrm{cm}^{2}$ (CHUNG; UM; KIM,1992), no entanto o valor médio para o temporal posterior neste trabalho foi de 3,77 , assim como no feixe médio apresentou um valor maior do que o limite superior para o padrão de normalidade.

A análise entre os grupos experimental e controle apresentou resultados semelhantes para todos os grupos musculares, com exceção do músculo masséter, no qual o grupo experimental obteve menor média do LDP em relação o controle $(p=0,012)$. Apesar da diferença estatística entre os grupos, o valor do LDP em ambos não se incluem em valores que possibilitem o diagnóstico de alguma patologia relacionada à sensação de dor nesses pacientes, estando estes com valores considerados normais, segundo a literatura (LIST; HELKIMO,1987; LIST et al., 1989; MURPHY et al., 1992; ISSELÉE et al., 1997; OHRBACH;GALE, 1989; 
FUJISAWA et al.,1999).

A dor orofacial é uma reclamação comum, sendo frequentemente relacionada aos músculos mastigatórios e dor articular, chamados de desordens tempromandibulares (DMT) (CARLSSON, 1984; DWORKIN. et al., 1990) . A estimativa da dor é um passo muito importante para a avaliação inicial, bem como no processo de seguimento para determinar a eficácia de estratégias de tratamentos (CONTI et al., 2001).

A escala de análise visual (EAV) tem se mostrado eficiente em comparação com outros tipos de escalas, por ela não apresentar números ou qualquer outra marcação, a não ser uma reta com duas extremidades, a possibilidade de resultados tendenciosos por parte do paciente diminui consideravelmente (CONTI et al., 2001).

Merskey (1973) discutiu em seu trabalho tópicos importantes sobre a percepção e avaliação de dor de indivíduos e relatou que apesar das diferenças metodológicas, os trabalhos concordam que o limite de tolerância da dor devido a um estímulo nocivo é altamente influenciado pela emoção e por variáveis psicológicas, como expectativa e atitude ligadas ao estado emocional do indivíduo. Esse fato pode explicar os resultados obtidos quanto a falta de mudança na percepção dolorosa relacionada à EAV. Indivíduos obesos mórbidos que buscam a cirurgia bariátrica estão sujeitos a diversas etapas que desencadeiam transformações psicológicas, entre as quais estresse, comportamentos ansiosos e hábitos deletérios. Contudo, observou-se neste estudo que após a confecção das próteses para desdentados parciais ou totais houve uma melhora significativa em relação à sensação dolorosa. Esse fato pode ter sido desencadeado pela satisfação estética-funcional ou pela adequação na condição ocluso-muscular, contribuindo para melhorar a qualidade de vida.

Ao se analisar dor em indivíduos deve-se reconhecer que esta é uma experiência subjetiva, que no entanto é ordinariamente atribuída a eventos físicos que afetam o corpo. Nesse cenário, não é possível separar subjetivamente o quanto esta dor é causada pelo estímulo e quanto é causada pelas emoções. As investigações que relacionam limiar de dor consideram que a queixa de dor depende de fatores psicológicos, os quais são relativamente constantes de pessoa para pessoa e de grupo para grupo e que influenciam a variação da percepção de dor (MERSKEY,1973).

O teste de fadiga é a união do teste do Limiar de dor a pressão com a escala 
de análise visual, porém com registro de dados em tempos distintos para uma avaliação progressiva durante o processo de mastigação e durante seu repouso.

Os dados encontrados nesta pesquisa para o LDP não mostraram diferença significativa entre os grupos experimental e controle, com exceção do músculo masséter do lado direito. No entanto, ao se analisar a alteração no decorrer do tempo (0, 9 e 18 minutos) houve uma modificação estatisticamente significativa para ambos os grupos.

A diferença não foi identificada entre os grupos possivelmente devido a sua condição assintomática para dor ou queixa de disfunção, muito embora, pesquisas que analisaram grupos com características sintomatológicas distintas, tenham encontrado resultados com tendência a apresentar diferença entre os grupos (SANTOS SILVA et al., 2005; FARELLA et al., 2001).

No presente estudo, para o grupo experimental houve modificação do LDP no decorrer do tempo para os músculos masseter (lado direito), temporal anterior direito, temporal médio direito e temporal posterior esquerdo. No entanto, para o grupo experimental houve modificação do LDP em todos os grupos musculares em ambos os lados, com exceção do feixe posterior do músculo temporal do lado direito.

Há a tendência que o LDP diminua após o estresse mastigatório, porém diferentemente do encontrado no presente trabalho, Farella et al. (2001) em seu estudo para fadiga mastigatória, não identificou mudanças significativas de valores médios do LDP durante o teste de fadiga mastigatória. Estudos futuros poderão demonstrar melhor essas diferenças encontradas na fadiga mastigatória.

Ao se avaliar as variações da sensação dolorosa (EAV) no teste durante o esforço e repouso não houve diferenças entre os grupos, porém apresentou diferença significativa no transcorrer das mensurações. Segundo Farella et al. (2001) a recuperação muscular após o teste de fadiga mastigatória se apresenta rápida, fato este que veio convergir com os dados na presente pesquisa. Apesar das alterações durante o teste, ao se verificar no tempo final (9 $\mathrm{min}$ ) após o término do esforço mastigatório, o EAV alcançou um nível semelhante ao inicial.

Ao se avaliar as estruturas musculares e suas funções é importante obter dados a respeito da autopercepção do paciente a respeito dessas estruturas e de seu funcionamento.

Dentre as avaliações subjetivas, pode-se relacionar a autopercepção do 
indivíduo em relação a sua própria mastigação. A capacidade mastigatória foi o termo usado na presente pesquisa, para determinar a avaliação do paciente a respeito de sua mastigação, assim como foi descrito por Helkimo, Calrsson e Helkimo (1978) e Allen e McMillan (2002). Essa avaliação se realiza por meio da aplicação de questionários, não apresentando nenhuma correlação aos testes objetivos para a determinação da qualidade da função mastigatória (AKEEL et al.,1992; BORETTI et al.,1995; ALLEN, MCMILLAN, 2002). Existe um consenso na literatura que os indivíduos edêntulos total ou parciais superestimem sua habilidade mastigatória (BORETTI et al.,1995). Os testes de capacidade mastigatória incluem também outros aspectos da mastigação, como os aspectos psicológicos e de adaptação (OOSTERHAVEN et al.,1988).

$\mathrm{Na}$ presente pesquisa foi utilizado um questionário sobre vários aspectos relacionados com a mastigação. O principal intuito deste questionário foi fazer com que $\mathrm{o}$ indivíduo refletisse sobre pontos importantes, a serem considerados ao classificar qualitativamente (em ótima, boa, regular e ruim) e quantitativamente (através da nota) a sua capacidade mastigatória (SLAGTER et al.,1992; TSUGA et al.,1998; LEAKE,1990).

Mediante as respostas dadas ao questionário pôde-se perceber que os indivíduos do grupo experimental apresentaram uma divergência em relação a sua percepção antes do tratamento protético e após a sua realização. Entretanto, ao se comparar os grupos experimental e controle encontrou-se diferença significativa na percepção da capacidade de mastigação de pacientes obesos mórbidos desdentados parciais ou totais com prótese e totalmente dentados $(p=0,000)$.

Quando os pacientes foram questionados sobre a impossibilidade de mastigar algum tipo de alimento, aproximadamente $93 \%$ dos indivíduos do grupo experimental antes da colocação da prótese declaram que sim, enquanto nenhum individuo do grupo controle declarou apresentar este problema. E ao questionar, qual alimento não poderia ser mastigado, indicaram carne, verduras cruas e frutas de maior consistência, como alimentos difíceis de ser consumidos. A incapacidade da ingestão de carne é de grande importância para o indivíduo após a cirurgia bariátrica, uma vez que os pacientes passam a desenvolver em algumas situações dificuldade na ingestão de proteínas, em especial carne vermelha devido as limitações sistêmicas que a cirurgia impõe. Ao se mostrar a incapacidade antes do ato cirúrgico o paciente pode estar predisposto a desenvolver um quadro de anemia 
pós cirúrgica. Desta forma, a reabilitação oral desses pacientes se torna imprescindivel (BRODEUR et al.,1993; ALVAREZ-LEITE, 2004; BLOOMBERG, 2005), especialmente para pacientes obesos mórbidos indicados à cirurgia bariátrica.

Para avaliar o desempenho mastigatório, os indivíduos são freqüentemente convidados a mastigar um alimento teste. No entanto, o seu desempenho depende de qual material de teste é usado, o tamanho e forma do bolus, o número de ciclos mastigatórios permitidos e a quantificação do seu desempenho (ALBERT et al., 2003).

Diversos tipos de alimento de teste vêm sendo utilizados, incluindo formalina, gelatina endurecido, amendoins, cenouras e amêndoas (DAHLBERG, 1946; YURKSTAS; MANLY, 1950; LAMBRECHT, 1965; HELKIMO, CARLSON; HELKIMO, 1978; JIFFRY, 1981). Os alimentos naturais podem variar muito em sua consistência física, dependendo das condições agrícolas, além da possibilidade de estragar com o tempo. Ao se considerar que o elevado teor de água de gelatinas, amendoins, amêndoas e cenouras afeta a padronização dos testes, Edlund e Lamm (1980) propuseram a utilização de um material de moldagem de silicone de condensação como um alimento de teste.

O produto indicado pelos autores foi o Optosil囚 por apresentar gosto e odor mínimos, não sendo afetado pela água, com a vantagem de poder ser armazenado durante 7 dias sem perder a estabilidade dimensional para o fim que se destina. Além disso, as linhas pré-determinadas de clivagem não são observadas, sendo facilmente examinada após a mastigação. Este material se adapta as formas,

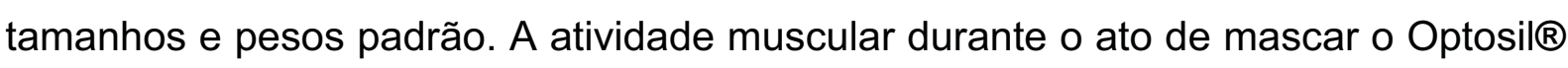
corresponde de forma similar a mastigar um alimento natural apesar da sua dureza (EDLUND; LAMM, 1980). Dessa forma, este material foi adotado na presente pesquisa.

Eficiência mastigatória é definida como uma medida da cominuição que os alimentos podem atingir sob condições de ensaio normais e indica a capacidade global necessária para a mastigação (PAPHANGKORAKIT e al., 2006).

Vários estudos têm validado métodos recentemente desenvolvidos, mostrando correlações positivas com a técnica que utiliza as peneiras, sendo esta adotada como controle (SATO et al., 2003; HIRANO et al., 2002).

Ao se analisar a eficiência mastigatória do grupo experimental inicial, notou- 
se que em uma condição bucal com perdas dentárias extensas, mesmo adotando-se o tempo máximo de mastigação (40 segundos), o resultado mostrou uma eficiência péssima, exceto em 11 indivíduos que apresentaram uma eficiência classificada como ruim. Após a confecção e adaptação das próteses segundo suas indicações houve melhora significativa no grupo experimental $(p=0,000)$. Houve melhora na condição classificada como péssima e ruim para regular em todos os indivíduos da amostra.

Contudo, ao se comparar grupo experimental e o controle os dados demonstraram que, mesmo com a melhora na condição do experimental, em relação ao inicial, ainda há uma diferença estatisticamente significativa para o grupo controle $(p=0,000)$. Tal diferença pode ser explicada pelo fato do grupo controle ser totalmente dentado e apresentar eficiência mastigatória classificada como ótima e boa. Estes achados vêm corroborar com os estudos de Akeel et al. (1993), Albert et al. (2003), Sato et al. (2003) e Prinz (2000), que demonstraram que mesmo próteses totais e removíveis bem adaptadas, apesar de melhorarem a condição dos desdentados totais ou parciais, não podem atingir um desempenho similar aos elementos dentários naturais.

Embora a perda dentária mesmo após a colocação de próteses não seja capaz de reabilitar a função mastigatória como a dos indivíduos dentados, o impacto dessa perda deve ser considerado e sua ação na qualidade de vida do indivíduo.

No presente estudo adotou-se a forma simplificada do questionário do Oral Health Impact Profile (OHIP-14) (SLADE,1994; SLADE,1996). Este instrumento vem sendo bastante utilizado para indicar os aspectos da qualidade de vida mais afetados pelo estado de saúde bucal e é um forte aliado no estabelecimento de melhores abordagens para atendimento integral ao paciente. O OHIP-14 permite indicar as dimensões da qualidade de vida afetadas pela condição de saúde bucal. Suas perguntas procuram relacionar a condição bucal ou das próteses em uso aos temas de cada uma delas.

A perda dentária pode ser considerada como uma saída para o fracasso de um tratamento conservador anteriormente realizado e pode se constituir em um evento de forte impacto, que, além de causar danos funcionais, é capaz de desequilibrar a organização psíquica e social das pessoas (MENDONÇA, 2001).

Ao se analisar as dimensões que compõem o OHIP, verificara-se diferença significativa em todas as dimensões ao se comparar o grupo experimental ao 
controle. Evidenciando que a falta de dentes causou um maior impacto na qualidade de vida desses indivíduos em relação aos seus pares dentados.

Para o grupo experimental as dimensões com os maiores escores foram de desconforto físico. A ausência total dos dentes também causou impacto negativo no que se refere à alimentação e inabilidade física. A estabilidade das próteses, especialmente as mandibulares e a adequada mastigação dos alimentos foram citados como fatores que muito interferem na qualidade de vida de pacientes desdentados, levando a uma pior condição de saúde geral, reforçando os achados de Oliveira (2003). No desconforto psicológico, a função estética dos dentes é, muitas vezes, considerada mais importante que a função mastigatória. Sob o ponto de vista subjetivo, já foi verificado que a perda de elementos localizados mais posteriormente na boca tem pouco ou nenhum impacto na vida das pessoas, diferentemente da perda dentária total ou de dentes anteriores, que motiva as pessoas a buscarem tratamento para substituição deles (JONES et al.,2003;). Para a incapacidade psicológica, a utilização de próteses totais removíveis inadequadas e a ausência total dos dentes podem causar efeitos como dificuldade para relaxar, embaraço, restrição em comer determinados alimentos e até perda da vontade de sair de casa (RIBEIRO et al.,2002).

O OHIP-14, somando os escores de todas as dimensões, mostrou que no grupo experimental obteve-se valor de 10,97 enquanto que para o grupo controle valor foi de 1,18 , diferença estatisticamente significativa $(p=0,000)$. Nos pacientes do grupo experimental, que apresentaram grandes perdas de elementos dentários, as pontuações do OHIP-14 foram maiores, o que indicou maior percepção do impacto da condição bucal na sua qualidade de vida. No entanto, os valores encontrados para o OHIP-14 no grupo experimental, apesar de diferente do controle ainda mostrou que a condição bucal não tem impacto sobre a qualidade de vida desses indivíduos, visto que o grau de obesidade no qual se enquadram acaba por ser o maior determinante em testes de qualidade de vida (BIAZEVIC et al., 2004).

Outros dados que apresentam interação com a obesidade foram identificados no presente estudo, como perdas dentárias por arcadas e grau de abertura bucal, tanto dos pacientes dentados como desdentados.

O número de dentes perdidos por arcada revela uma perspectiva da condição dentária que aquele paciente apresenta. A condição de desdentado parcial ou total pode ter uma correlação com o estado de obesidade nesses pacientes. Os achados 
da presente pesquisa, que relacionam número de dentes perdidos por arcada vai ao encontro de outros estudos descritos na literatura, uma vez que a perda dentária esteve associada à obesidade (GOMES et al., 2008; LUND; WIDMER; FEINE, 1995;)

No estudo de Bernardo et al., (2012) a diferença do IMC entre homens com diferentes números de dentes não foi estatisticamente significativo ( $p=0,193)$. Contudo, nas mulheres, com menos 10 dentes em pelo menos um arco e desdentadas apresentaram maior média de IMC do que aquelas com 10 ou mais dentes de ambos os arcos ( $p<0,001)$. A média do IMC foi menor em mulheres do que em homens com 10 ou mais dentes em ambas as arcadas ( $p<0,001$ ).

De acordo com o mesmo autor, uma análise de regressão multivariada de Poisson mostrou que a prevalência de obesidade geral foi 50\% maior em pessoas com menos de 10 dentes em pelo menos um arco quando comparados com aqueles com 10 ou mais dentes em ambos os arcos (BERNARDO et al., 2012). Esses dados convergem aos encontrados no presente estudo, no qual houve média de 8,80 dentes perdidos por arcada. A casuística relativa a perda dentária e obesidade ainda se apresenta inconclusiva. A ação do agente etiológico ainda não está clara, uma vez que não se pode afirmar que a obesidade causa a perda dentária, ou se a perda dentária contribui para o processo da obesidade. Estudos futuros devem ser realizados para se identificar o mecanismo de interação entre os dois desfechos.

A avaliação da função mandibular pode ser realizada por meio de vários testes de diagnóstico, incluindo palpação muscular, a avaliação oclusal e exames radiográficos. Um dos testes para auxiliar a avaliação da função das articulações temporomandibulares é a medição da amplitude de movimento das articulações durante a abertura máxima da bucal (AMB) e movimentos laterais e protrusivos. (FRIEDMAN,1992; OKESON,1998; DWORKIN,1990).

A abertura bucal no grupo experimental apresentou uma alteração estatisticamente significativa $(p=0,003)$ quando comparado o período inicial e final (edêntulo total ou parcial (T1) e após a reabilitação (T2). Porém, ao se analisar o T2 com o grupo controle essa condição não obteve diferenças significativas.

Em relação a abertura máxima bucal, tem sido apresentada uma varianção entre 43,3mm (RIEDER,1978) até 59,0mm em indivíduos normais (ZAWAWI et al., 2003). O parâmetro para essa análise envolve uma faixa relativamente ampla que compreende de 32-62 mm (apenas para as mulheres) e 39-75mm (para ambos os 
gêneros) (ZAWAWl et al., 2003). De acordo com Rieder (1978), os homens geralmente têm uma abertura de bucal maior do que as mulheres, pois em seu estudo, $83 \%$ dos homens tinham uma abertura de boca de $40-60 \mathrm{~mm}$, enquanto que $87 \%$ das mulheres tiveram uma abertura de boca de $35-55 \mathrm{~mm}$ (ZAWAWI et al., 2003). No presente estudo a variação da abertura bucal para o gênero feminino, que compôs cerca de 2/3 da amostra, variou de $37-56 \mathrm{~mm}$ com uma média de 49,52mm. Valores que se enquadram nos parâmetros proposto por Zawawi et al., (2003).

Devido à variabilidade no intervalo de abertura da boca ser muito grande, os clínicos não têm geralmente um referencial de medição para um determinado indivíduo, que se evidencie limitação na abertura bucal. Esta variabilidade pode estar relacionada a diferentes fatores, tais como a hipomobilidade ou hipermobilidade articular generalizada (ZAWAWI et al., 2003).

Dessa forma, analisando os resultados referentes a abertura bucal, o grau de abertura bucal encontrado tanto no grupo experimental (Média $=50,33 \mathrm{~mm}$ ) como no controle (Média $=51,43 \mathrm{~mm}$ ) se mostrou dentro dos padrões de normalidades, levando a um entendimento primário que a obesidade não afetaria na abertura bucal máxima. No entanto, não se pode afirmar com precisão devido a falta de parâmetro com limites bem definidos aceitos na comunidade científica (RIEDER,1978; ZAWAWI et al., 2003)

A análise do LDP como instrumento de diagnóstico para uma possível disfunção é uma etapa importante no estudo de pacientes que se submeterão à cirurgia bariátrica, visto o período que este paciente será submetido à mudança em seus hábitos alimentares, o que poderá promover alterações em seu sistema estomatognático.

A capacidade e eficiência mastigatória de pacientes obesos mórbidos com indicação para cirurgia bariátrica irá dispor na literatura dados para colaborar com o planejamento odontológico pré e pós cirúrgico, bem como embasar a equipe médica sobre a condição mastigatória desse grupo especial de pacientes, visando uma melhor adaptação a nova condição sistêmica e aos novos hábitos alimentares. 
7 conclusões

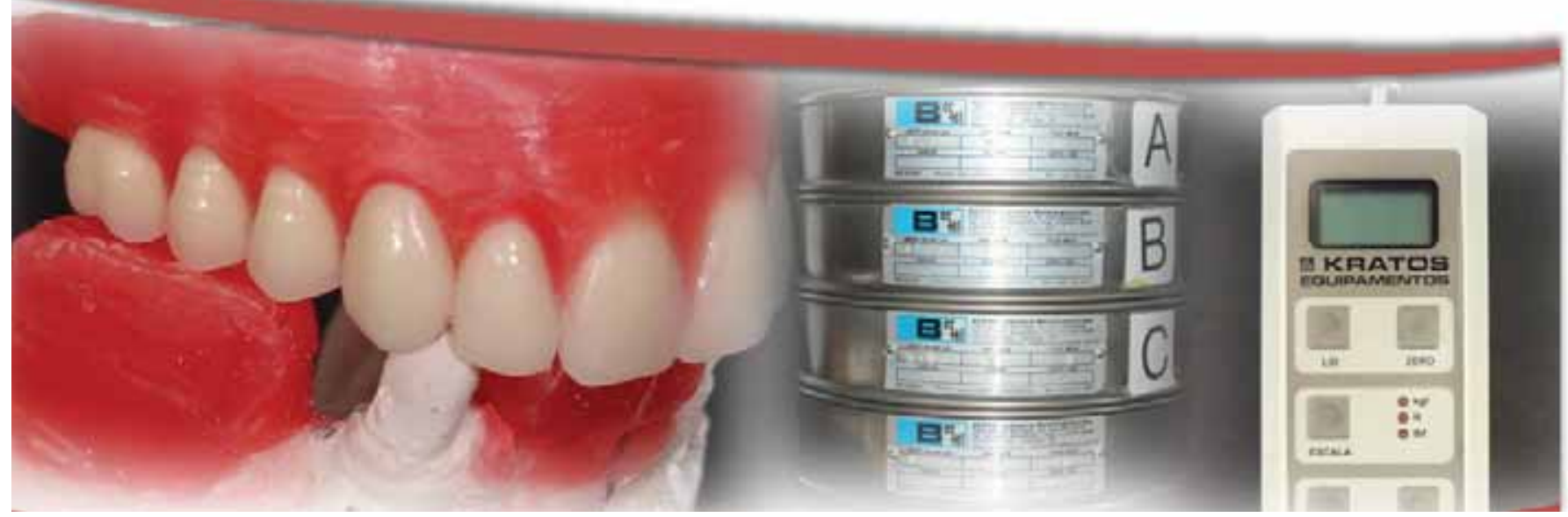



7 CONCLUSÕES

A reabilitação protética de pacientes desdentados na fase pré cirurgia bariátrica promoveu um impacto positivo nas condições de saúde bucal, especialmente na capacidade e eficiência mastigatórias, melhorando sua condição mecânica, promovendo entendimento da sua condição muscular e reduzindo sua percepção em relação à dor orofacial. Assim sendo, constatou-se a aceitação parcial das hipóteses 1, 2, 3 e 6 e aceitação total da hipótese 9, além da rejeição das hipóteses 4, 5, 7 e 8, uma vez que:

1. O Limiar de Dor a Pressão após a instalação da prótese dentária não apresentou diferença com significância clínica.

2. Houve Diferenças pontuais em alguns valores no LDP entre os pacientes usuários de prótese dentária e os dentados, principalmente no músculo masseter. Entretanto, todos os dados se encontraram dentro dos limites considerados como normais para pacientes assintomáticos.

3. Os valores do LDP para ambos os grupos se alteraram no decorrer do teste, embora sem sair de limites fora dos padrões normais.

4. No tempo inicial houve alteração na percepção de dor pelo paciente após a instalação da prótese no grupo experimental.

5. Após a reabilitação oral o grupo experimental apresentou uma evolução significativa da auto percepção da capacidade mastigatória após 45 dias de uso das próteses.

6. A capacidade mastigatória dos pacientes usuários de prótese foi em grande parte semelhante ao dos dentados, porém ainda apresentou questões com diferenças significativas em relação à auto percepção em algumas questões.

7. Após a instalação das próteses houve evolução na eficiência mastigatória do grupo experimental, o qual no tempo inicial apresentou eficiências nulas e atingiram condição regular no tempo final.

8. Com a reabilitação oral dos pacientes desdentados houve uma evolução na eficiência mastigatória, porém esse avanço não foi suficiente para alcançar os 
patamares de eficiência dos pacientes dentados.

9. A saúde bucal mostrou causar impacto moderado na qualidade de vida para o grupo experimental e baixo impacto para o grupo controle. 

Referências 





\section{REFERÊNCIAS}

Akeel R, Nilner M, Nilner K. Masticatory efficiency in individuals with natural dentition. Swed Dent J. 1992;16(5):191-8.

Albert TE, Buschang PH, Throckmorton GS. Masticatory performance: a protocol for standardized production of an artificial test food. J Oral Rehabil. 2003;30(7):720-2.

Allen F, McMillan A. Food selection and perceptions of chewing ability following provision of implant and conventional prostheses in complete denture wearers. Clin Oral Implants Res. 2002;13(3):320-6.

Alvarez-Leite JI. Nutrient deficiencies secondary to bariatric surgery. Curr Opin Clin Nutr Metab Care. 2004;7(5):569-75.

Arasaki CH, Del Grande JC, Yanagita ET, Alves AK, Oliveira DR. Incidence of regurgitation after the banded gastric bypass. Obes Surg. 2005;15(10):1408-17.

Baceviciene M, Reklaitiene R, Tamosiunas A. Effect of excess body weight on quality of life and satisfaction with body image among middle-aged Lithuanian inhabitants of Kaunas city. Medicina (Kaunas). 2009;45(7):565-73.

Barreto Villela N, Braghrolli Neto O, Lima Curvello K, Eduarda Paneili B, Seal C, Santos D, Cruz T. Quality of life of obese patients submitted to bariatric surgery. Nutr Hosp. 2004;19(6):367-71.

Bellisle F, Le Magnen J. The structure of meals in humans: eating and drinking patterns in lean and obese subjects. Physiol Behav. 1981;27(4):649-58.

Bendtsen L, Jensen R, Jensen NK, Olesen J. Muscle palpation with controlled finger pressure: new equipment for the study of tender myofascial tissues. Pain. 1994;59(2):235-9.

Berg E. Acceptance of full dentures. Int Dent J. 1993;43(3 Suppl 1):299-306.

Bernardo Cde O, Boing AF, Vasconcelos Fde A, Peres KG, Peres MA. Association between tooth loss and obesity in Brazilian adults: a populationbased study. Rev Saude Publica. 2012;46(5):834-42.

Beyron HL. Characteristics of functionally optimal occlusion and principles of occlusal rehabilitation. J Am Dent Assoc. 1954;48(6):648-56.

Biazevic MG, Michel-Crosato E, lagher F, Pooter CE, Correa SL, Grasel CE. Impact of oral health on quality of life among the elderly population of Joaçaba, Santa Catarina, Brazil. Braz Oral Res. 2004;18(1):85-91.

Bloomberg RD, Fleishman A, Nalle JE, Herron DM, Kini S. Nutritional deficiencies following bariatric surgery: what have we learned? Obes Surg. 2005;15(2):14554. 
Boretti G, Bickel M, Geering AH. A review of masticatory ability and efficiency. J Prosthet Dent. 1995;74(4):400-3.

Brodeur JM, Laurin D, Vallee R, Lachapelle D. Nutrient intake and gastrointestinal disorders related to masticatory performance in the edentulous elderly. J Prosthet Dent. 1993;70(5):468-73.

Buchwald H, Estok R, Fahrbach K, Banel D, Sledge I. Trends in mortality in bariatric surgery: a systematic review and meta-analysis. Surgery. 2007;142:621-32.

Buchwald H, Williams SE. Bariatric surgery worldwide 2003. Obes Surg. 2004;14(9):1157-64.

Carlsson GE, Omar R. The future of complete dentures in oral rehabilitation. A critical review. J Oral Rehabil. 2010;37(2):143-56.

Carlsson GE. Masticatory efficiency:the effect of age, the loss of teeth and prosthetic rehabilitation. Int Dent J. 1984;34:93-7.

Carvalho PS, Moreira CLCB, Barelli MC, Oliveira FH, Guzzo MF, Miguel GPS, Zandonade E. Cirurgia bariátrica cura síndrome metabólica? Arq Bras Endocrinol Metab. 2007;51(1):79-85.

Chaffee BW, Weston SJ. Association between chronic periodontal disease and obesity: a systematic review and meta-analysis. J Periodontol. 2010;81(12):170824.

Chauncey $\mathrm{HH}$, Muench ME, Kapur KK, Wayler AH. The effect of the loss of teeth on diet and nutrition. Int Dent J. 1984;34(2):98-104.

Christensen GJ. Provisional restorations for fixed prosthodontics. J Am Dent Assoc. 1996;127(2):249-52.

Chung SC, Kim JH, Kim HS. Reliability of the pressure pain thresholds (PPT) in the TMJ capsules by electronic algometer. Cranio. 1993;11(3):171-6.

Chung SC, Um BY, Kim HS. Evaluation of a pressure pain threshold in head and neck muscles by electronic algometer: intrarater and interrrater reliability.

Cranio. 1992;10(1):28-34.

Cleary TJ, Hutton JE. An assessment of the association between functional edentulism, obesity, and NIDDM. Diabetes Care. 1995;18(7):1007-9.

Confederação Nacional de Saúde . [Homepage na internet] Brasília: CNS 2012 [acesso em 2012 Nov 13]. Disponível em: http://www.cns.org.br/cns/_circ/2012/09/CNS_081_2012.doc

Conti PC, de Azevedo LR, de Souza NV, Ferreira FV. Pain measurement in TMD 
patients: evaluation of precision and sensitivity of different scales J Oral Rehabil. 2001;28(6):534-9.

Conti PC, Silva Rdos S, Araujo Cdos R, Rosseti LM, Yassuda S, da Silva $\mathrm{RO}$, Pegoraro LF. Effect of experimental chewing on masticatory muscle pain onset. J Appl Oral Sci. 2011;19(1):34-40.

Custodio W, Gomes SG, Faot F, Garcia RC, Del Bel Cury AA. Occlusal force electromyographic activicty of masticatory muscles and mandibular flexure of subjects with different facial types. J Appl Oral Sci. 2011; 19(4):343-9.

Dahlberg B. The masticatory habits; an analysis of the number of chews when consuming food. J Dent Res. 1946;25:67-72.

De Jonge L, Garrel DR. Role of the autonomic nervous system in the thermogenic response to food in lean individuals. Am J Physiol. 1997;272(5 Pt-1):E775-80.

De Lucena SC, Gomes SG, Da Silva WJ, Del Bel Cury AA. Patients' satisfaction and functional assessment of existing complete dentures: correlation with objective masticatory function J Oral Rehabil. 2011;38(6):440-6

De Oliveira CM, Sheiham A.The relationship between normative orthodontic treatment need and oral health-related quality of life. Community Dent Oral Epidemiol. 2003;31(6):426-36.

Dinsa GD, Goryakin Y, Fumagalli E, Suhrcke M. Obesity and socioeconomic status in developing countries: a systematic review. Obes Rev. 2012;13(11):106779.

Dworkin SF, LeResche L, DeRouen T, Von Korff M. Assessing clinical signs of temporomandibular disorders: Reliability of clinical examiners. J Prosthet Dent. 1990;63(5):574-9.

Edlund J, Lamm CJ. Masticatory efficiency. J Oral Rehabil. 1980;7(2):123-30.

Elder KA, Wolfe BM. Bariatric surgery: a review of procedures and outcomes. Gastroenterology. 2007;132(6):2253-71.

Encinosa WE, Bernard DM, Du D, Steiner CA. Recent improvements in bariatric surgery out- comes. Med Care. 2009;47(5):531-5.

Ernest SL. Dietary intake, food preferences, stimulated salivary flow rate, and masticatory ability in older adults with complete dentitions. Spec Care Dentist. 1993;13(3):102-6.

Fandiño J, Benchimol AK, Coutinho WF, Appolinário JC. Cirurgia Bariátrica: aspectos clínicos-cirúrgico e psiquiátricos. R Psiquiatr RS. 2004;26(1):47-51.

Farella M, Bakke M, Michelotti A, Martina R. Effects of prolonged gum chewing on pain and fatig in human jaw muscles. Eur J Oral Sci. 2001;109(2):81-5. 
Ferraz EM. Cirurgia bariátrica: indicações e importância do trabalho multidisciplinar. São Paulo:Einstein, 2006.

Ferreira VA, Magalhães R. Obesity among the poor in Brazil: female vulnerability. Cien Saude Colet. 2011;16(4):2279-87.

Fillion L, Henry CJ. Nutrient losses and gains during frying: a review. Int J Food Sci Nutr. 1998;49(2):157-68.

Flegal KM, Carroll MD, Ogden CL, Curtin LR. Prevalence and trends in obesity among US adults, 1999-2008. Jama. 2010;303(3):235-41.

Fontijn-Tekamp FA, van der Bilt A, Abbink JH, Bosman F. Swallowing threshold and masticatory performance in dentate adults. Physiol Behav. 2004;83(3):431-6.

Francischi RPP, Pereira LO, Freitas CS, Klopfer M, Santos RC, Vieira P, Lancha Junior AH. Obesidade: atualização sobre sua etiologia, morbidade e tratamento. Rev Nutr. 2000;13(1):17-28.

Fredriksson L, Alstergren $\mathrm{P}$, Kopp S. Absolute and relative facial pressure-pain thresholds in healthy individuals. J Orofac Pain. 2000;14(2):98-104.

Fujisawa M, Shoji S, Ishibashi K, Clark GT. Pressure pain threshold with and without iontophoretic anesthesia of the masseter muscle in asymptomatic males. J Orofac Pain. 1999;13(2):97-103.

Geissler CA, Bates JF. The nutritional effects of tooth loss. Am J Clin Nutr. 1984;39(3):478-89.

Genco RJ, Grossi SG, Ho A, Nishimura F, Murayama Y. A proposed model linking inflammation to obesity, diabetes, and periodontal infections. J Periodontol. 2005;76(11):2075-84.

Gibbs $\mathrm{CH}$, Mahan PE, Lundeen HC, Brehnan K, Walsh EK, Sinkewiz SL, Ginsberg SB. Occlusal forces during chewing--influences of biting strength and food consistency. J Prosthet Dent. 1981;46(5):561-7.

Gil C, Nakamae AEM. Avaliação das disfunções craniomandibulares em pacientes parcialmente edentados unilaterais - um estudo longitudinal sobre o efeito da utilização de prótese parcial removível (PPR). Rev Odontol Univ São Paulo. 1999; 13(3):275-82.

Godlewski AE, Veyrune JL, Nicolas E. Obesity and oral health: risk factors of obese patients in dental practice. Odontostomatol Trop. 2008;31(123):25-32.

Godlewski AE, Veyrune JL, Nicolas E, Ciangura CA, Chaussain CC, Czernichow $S$, Basdevant A, Hennequin M. Effect of dental status on changes in mastication in patients with obesity following bariatric surgery. PLoS One. 2011;6(7):e22324. 
Goiato MC, Garcia AR, dos Santos DM. Electromyographic evaluation of masseter and anterior temporalis muscles in resting position and during maximum tooth clenching of edentulous patients before and after new complete dentures. Acta Odontol Latinoam. 2007;20(2):67-72.

Goiato MC, Ribeiro Pdo P, Garcia AR, dos Santos DM. Complete denture masticatory efficiency: a literature review. J Calif Dent Assoc. 2008;36(9):683-6.

Gomes MB, Guimaraes JP, Guimaraes FC, Neves AC. Palpation and pressure pain threshold: reliability and validity in patients with temporomandibular disorders. Cranio. 2008;26(3):202-10.

Goulet JP, Clark GT, Flack VF, Liu C. The reproducibility of muscle and joint tenderness detection methods and maximum mandibular movement measurement for the temporomandibular system. J Orofac Pain. 1998;12(1):1726.

Gunne HS, Bergman B, Enbom L, Hogstrom J. Masticatory efficiency of complete denture patients. A clinical examination of potential changes at the transition from old to new denture. Acta Odontol Scand. 1982;40(5):289-97.

Harris AA, Barger MK. Specialized care for women pregnant after bariatric surgery. J Midwifery Womens Health. 2010;55(6):529-39.

Hasegawa Y, Sakagami J, Ono T, Hori K, Zhang M, Maeda Y. Circulatory response and autonomic nervous activity during gum chewing. Eur J Oral Sci. 2009;117(4):470-3.

Hatch JP, Shinkai RS, Sakai S, Rugh JD, Paunovich ED. Determinants of masticatory performance in dentate adults. Arch Oral Biol. 2001;46(7):641-8.

Helkimo E, Carlsson GE, Helkimo M. Chewing efficiency and state of dentition. A methodologic study. Acta Odontol Scand. 1978;36:33-41.

Henderson L, Gregory J, Irving K, Swan G. The National Diet and Nutrition Survey: adults aged 19 to 64 years. Volume 2: Energy, pro- tein, carbohydrate, fat and alcohol intake. Norwich: HMSO; 2003.

Henderson L, Gregory J, Swan G. The National Diet and Nutrition Survey: adults aged 19 to 64 years. Volume 1: Types and quantities of foods consumed. Norwich: HMSO; 2002.

Hildebrandt GH, Loesche WJ, Lin CF, Bretz WA. Comparison of the number and type of dental functional units in geriatric populations with diverse medical backgrounds. J Prosthet Dent. 1995;73(3):253-61.

Hilgert JB, Hugo FN, de Sousa Mda L, Bozzetti MC. Oral status and its association with obesity in Southern Brazilian older people. Gerodontology. 2009;26(1):46-52.

Hirano K, Hirano S, Hayakawa I. The role of oral sensorimotor function in 
masticatory ability. J Oral Rehabil. 2004;31(3):199-205.

Honma K, Kohno S, Honma W, Sakurai N. A study on the differences in function of free-sided and unilateral chewing. Nihon Hotetsu Shika Gakkai Zasshi. 2005;49(3):459-68.

IBGE - Instituto Brasileiro de Geografia e Estatística. [Homepage na internet] Brasília IBGE 2010 [acesso em 2012 Nov 02]; Disponível em:

http://www.ibge.gov.br/home/presidencia/noticias/noticia_visualiza.php?id_noticia $=1$ 699\&id_pagina=1

Isselée H, De Laat A, De Mot B, Lysens R. Pressure-pain threshold variation in temporomandibular disorder myalgia over the course of the menstrual cycle. $J$ Orofac Pain. 2002;16(2):105-17.

Isselée H, De Laat A, Lesaffre E, Lysens R. Short-term reproducibility of pressure pain threshold in masseter and temporalis muscles of symptom-free subjects. Europ. Eur J Oral Sci. 1997;105(6):583-7.

James PT, Rigby N, Leach R. The obesity epidemic, metabolic syndrome and future prevention strategies. Eur J Cardiovasc Prev Rehabil. 2004;11(1):3-8.

Jansson L, Lavstedt S, Ffrithiof L. Relationship between oral health and mortality rate. J Clin Periodontol 2002;29(11):1029-1034.

Jensen R, Rasmussen BK, Pedersen B, Lous I, Olesen J. Cephalic muscle tenderness and pressure pain threshold in a general population.

Pain. 1992;48(2):197-203.

Jiffry MT. Variations in the particles produced at the end of mastication in subjects with different types of dentition. J Oral Rehabil. 1983;10(4):357-62.

Johansson I, Tidehag P, Lundberg V, Hallmans G. Dental status, diet and cardiovascular risk factors in middle-aged people in northern Sweden. Community Dent Oral Epidemiol. 1994;22(6):431-6.

Jones JA, Orner MB, Spiro A, 3rd, Kressin NR. Tooth loss and dentures: patients' perspectives. Int Dent J. 2003;53(5):327-34.

Joshipura KJ, Willett WC, Douglass CW. The impact of edentulousness on food and nutrient intake. J Am Dent Assoc. 1996;127(4):459-67.

Kayser AF. Shortened dental arches and oral function. J Oral Rehabil. 1981;8(5):457-62.

Kopelman PG. Obesity as a medical problem. Nature. 2000;404(6778):635-43. Lambrecht JR. The influence of occlusal contact area on chewing performance. J Prosthet Dent. 1965;15:444-50. 
Leake JL. An index of chewing ability. J Public Health Dent. 1990;50(4):262-7. Liedberg B, Owall B. Masticatory ability in experimentally induced xerostomia. Dysphagia. 1991;6(4):211-3.

List T, Helkimo M, Falk G. Reliability and validity of a pressure threshold meter in recording tenderness in the masseter muscle and the anterior temporalis muscle. Cranio. 1989;7(3):223-9.

List T, Helkimo M. Method for measuring muscle pain with the aid of algometer. Sweed Dent. J. 1987;11: 294 (Abstract 69)

Loesche WJ. Dental caries: a treatable infection. Ann Arbor: University of Michigan Dental Publications, 1982:165-85.

Lowe G, Woodward M, Rumley A, Morrison C, Tunstall-Pedoe H, Stephen K. Total tooth loss and prevalent cardiovascular disease in men and women: possible roles of citrus fruit consumption, vitamin $\mathrm{C}$, and inflammatory and thrombotic variables. J Clin Epidemiol. 2003;56(7):694-700.

Lund JP, Widmer CG, Feine JS. Validity of diagnostic and monitoring tests used for temporomandibular disorders. J Dent Res. 1995;74(4):1133-43.

Malinowski SS. Nutritional and metabolic complications of bariatric surgery. Am J Med Sci. 2006;331(4):219-25.

Marsicano JA, Grec PG, Belarmino LB, Ceneviva R, Peres SH. Interfaces between bariatric surgery and oral health: a longitudinal survey. Acta Cir Bras. 2011;26 Suppl 2:79-83.

Mathus-Vliegen EM, Nikkel D, Brand HS. Oral aspects of obesity. Int Dent J. 2007;57(4):249-56.

Mattes RD. Physiologic responses to sensory stimulation by food: nutritional implications. J Am Diet Assoc. 1997;97(4):406-13.

McMillan AS, Blasberg B. Pain-pressure threshold in painful jaw muscles following trigger point injection. J Orofac Pain. 1994;8(4):384-90.

Meisel P, Wilke P, Biffar R, Holtfreter B, Wallaschofski H, Kocher T. Total tooth loss and systemic correlates of inflammation: role of obesity. Obesity (Silver Spring). 2012;20(3):644-50.

Mendonça TC. Dental mutilation: rural workers' concepts of responsibility for tooth loss. Cad Saude Publica. 2001;17(6):1545-7.

Mense S, Simons DG. Muscle pain: understanding its nature, diagnosis and treatment. Philadelphia: Lippincott Williams \& Wilkins, 2001.

Merskey $\mathrm{H}$. The perception and measurement of pain. J Psychosom Res. 1973;17(4):251-5. 
Michael CG, Javid NS, Colaizzi FA, Gibbs CH. Biting strength and chewing forces in complete denture wearers. J Prosthet Dent. 1990;63(5):549-53.

Momose T, Nishikawa J, Watanabe T, Sasaki Y, Senda M, Kubota K, Sato Y, Funakoshi M, Minakuchi S. Effect of mastication on regional cerebral blood flow in humans examined by positron-emission tomography with (1)(5)O-labelled water and magnetic resonance imaging. Arch Oral Biol. 1997;42(1):57-61.

Mondini L, Monteiro CA. Relevance of under and overnutrition in different social classes: methods and application to the Brazilian population. Rev Bras Epimiol. 1998; 1(1):28-39.

Monteiro CA, Moura EC, Conde WL, Popkin BM. Socioeconomic status and obesity in adult populations of developing countries:a review. Bull World Health Organ. 2004; 82(12): 940-46.

Moura-Grec PG, Assis VH, Cannabrava VP, Vieira VM, Siqueira TL, Anaguizawa $\mathrm{WH}$, Sales-Peres SH. Systemic consequences of bariatric surgery and its repercussions on oral health. Arq Bras Cir Dig. 2012;25(3):173-7.

Moynihan P, Bradbury J. Compromised Dental Function and Nutrition. Nutrition. 2001;17(2):177-8.

Murphy GJ, Mckinney MW, Gross WG. Temporomandibular-related pressure thresholds: a model for establishing baselines. Cranio. 1992;10(2):118-23.

Murphy WM. The effect of complete dentures upon taste perception. Br Dent J. 1971;130(5):201-5.

N'Gom PI, Woda A. Influence of impaired mastication on nutrition. J Prosthet Dent. 2002;87(6):667-73.

Nishida N, Tanaka M, Hayashi N, Nagata H, Takeshita T, Nakayama K, Morimoto $\mathrm{K}$, Shizukuishi S. Determination of smoking and obesity as periodontitis risks using the classification and regression tree method. J Periodontol. 2005;76(6):923-8.

Nowjack-Raymer RE, Sheiham A. Numbers of natural teeth, diet, and nutritional status in US adults. J Dent Res. 2007;86(12):1171-5.

Ohrbach R, Crow H, Kamer A. Examiner expectancy effects in the measurement of pressure pain thresholds. Pain. 1998;74(2-3):163-70.

Ohrbach R, Gale EN. Pressure pain threshold in normal muscles: reliability, measurement effects, and topographic differences. Pain. 1989;37(3):257-63.

Okeson JP. Management of Temporomandibular Disorders and Occlusion. St. Louis: Mosby; 1998. 
Okiyama S, Ikebe K, Nokubi T. Association between masticatory performance and maximal occlusal force in young men. J Oral Rehabil. 2003;30(3):278-82.

Olthoff LW, van der Bilt A, Bosman F, Kleizen HH. Distribution of particle sizes in food comminuted by human mastication. Arch Oral Biol. 1984;29(11):899-903.

Oosterhaven SP, Westert GP, Schaub RM, van der Bilt A. Social and psychologic implications of missing teeth for chewing ability. Community Dent Oral Epidemiol. 1988;16(2):79-82.

Ottenhoff FA, van der Bilt A, van der Glas HW, Bosman F. Control of elevator muscle activity during simulated chewing with varying food resistance in humans. J Neurophysiol. 1992;68(3):933-44.

Palacios C, Joshipura K, Willett W. Nutrition and health: guidelines for dental practitioners. Oral Dis. 2009;15(6):369-81.

Paphangkorakit J, Thothongkam N, Supanont N. Chewing-side determination of three food textures. J Oral Rehabil. 2006;33(1):2-7.

Pera P, Bucca C, Borro P, Bernocco C, De LA, Carossa S. Influence of mastication on gastric emptying. J Dent Res. 2002;81(3):179-81.

Piancino MG, Farina D, Talpone F, Castroflorio T, Gassino G, Margarino $V$, Bracco P. Surface EMG of jaw-elevator muscles and chewing pattern in complete denture wearers. J Oral Rehabil. 2005;32(12):863-70.

Pischon N, Heng N, Bernimoulin JP, Kleber BM, Willich SN, Pischon T. Obesity, inflammation, and periodontal disease. J Dent Res. 2007;86(5):400-9.

Prinz JF, Heath MR.Bolus dimensions in normal chewing.J Oral Rehabil. 2000;27(9):765-8.

Renquist K. Obesity classification. Obes Surg. 1998;8(4):480.

Ribeiro RA, Mollo Júnior FA, Pinelli LAP, Arioli Júnior JN, Ricci WA. Prevalência de disfunção craniomandibular em pacientes portadores de próteses totais duplas e pacientes dentados naturais. Cienc Odontol Bras, 2002;5(3):84-89.

Rieder CE. Maximum mandibular opening in patients with and without a history of TMJ dysfunction. J Prosthet Dent. 1978;39(4):441-6.

Ritchie CS. Obesity and periodontal disease. Periodontol 2000. 2007;44(1):15463.

Saito T, Shimazaki Y, Kiyohara Y, Kato I, Kubo M, lida M, Yamashita Y. Relationship between obesity, glucose tolerance, and periodontal disease in Japanese women: the Hisayama study. J Periodontal Res. 2005;40(4):346-53.

Saito T, Shimazaki Y. Metabolic disorders related to obesity and periodontal 
disease. Periodontol 2000. 2007;43:254-66.

Santo MA, Cecconello I. Obesidade mórbida: controle dos riscos. Arq Gastroenterol. 2008;45(1):1-2.

Santos Silva RS, Conti PC, Lauris JR, da Silva RO, Pegoraro LF. Pressure pain threshold in the detection of masticatory myofascial pain: an algometer-based study. J Orofac Pain. 2005; 19(4):318-24.

Sato H, Fueki K, Sueda S, Sato S, Shiozaki T, Kato M, Ohyama T. A new and simple method for evaluating masticatory function using newly developed artificial test food. J Oral Rehabil. 2003;30(1):68-73.

Sears D, Fillmore G, Bui M, Rodriguez J. Evaluation of gastric bypass patients 1 year after surgery: changes in quality of life and obesity-related conditions. Obes Surg. 2008;18(12):1522-5.

Sebring NG, Guckes AD, Li SH, McCarthy GR. Nutritional adequacy of reported intake of edentulous subjects treated with new conventional or implant-supported mandibular dentures. J Prosthet Dent. 1995;74(4):358-63.

Sheiham A, Steele JG, Marcenes W, Finch S, Walls AW. The relationship between oral health status and Body Mass Index among older people: a national survey of older people in Great Britain. Br Dent J. 2002;192(12):703-6.

Sheiham A. Dietary effects on dental diseases. Public Health Nutr. 2001;4(2B):569-91.

Shi CS, Ouyang G, Guo TW. Comparison of food particle distribution masticated by subjects wearing complete dentures and with natural teeth. J Oral Rehabil. 1990;17(6):611-5.

Sierpinska T, Golebiewska M, Dlugosz JW. The relationship between masticatory efficiency and the state of dentition at patients with non rehabilitated partial lost of teeth. Adv Med Sci. 2006;51 Suppl 1:196-9.

Slade GD, Spencer AJ, Locker D, Hunt RJ, Strauss RP, Beck JD. Variations in the social impact of oral conditions among older adults in South Australia, Ontario, and North Carolina. J Dent Res. 1996;75(7):1439-50.

Slade GD, Spencer AJ. Development and evaluation of the Oral Health Impact Profile. Community Dent Health. 1994;11(1):3-11.

Slagter AP, Olthoff LW, Bosman F, Steen WH. Masticatory ability, denture quality, and oral conditions in edentulous subjects. J Prosthet Dent. 1992;68(2):299-307.

Smith PW, McCord JF. What do patients expect from complete dentures?. J Dent. 2004;32(1):3-7.

Suda S, Matsugishi K, Seki Y, Sakurai K, Suzuki T, Morita S, Hanada K, Hara K. 
A multiparametric analysis of occlusal and periodontal jaw reflex characteristics in young adults with normal occlusion. J Oral Rehabil. 1997;24(8):610-3.

Suter M, Giusti V, Heraief E, Zysset F and Calmes JM. Laparoscopic Roux-en Y gastric bypass: initial 2-year experience. Surg Endosc. 2003;17(4):603-9.

Svensson P, Arendt-Nielsen L, Nielsen H, Larsen JK. Effect of chronic and experimental jaw muscle pain on pain-pressure threshold and stimulus-response curves. J Orofac Pain. 1995;9(4):347-56.

Touger-Decker R. Diet, cardiovascular disease and oral health: promoting health and reducing risk. J Am Dent Assoc. 2010;141(2):167-70.

Tsakos G, Herrick K, Sheiham A, Watt RG. Edentulism and fruit and vegetable intake in low-income adults. J Dent Res. 2010;89(5):462-7.

Tsuga K, Carlsson GE, Osterberg T, Karlsson S. Self-assessed masticatory ability in relation to maximal bite force and dental state in 80 -year-old subjects. J Oral Rehabil. 1998;25(2):117-24.

Valezi AC, Mali Júnior J, Brito EM, Marson AC. Gastroplastia vertical com bandagem em Y-de-Roux: análise de resultados. Rev Col Bras Cir. 2004;31(1):49-56.

van der Bilt A, Fontijn-Tekamp FA. Comparison of single and multiple sieve methods for the determination of masticatory performance. Arch Oral Biol. 2004;49(2):155-60.

Visscher CM, Lobbezoo F, de Boer W, van der Zaag J, Verheij JG, Naeije M. Clinical tests in distinguishing between persons with or without craniomandibular or cervical spinal pain complaints. Eur J Oral Sci. 2000;108(6):475-83.

Wang Y, Beydoun MA. The obesity epidemic in the United States--gender, age, socioeconomic, racial/ethnic, and geographic characteristics: a systematic review and meta-regression analysis. Epidemiol Rev. 2007;29:6-28.

Wilding RJ, Adams LP, Lewin A. Absence of association between a preferred chewing side and its area of functional occlusal contact in the human dentition.Arch Oral Biol. 1992;37(5):423-8.

Wolk A, Rossner S. Obesity and self-perceived health in Sweden. Int J Obes Relat Metab Disord. 1996;20(4):369-72.

Wood N, Johnson RB, Streckfus CF. Comparison of body composition and periodontal disease using nutritional assessment techniques: Third National Health and Nutrition Examination Survey (NHANES III). J Clin Periodontol. 2003;30(4):321-7.

World Health Organization (WHO). Obesity: pre-venting and managing the global epidemic. Geneva: WHO; 2000. 
Yadav SK, Sehgal S. Effect of home processing on ascorbic acid and betacarotene content of spinach (Spinacia oleracia) and amaranth (Amaranthus tricolor) leaves. Plant Foods Hum Nutr. 1995;47(2):125-31.

Yuan JC, Lee DJ, Afshari FS, Galang MT, Sukotjo C. Dentistry and obesity: a review and current status in u.s. Predoctoral dental education. J Dent Educ. 2012;76(9):1129-36.

Yurkstas A, Manly RS. Value of different test foods in estimating masticatory ability. J Appl Physiol. 1950;3(1):45-53.

Yurkstas A. The effect of masticatory exercise on the maximum force tolerance of individual teeth. J Dent Res. 1953;32(3):322-7.

Yurkstas AA,EmersonWH. Dietary selections of persons with natural and artificial teeth. J Prosthetdent 1964;14:695-7.

Zawawi KH, Al-Badawi EA, Lobo SL, Melis M, Mehta NR. An index for the measurement of normal maximum mouth opening. J Can Dent Assoc. 2003;69(11):737-41. 
Apêndices 





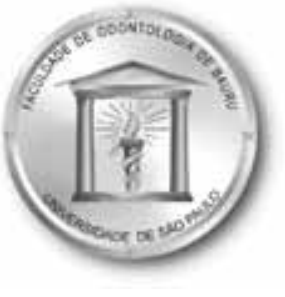

\section{Universidade de São Paulo Faculdade de Odontologia de Bauru}

Al. Dr. Octávio Pinheiro Brisolla, 9-75 - Bauru-SP - CEP 17012-901 - C.P. 73 PABX (0XX14)3235-8000 - FAX (0XX14)3223-4679

\section{TERMO DE CONSENTIMENTO LIVRE E ESCLARECIDO}

Você foi selecionado para participar de uma pesquisa para avaliar a função muscular e capacidade mastigatória e sua correlação com a obesidade e cirurgia bariátrica. O objetivo desse estudo é observar pacientes obesos que tenham perdas de unidades dentárias posteriores se haverá perda da capacidade mastigatória e defasagem da função muscular e se há correlação com a obesidade. A obtenção desses dados nos permitirá conhecer melhor as condições mastigatórias e como a musculatura se comporta e tentar interferir nas possíveis alterações em ambos os aspectos decorrentes da perda de dentes antes e após a cirurgia bariátrica.

\section{Sua participação nesse estudo é completamente voluntária.}

Caso concorde em participar da pesquisa, precisaremos que você responda a um questionário, onde um examinador previamente treinado fará os questionamentos a respeito da sua capacidade mastigatória. Nesse primeiro momento será também realizado mais dois testes: uma algometria, que é um teste que utiliza um aparelho que simula a ponta de um dedo indicador. Nesse aparelho o pesquisador irá pressionar alguns músculos relacionados com a sua mastigação e quando se perceber que deixa de ser pressão e passa a ser o mínimo de desconforto ou dor o $\operatorname{Sr}(a)$ deverá pressionar um botão onde irá realizar o registro de quão resistente é seu músculo a pressão. E um teste de eficiência mastigatória, onde o selecionado irá realizar ciclos mastigatórios com alimentos testes ( castanha de caju ) e depois depositar o bolo alimentar em tâmisas ( peneiras ) para avaliação das partículas. O tempo total para a realização dos testes é cerca de 1 hora e meia.

Todos os dados coletados são sigilosos. Você poderá tirar duvidas a respeito desse estudo ou desistir de participar em qualquer momento no decorrer da pesquisa.

Os dados encontrados serão informados para você ao final do estudo.

Caso não queira participar do estudo, sinta-se livre para fazê-lo, sem nenhum prejuízo pra você. 
Se necessitar de mais esclarecimentos a respeito dessa pesquisa, por favor, entre em contato com Mestrando Francisco Juliherme Pires de Andrade (14) 81502792 ou no Departamento de Saúde Coletiva, Ortodontia e Odontopediatria (14) 32358260. Caso tenha dúvidas sobre o aspecto ético ou o andamento da pesquisa, entre em contato com o Comitê de Ética em Pesquisa da Fundação Amaral Carvalho (CEPFAC) que a aprovou pelo número (14) 36021194 - ramal 1552 falar com Dr Éderson.

Pelo presente instrumento que atende às exigências legais, o Sr. (a)

portador da cédula de identidade , após leitura minuciosa das informações constantes neste TERMO DE CONSENTIMENTO LIVRE E ESCLARECIDO, devidamente explicada pelos profissionais em seus mínimos detalhes, ciente dos serviços e procedimentos aos quais será submetido, não restando quaisquer dúvidas a respeito do lido e explicado, firma seu CONSENTIMENTO LIVRE E ESCLARECIDO concordando em participar da pesquisa proposta.

Fica claro que o sujeito da pesquisa ou seu representante legal, pode a qualquer momento retirar seu CONSENTIMENTO LIVRE E ESCLARECIDO e deixar de participar desta pesquisa e ciente de que todas as informações prestadas tornar-se-ão confidenciais e guardadas por força de sigilo profissional (Art. $9^{\circ}$ do Código de Ética Odontológica).

Por estarem de acordo assinam o presente termo.

Bauru-SP, de de 


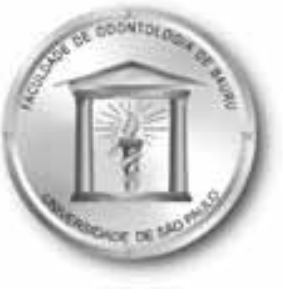

\section{Universidade de São Paulo Faculdade de Odontologia de Bauru}

Al. Dr. Octávio Pinheiro Brisolla, 9-75 - Bauru-SP - CEP 17012-901 - C.P. 73 PABX (0XX14)3235-8000 - FAX (0XX14)3223-4679

\section{TERMO DE CONSENTIMENTO LIVRE E ESCLARECIDO}

Você foi selecionado para participar de uma pesquisa para avaliar a função muscular e capacidade mastigatória e sua correlação com a obesidade e cirurgia bariátrica. O objetivo desse estudo é observar pacientes obesos com indicação a cirurgia bariátrica que tenha uma oclusão funcional, ou seja, possuam dentes naturais ou próteses fixas e que consigam mastigar bem com ambos, para avaliar sua capacidade mastigatória e condição da função muscular e se há correlação com a obesidade. A obtenção desses dados nos permitirá conhecer melhor as condições mastigatórias e como a musculatura se comporta no processo pré cirúrgico e tentar interferir nas possíveis alterações em ambos os aspectos antes e após a cirurgia bariátrica.

\section{Sua participação nesse estudo é completamente voluntária.}

Caso concorde em participar da pesquisa, precisaremos que você responda a um questionário, onde um examinador previamente treinado fará os questionamentos a respeito da sua capacidade mastigatória. Nesse primeiro momento será também realizado mais dois testes: uma algometria, que é um teste que utiliza um aparelho que simula a ponta de um dedo indicador. Nesse aparelho o pesquisador irá pressionar alguns músculos relacionados com a sua mastigação e quando se perceber que deixa de ser pressão e passa a ser o mínimo de desconforto ou dor o $\operatorname{Sr}(a)$ deverá pressionar um botão onde irá realizar o registro de quão resistente é seu músculo a pressão.Esse teste indicará o quanto resistente a esforços seu músculo se apresenta antes da cirurgia, já que no pós operatório eles deverão estar aptos para uma nova dieta. E um teste de eficiência mastigatória, onde o selecionado irá realizar ciclos mastigatórios com alimentos testes ( castanha de cajú ) e depois depositar o bolo alimentar em tâmisas ( peneiras ) para avaliação das partículas. 0 tempo total para a realização dos testes é cerca de 1 hora e meia.

Todos os dados coletados são sigilosos. Você poderá tirar duvidas a respeito desse estudo ou desistir de participar em qualquer momento no decorrer da pesquisa.

Os dados encontrados serão informados para você ao final do estudo. 
Caso não queira participar do estudo, sinta-se livre para fazê-lo, sem nenhum prejuízo pra você.

Se necessitar de mais esclarecimentos a respeito dessa pesquisa, por favor, entre em contato com Mestrando Francisco Juliherme Pires de Andrade (14) 81502792 ou no Departamento de Saúde Coletiva, Ortodontia e Odontopediatria (14) 32358260. Caso tenha dúvidas sobre o aspecto ético ou o andamento da pesquisa, entre em contato com o Comitê de Ética em Pesquisa da Fundação Amaral Carvalho (CEPFAC) que a aprovou pelo número (14) 36021194 - ramal 1552 falar com Dr Éderson.

Pelo presente instrumento que atende às exigências legais, o Sr. (a)

portador da cédula de identidade após leitura minuciosa das informações constantes neste TERMO DE CONSENTIMENTO LIVRE E ESCLARECIDO, devidamente explicada pelos profissionais em seus mínimos detalhes, ciente dos serviços e procedimentos aos quais será submetido, não restando quaisquer dúvidas a respeito do lido e explicado, firma seu CONSENTIMENTO LIVRE E ESCLARECIDO concordando em participar da pesquisa proposta.

Fica claro que o sujeito da pesquisa ou seu representante legal, pode a qualquer momento retirar seu CONSENTIMENTO LIVRE E ESCLARECIDO e deixar de participar desta pesquisa e ciente de que todas as informações prestadas tornar-se-ão confidenciais e guardadas por força de sigilo profissional (Art. $9^{\circ}$ do Código de Ética Odontológica).

Por estarem de acordo assinam o presente termo.

Bauru-SP, de de 
APÊNDICE C. Ficha para coleta de dados (Capacidade e Eficiência mastigatória; LDP; EAV e OHIP)

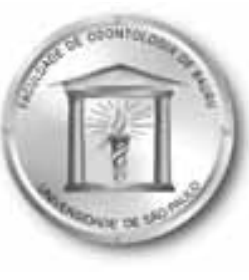

\section{Universidade de São Paulo Faculdade de Odontologia de Bauru}

Al. Dr. Octávio Pinheiro Brisolla, 9-75 - Bauru-SP - CEP 17012-901 - C.P. 73 PABX (0XX14)3235-8000 - FAX (0XX14)3223-4679

FICHA CLÍNICA

Dados Pessoais

Prontuário $\mathrm{n}^{\circ}$

Nome

Data de Nascimento

Naturalidade

Estado Civil Profissão

Endereço Residencial:

Endereço Profissional:

Percepção sobre a necessidade de prótese e capacidade mastigatória:

01. Na sua concepção, você necessita usar algum tipo de prótese dentária?

( ) $\operatorname{Sim}($ ) Não

02. Você está impossibilitado de mastigar algum tipo de alimento que gostaria de comer?

( ) Sim ( ) Não

Que tipos? ( ) sólidos; ( ) pastosos; ( ) líquidos.

( ) duros; ( ) macios; ( ) pegajosos. ( ) secos; ( ) umedecidos.

Por quê? (Dor? A prótese movimenta-se? Muito tempo para mastigar

referido alimento?)

03. Que tipos de alimentos você tem mais dificuldade de mastigar?

04. Você precisa fazer algum preparo especial nos alimentos para poder mastigá-los? (cozinhar, cortar em pedaços menores, umedecer)

( ) $\operatorname{Sim}($ ) Não

O quê precisa fazer?

05. Você consegue mastigar normalmente os alimentos abaixo especificados?

A - Cenoura fresca ( ) sim ( ) não

B - Salada de alface ( ) sim ( ) não

C - Carne moída ( ) sim ( ) não

$D$ - Legumes cozidos ( ) sim ( ) não

E - Bife de carne vermelha ( ) sim ( ) não

F - Carnes brancas (aves e peixe) ( ) sim ( ) não

G - Maçã, pêra, goiaba ( ) sim ( ) não

06. Você precisa fazer força para engolir os alimentos após a mastigação dos mesmos?

( ) $\operatorname{sim}($ ) não

07. Você acha que está conseguindo fragmentar (mastigar) os alimentos em pedaços pequenos o suficiente antes de engoli-los?

( ) $\operatorname{sim}($ ) não 
08. Você mastiga com todos os dentes de suas próteses?

( ) $\operatorname{sim}$ ( ) não Edentado

09. Você mastiga de apenas um lado?

( ) sim ( ) não Dentado

somente com lado esquerdo ( )

somente com lado direito ( )

somente com os dentes anteriores ( )

somente com os dentes posteriores ( )

Não consegue mastigar com todos os dentes por quê? A prótese desloca-

se? Machuca a gengiva? Não consegue morder alimentos em

algum dos lados?

Mesmo mastigando apenas em um dos lados, sua mastigação é boa?

( ) $\operatorname{sim}$ ( )não

10. Em relação às outras pessoas, você leva mais tempo para mastigar

os alimentos durante as refeições?

( ) $\operatorname{sim}$ ( ) não

11. Você está satisfeito com o tempo que leva para mastigar durante

as refeições?

( ) $\operatorname{sim}($ ) não

Por quê?

12. Você evita comer junto com outras pessoas?

( ) $\operatorname{sim}($ ) não

Por quê? (As próteses fazem barulho? Medo que as próteses caiam?

Demora muito tempo para mastigar e engolir? Outros?

13. Baseado nas respostas das questões acima, observando sua capacidade de mastigar vários tipos de alimentos, sejam macios ou duros, dê uma nota de 0 (zero) a 10 (dez) para sua Capacidade

Mastigatória (CM). Nota :

Capacidade mastigatória variando de 0 a 70 de acordo com os resultados de sim e de não.

\section{Eficiência Mastigatória}

( ) Eficiência Mastigatória Ótima (Em1): ausência de partículas maiores que 4,75 mm e presença de poucas partículas maiores que $4 \mathrm{~mm}$ após a fragmentação da castanha por 10 segundos.

( ) Eficiência Mastigatória Boa (Em2): ausência de partículas maiores que 4,75 mm e presença de poucas partículas maiores que $4 \mathrm{~mm}$ após a fragmentação da castanha por 20 segundos.

( ) Eficiência Mastigatória Regular (Em3): presença de poucas partículas maiores que 4,75 $\mathrm{mm}$ e $4 \mathrm{~mm}$ após a fragmentação da castanha por 20 segundos.

( ) Eficiência Mastigatória Ruim (Em4): paciente não se enquadra nas classificações EM1, EM2, EM3; entretanto, não há presença de partículas de 4,75 mm após a fragmentação da castanha por 40 segundos.

( ) Eficiência Mastigatória Péssima (Em5): presença de partículas de 4,75 mm após a fragmentação da amêndoa por 40 segundos 


\section{Exame intra-oral}

Marcar com um X os elementos ausentes.

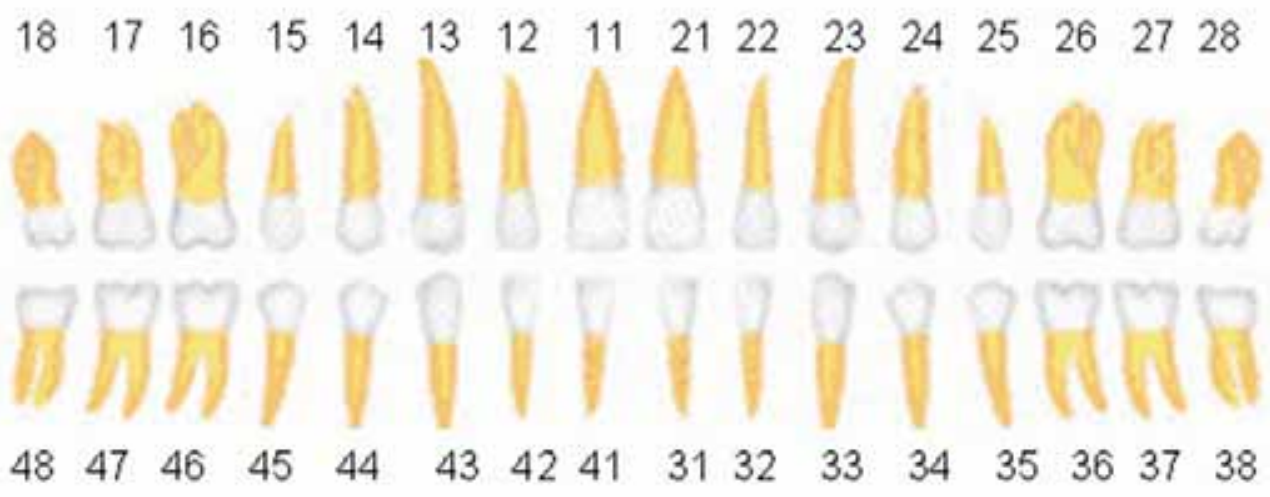

\section{Exame extra-oral:}

Abertura Bucal:

Inicial:

$\mathrm{mm}$

Pós-reabilitação protética:

$\mathrm{mm}$

Pós-cirurgia bariátrica: $\mathrm{mm}$

\section{Plano de Tratamento}

$\begin{array}{ll}\text { ( ) Prótese Parcial Fixa } & \text { ( ) Superior ( ) Inferior } \\ \text { ( ) Prótese Parcial Removível } & \text { ( ) Superior ( ) Inferior } \\ \text { ( ) Prótese Total } & \text { ( ) Superior ( ) Inferior }\end{array}$

\begin{tabular}{|c|c|c|}
\hline Data & $\begin{array}{c}\text { Evolução e Intercorrências do } \\
\text { Tratamento }\end{array}$ & Assinatura \\
\hline & & \\
\hline & & \\
\hline & & \\
\hline & & \\
\hline & & \\
\hline & & \\
\hline & & \\
\hline & & \\
\hline & & \\
\hline & & \\
\hline
\end{tabular}




\section{AVALIAÇÃO e REAVALIAÇÃO LDP E EAV}

Data:

Nome:

Escala de Análise Visual

Sem dor

Pior Dor Imaginável

Indique a média de seu nível de dor neste momento, marcando com uma linha vertical a escala abaixo, a extremidade esquerda indica a ausência total de dor e a direita indica a pior dor imaginável.

\begin{tabular}{|l|l|l|l|}
\hline Sítio Muscular & LDP 1 & LDP 2 & Média \\
\hline Temporal anterior & & & \\
\hline Temporal médio & & & \\
\hline $\begin{array}{l}\text { Temporal } \\
\text { posterior }\end{array}$ & & \\
\hline Masseter corpo & & & \\
\hline
\end{tabular}

Em relação ao conforto:

Manteve-se ( )

Alterou para melhor ( )

Alterou para pior ( )

Não sabe ( )

Abertura Máxima Ativa: $\mathrm{mm}$

EXAMINADOR: 


\section{OHIP-14}

\begin{tabular}{|c|c|}
\hline \multicolumn{2}{|c|}{$\begin{array}{l}\text { Marque a resposta que desejar lembrando que as perguntas se referem aos problemas que podem te } \\
\text { ocorrido com você no último ano. }\end{array}$} \\
\hline $\begin{array}{l}1 \text { - você teve problemas em pronunciar alguma palavra por } \\
\text { causa de problemas com seus dentes, boca ou dentaduras? }\end{array}$ & $\begin{array}{c}\text { (0) nunca (1) raramente } \\
(2) \text { às vezes ( } 3 \text { ) repetidamente } \\
\text { (4) sempre }\end{array}$ \\
\hline $\begin{array}{l}2 \text { - você sentiu que o seu paladar piorou por causa de } \\
\text { problemas com seus dentes, boca ou dentaduras? }\end{array}$ & $\begin{array}{c}\text { (0) nunca (1) raramente } \\
\text { (2) às vezes (3) repetidamente } \\
(4) \text { sempre }\end{array}$ \\
\hline 3 - você teve dores na sua boca? & $\begin{array}{c}\text { (0) nunca (1) raramente } \\
\text { (2) às vezes (3) repetidamente } \\
(4) \text { sempre }\end{array}$ \\
\hline $\begin{array}{l}4 \text { - você já achou desconfortável mastigar algum alimento por } \\
\text { causa de problemas com seus dentes, boca ou dentaduras? }\end{array}$ & $\begin{array}{c}\text { (0) nunca (1) raramente } \\
\text { (2) às vezes (3) repetidamente } \\
(4) \text { sempre }\end{array}$ \\
\hline $\begin{array}{c}5 \text { - você esteve preocupado por causa de problemas } \\
\text { dentários? }\end{array}$ & $\begin{array}{c}\text { (0) nunca (1) raramente } \\
\text { (2) às vezes (3) repetidamente } \\
\text { (4) sempre }\end{array}$ \\
\hline $\begin{array}{l}6 \text { - você se sentiu tenso por causa de problemas com seus } \\
\text { dentes, boca ou dentaduras? }\end{array}$ & $\begin{array}{c}\text { (0) nunca (1) raramente } \\
\text { (2) às vezes (3) repetidamente } \\
\text { (4) sempre }\end{array}$ \\
\hline $\begin{array}{l}7 \text { - sua alimentação ficou prejudicada por causa de } \\
\text { problemas com seus dentes, boca ou dentaduras? }\end{array}$ & $\begin{array}{c}\text { (0) nunca (1) raramente } \\
\text { (2) às vezes (3) repetidamente } \\
\text { (4) sempre }\end{array}$ \\
\hline $\begin{array}{l}8 \text { - você teve que parar suas refeições por causa de } \\
\text { problemas com seus dentes, boca ou dentaduras? }\end{array}$ & $\begin{array}{c}\text { (0) nunca (1) raramente } \\
\text { (2) às vezes (3) repetidamente } \\
(4) \text { sempre }\end{array}$ \\
\hline $\begin{array}{l}9 \text { - você teve dificuldade de relaxar por causa de problemas } \\
\text { com seus dentes, boca ou dentaduras? }\end{array}$ & $\begin{array}{l}\text { (0) nunca (1) raramente } \\
\text { (2) às vezes (3) repetidamente } \\
\text { (4) sempre }\end{array}$ \\
\hline $\begin{array}{l}10 \text { - você ficou envergonhado por causa de problemas com } \\
\text { seus dentes, boca ou dentaduras? }\end{array}$ & $\begin{array}{c}\text { (0) nunca (1) raramente } \\
\text { (2) às vezes (3) repetidamente } \\
(4) \text { sempre }\end{array}$ \\
\hline $\begin{array}{l}11 \text { - você ficou um pouco irritado com outras pessoas por } \\
\text { causa de problemas com seus dentes, boca ou dentaduras? }\end{array}$ & $\begin{array}{c}\text { (0) nunca (1) raramente } \\
\text { (2) às vezes (3) repetidamente } \\
\text { (4) sempre }\end{array}$ \\
\hline $\begin{array}{c}12 \text { - você teve dificuldades em fazer suas atividades diárias } \\
\text { por causa de problemas com seus dentes, boca ou } \\
\text { dentaduras? }\end{array}$ & $\begin{array}{c}\text { (0) nunca (1) raramente } \\
\text { (2) às vezes (3) repetidamente } \\
(4) \text { sempre }\end{array}$ \\
\hline $\begin{array}{l}13 \text { - você sentiu que a vida em geral ficou pior por causa de } \\
\text { problemas com seus dentes, boca ou dentaduras? }\end{array}$ & $\begin{array}{c}\text { (0) nunca (1) raramente } \\
\text { (2) às vezes (3) repetidamente } \\
\text { (4) sempre }\end{array}$ \\
\hline $\begin{array}{l}14 \text { - você teve sua capacidade de trabalho reduzida por } \\
\text { causa de problemas com seus dentes, boca ou dentaduras? }\end{array}$ & $\begin{array}{c}\text { (0) nunca (1) raramente } \\
\text { (2) às vezes (3) repetidamente } \\
(4) \text { sempre }\end{array}$ \\
\hline
\end{tabular}


APÊNDICE D. Ficha para o teste de Fadiga Mastigatória

\section{Universidade de São Paulo Faculdade de Odontologia de Bauru}

Al. Dr. Octávio Pinheiro Brisolla, 9-75 - Bauru-SP - CEP 17012-901 - C.P. 73

PABX (0XX14)3235-8000 - FAX (0XX14)3223-4679

Ficha Fadiga Muscular

Nome:

Data:

Inicial

\begin{tabular}{|l|l|l|l|}
\hline Sítio Muscular & LDP 1 (DIR) & LDP 2 (ESQ) & Média \\
\hline Temporal anterior & & & \\
\hline Temporal médio & & & \\
\hline $\begin{array}{l}\text { Temporal } \\
\text { posterior }\end{array}$ & & & \\
\hline Masseter corpo & & & \\
\hline
\end{tabular}

P3 - EAV ( Mascando )

Escala de Análise Visual

Sem dor

Pior Dor

Imaginável

Indique a média de seu nível de dor neste momento, marcando com uma linha vertical a escala abaixo, a extremidade esquerda indica a ausência total de dor e a direita indica a pior dor imaginável.

P6 - EAV ( Mascando )

Escala de Análise Visual

Sem dor

Pior Dor

Imaginável 
P9 - EAV ( Mascando )

Escala de Análise Visual

Sem dor

Pior Dor

Imaginável

Mascar chiclete por 9 minutos ( P9 )

\begin{tabular}{|l|l|l|l|}
\hline Sítio Muscular & LDP 1 (DIR) & LDP 2 (ESQ) & Média \\
\hline Temporal anterior & & & \\
\hline Temporal médio & & & \\
\hline $\begin{array}{l}\text { Temporal } \\
\text { posterior }\end{array}$ & & & \\
\hline Masseter corpo & & & \\
\hline
\end{tabular}

P12 - EAV ( Respuso )

Escala de Análise Visual

Sem dor

Imaginável

Pior Dor

Indique a média de seu nível de dor neste momento, marcando com uma linha vertical a escala abaixo, a extremidade esquerda indica a ausência total de dor e a direita indica a pior dor imaginável.

P15 - EAV ( Respuso )

Escala de Análise Visual

Sem dor

Pior Dor

Imaginável

P18 - EAV ( Respuso )

Escala de Análise Visual 


\section{Repouso 9 Minutos ( P18)}

\begin{tabular}{|l|l|l|l|}
\hline Sítio Muscular & LDP 1 (DIR) & LDP 2 (ESQ) & Média \\
\hline Temporal anterior & & & \\
\hline Temporal médio & & & \\
\hline $\begin{array}{l}\text { Temporal } \\
\text { posterior }\end{array}$ & & & \\
\hline Masseter corpo & & & \\
\hline
\end{tabular}


APÊNDICE E. Tabelas dos valores do LDP e suas médias para o grupo experimental e controle

\begin{tabular}{|c|c|c|c|c|c|c|c|c|}
\hline Músculo & Tempo & Média & $\begin{array}{l}\text { Desvio } \\
\text { Padrão }\end{array}$ & $\mathbf{n}$ & df & p & $\mathrm{Cl}$ - & $\mathrm{Cl}+$ \\
\hline \multirow{3}{*}{$\begin{array}{l}\text { (1)Temporal } \\
\text { Anterior }\end{array}$} & Inicial & 2,85 & $\pm 0,86$ & \multirow{3}{*}{60} & \multirow{3}{*}{29} & \multirow{3}{*}{$0,005^{*}$} & \multirow{3}{*}{0,95} & \multirow{3}{*}{5,22} \\
\hline & & & & & & & & \\
\hline & Final & 2,54 & $\pm 0,56$ & & & & & \\
\hline \multirow{3}{*}{$\begin{array}{l}\text { (1)Temporal } \\
\text { Médio }\end{array}$} & Inicial & 3,60 & $\pm 1,20$ & \multirow{3}{*}{60} & \multirow{3}{*}{29} & \multirow{3}{*}{$0,004^{*}$} & \multirow{3}{*}{1,21} & \multirow{3}{*}{5,82} \\
\hline & & & & & & & & \\
\hline & Final & 3,25 & $\pm 0,97$ & & & & & \\
\hline \multirow{3}{*}{$\begin{array}{l}\text { (1)Temporal } \\
\text { Posterior }\end{array}$} & Inicial & 3,43 & $\pm 0,97$ & \multirow{3}{*}{60} & \multirow{3}{*}{29} & \multirow{3}{*}{0,653} & \multirow{3}{*}{$-1,28$} & \multirow{3}{*}{2,01} \\
\hline & & & & & & & & \\
\hline & Final & 3,40 & $\pm 1,08$ & & & & & \\
\hline \multirow{3}{*}{ (1)Masseter } & Inicial & 2,21 & $\pm 0,61$ & \multirow{3}{*}{60} & \multirow{3}{*}{29} & \multirow{3}{*}{0,351} & \multirow{3}{*}{$-1,13$} & \multirow{3}{*}{3,09} \\
\hline & & & & & & & & \\
\hline & Final & 2,11 & $\pm 0,48$ & & & & & \\
\hline \multirow{3}{*}{$\begin{array}{l}\text { (2)Temporal } \\
\text { Anterior }\end{array}$} & Inicial & 2,94 & $\pm 0,88$ & \multirow{3}{*}{60} & \multirow{3}{*}{29} & & & \\
\hline & & & & & & $0,002^{*}$ & 1,28 & 5,63 \\
\hline & Final & 2,59 & $\pm 0,64$ & & & & & \\
\hline (2)Temporal & Inicial & 3,48 & $\pm 1,02$ & & & & & \\
\hline & & & & 60 & 29 & 0,990 & $-2,03$ & 2,06 \\
\hline & Final & 3,48 & $\pm 1,00$ & & & & & \\
\hline (2)Temporal & Inicial & 3,97 & $\pm 1,30$ & & & & & \\
\hline Posterior & & & & 60 & 29 & $0,009^{*}$ & 1,08 & 7,19 \\
\hline & Final & 3,55 & $\pm 1,03$ & & & & & \\
\hline (2)Masseter & Inicial & 1,96 & $\pm 0,81$ & & & & & \\
\hline & & & & 60 & 29 & $0,006^{*}$ & $-3,60$ & $-0,65$ \\
\hline & Final & 2,18 & $\pm 0,83$ & & & & & \\
\hline Média & Inicial & 2,90 & $\pm 0,81$ & & & & & \\
\hline $\begin{array}{l}\text { Anterior (1) } \\
\text { e (2) }\end{array}$ & Final & 2,57 & $\pm 0,58$ & 60 & 29 & $0,001^{*}$ & 1,34 & 5,19 \\
\hline Média & Inicial & 3,55 & $\pm 1,03$ & & & & & \\
\hline $\begin{array}{c}\text { lemporal } \\
\text { médio (1) e } \\
(2)\end{array}$ & Final & 3,36 & $\pm 0,91$ & 60 & 29 & 0,073 & $-0,19$ & 3,99 \\
\hline Média & Inicial & 3,70 & $\pm 1,11$ & & & & & \\
\hline posterior (1) & & & & 60 & 29 & $0,037^{*}$ & 0,14 & 4,35 \\
\hline e (2) & Final & 3,47 & $\pm 1,01$ & & & & & \\
\hline Média & Inicial & 2,08 & $\pm 5,30$ & & & & & \\
\hline Masseter (1) & & & & 60 & 29 & 0,277 & $-0,16$ & 0,48 \\
\hline e (2) & Final & 2,14 & $\pm 6,00$ & & & & & \\
\hline
\end{tabular}

\begin{tabular}{ccccccccc}
\hline $\begin{array}{c}\text { LDP Experimental(V1) } \mathbf{x} \\
\text { Controle(V2) }\end{array}$ & $\begin{array}{c}\text { Média } \\
\text { V1 }\end{array}$ & $\begin{array}{c}\text { Média } \\
\text { V2 }\end{array}$ & t & df & p & n (V1) & n (V2) \\
\hline LDP1 Temp Anterior (V1) X & 2,547 & 2,706 & $-0,737$ & 42 & 0,464 & 60 & 30
\end{tabular}




\begin{tabular}{|c|c|c|c|c|c|c|c|}
\hline LDP1 Temporal Anterior (V2) & & & & & & & \\
\hline $\begin{array}{l}\text { LDP1 Temporal Médio (V1) X } \\
\text { LDP1 Temporal Médio (V2) }\end{array}$ & 3,253 & 3,618 & $-1,137$ & 42 & 0,261 & 60 & 30 \\
\hline \multicolumn{8}{|l|}{ LDP1 Temporal Posterior (V1) } \\
\hline $\begin{array}{c}\text { X LDP1 Temporal Posterior } \\
\text { (V2) }\end{array}$ & 3,400 & 3,699 & $-0,961$ & 42 & 0,341 & 60 & 30 \\
\hline $\begin{array}{c}\text { LDP Experimental(V1) x } \\
\text { Controle(V2) }\end{array}$ & $\begin{array}{c}\text { Média } \\
\text { v1 }\end{array}$ & $\begin{array}{c}\text { Média } \\
\text { V2 }\end{array}$ & $\mathbf{t}$ & df & $\mathbf{p}$ & n (V1) & n (V2) \\
\hline $\begin{array}{c}\text { LDP1 Masseter (V1) X LDP1 } \\
\text { Masseter (V2) }\end{array}$ & 2,112 & 2,794 & $-3,218$ & 42 & $0,002^{*}$ & 60 & 30 \\
\hline $\begin{array}{l}\text { LDP2 Temporal Anterior (V1) } \\
\text { X LDP2 Temporal Anterior(V2) }\end{array}$ & 2,599 & 2,942 & $-1,274$ & 42 & 0,209 & 60 & 30 \\
\hline $\begin{array}{l}\text { LDP2 Temporal Médio (V1) X } \\
\text { LDP2 Temporal Médio (V2) }\end{array}$ & 3,486 & 3,844 & $-1,072$ & 42 & 0,289 & 60 & 30 \\
\hline \multicolumn{8}{|l|}{ LDP2 Temporal Posterior (V1) } \\
\hline $\begin{array}{c}\text { X LDP2 Temporal Posterior } \\
\text { (V2) }\end{array}$ & 3,557 & 3,954 & $-1,208$ & 42 & 0,233 & 60 & 30 \\
\hline $\begin{array}{c}\text { LDP2 Masseter (V1) X LDP2 } \\
\text { Masseter (V2) }\end{array}$ & 2,182 & 2,792 & $-2,080$ & 42 & 0,043 & 60 & 30 \\
\hline \multicolumn{8}{|l|}{ Média Temporal Anterior (V1) } \\
\hline $\begin{array}{c}\text { X Média Temporal Anterior } \\
\text { (V2) }\end{array}$ & 2,573 & 2,806 & $-0,980$ & 42 & 0,332 & 60 & 30 \\
\hline $\begin{array}{l}\text { Média Temporal Médio (V1) X } \\
\text { Média Temporal Médio (V2) }\end{array}$ & 3,361 & 3,731 & $-1,206$ & 42 & 0,234 & 60 & 30 \\
\hline $\begin{array}{c}\text { Média Temporal Posterior } \\
\text { (V1) X Média Temporal } \\
\text { Posterior (V2) }\end{array}$ & 3,478 & 3,777 & $-0,951$ & 42 & 0,346 & 60 & 30 \\
\hline $\begin{array}{c}\text { Média Masseter (V1) X Média } \\
\text { Masseter (V2) }\end{array}$ & 2,147 & 2,778 & $-2,614$ & 42 & 0,012 & 60 & 30 \\
\hline
\end{tabular}


APÊNDICE F - Análise através do teste t de Student analisando os tempos do grupo experimental.

Análise do GE para a questão - Você está impossibilitado de mastigar algum alimento que gostaria de comer?

\begin{tabular}{llcrrrr}
\hline Variável & Média & Desvio Padrão & N & df & p & IC (95\%) \\
Q 2 & 0,733333 & $\pm 0,449776$ & & & & \\
Q 2 final & 0,000000 & $\pm 0,000000$ & 60 & 29 & 0,000 & $0,565-0,901$ \\
\hline
\end{tabular}

Análise do GE para a questão - Você precisa fazer algum preparo especial nos alimentos para poder mastigá-los?

\begin{tabular}{lllllll}
\hline Variável & Média & Desvio Padrão & N & df & p & IC(95\%) \\
Q 4 & 0,600000 & $\pm 0,498273$ & & & & $0,167-0,632$ \\
Q 4 final & 0,200000 & $\pm 0,406838$ & 60 & 29 & 0,001 & \\
\hline
\end{tabular}

Análise do GE para a questão - Você consegue mastigar normalmente CENOURA FRESCA?

\begin{tabular}{lllllll}
\hline Variável & Média & Desvio Padrão & N & df & $\mathbf{p}$ & IC(95\%) \\
Q 5 A & 0,233333 & $\pm 0,430183$ & & & & \\
Q 5 A final & 0,733333 & $\pm 0,449776$ & 60 & 29 & 0,000 & $-0,689-(-0,310)$ \\
\hline
\end{tabular}

Análise do GE para a questão - Você consegue mastigar normalmente SALADA DE ALFACE?

\begin{tabular}{lllllll}
\hline Variável & Média & Desvio Padrão & N & df & p & IC $(95 \%)$ \\
\hline Q 5 B & 0,700000 & $\pm 0,466092$ & & & & \\
Q 5 B Final & 1,000000 & $\pm 0,000000$ & 60 & 29 & 0,001 & $-0,474-(-0,125)$ \\
\hline
\end{tabular}

Análise do GE para a questão - Você consegue mastigar normalmente CARNE MOÍDA?

\begin{tabular}{lllllll}
\hline Variável & Média & Desvio Padrão & N & df & p & IC(95\%) \\
\hline Q 5 C & 0,933333 & $\pm 0,253708$ & 60 & 29 & 0,160 & $-0,161-0,028$
\end{tabular}


Q 5 C Final $1,000000 \quad \pm 0,000000$

Análise do GE para a questão - Você consegue mastigar normalmente LEGUMES COZIDOS?

\begin{tabular}{lllllll}
\hline Variável & Média & Desvio Padrão & N & df & P & IC(95\%) \\
\hline Q 5 D & 0,933333 & $\pm 0,253708$ & & & & \\
Q 5 D Final & 1,000000 & $\pm 0,000000$ & 60 & 29 & 0,160 & $-0,161-0,028$
\end{tabular}

Análise do GE para a questão - Você consegue mastigar normalmente BIFE DE CARNE VERMELHA?

\begin{tabular}{lllllll}
\hline Variável & Média & Desvio Padrão & N & df & p & IC $(\mathbf{9 5 \%})$ \\
\hline Q 5 E & 0,233333 & $\pm 0,430183$ & & & & \\
Q 5 E final & 0,933333 & $\pm 0,253708$ & 60 & 29 & 0,000 & $-0,874-(-0,525)$ \\
\hline
\end{tabular}

Análise do GE para a questão - Você consegue mastigar normalmente CARNES BRANCAS(AVES E PEIXES)?

\begin{tabular}{lllllll}
\hline Variável & Média & Desvio Padrão & N & df & p & IC(95\%) \\
\hline Q 5 F & 0,733333 & $\pm 0,449776$ & & & & \\
Q 5 F Final & 1,000000 & $\pm 0,000000$ & 60 & 29 & 0,002 & $-0,434-(-0,098)$ \\
\hline
\end{tabular}

Análise do GE para a questão - Você consegue mastigar normalmente MAÇÃ, PÊRA E GOIABA?

\begin{tabular}{lllllll}
\hline Variável & Média & Desvio Padrão & N & df & p & IC(95\%) \\
\hline Q 5 G & 0,066667 & $\pm 0,253708$ & & & & \\
Q 5 G Final & 0,933333 & $\pm 0,253708$ & 60 & 29 & 0,000 & $-0,995-(-0,737)$ \\
\hline
\end{tabular}

Análise do GE para a questão - Você precisa fazer força para engolir os alimentos após a mastigação?

\begin{tabular}{lllllll}
\hline Variável & Média & Desvio Padrão & N & df & p & IC (95\%) \\
\hline Q 6 & 0,466667 & $\pm 0,507416$ & & & &
\end{tabular}




\begin{tabular}{lllllll}
\hline Q 6 final & 0,000000 & $\pm 0,000000$ & 60 & 29 & 0,000 & $0,277-0,656$
\end{tabular}

Análise do GE para a questão - Você acha que está conseguindo fragmentar (mastigar) os alimentos em pedaços pequenos o suficiente antes de engoli-los?

\begin{tabular}{lllllll}
\hline Variável & Média & Desvio Padrão & N & df & P & IC (95\%) \\
\hline Q 7 & 0,233333 & $\pm 0,430183$ & & & & \\
Q 7 final & 1,000000 & $\pm 0,000000$ & 60 & 29 & 0,000 & $-0,927-(-0,606)$
\end{tabular}

Análise do GE para a questão - Você mastiga com todos os dentes ou com todos os dentes da sua prótese?

\begin{tabular}{lllllll}
\hline Variável & Média & Desvio Padrão & N & df & p & IC(95\%) \\
\hline Q 8 & 0,066667 & $\pm 0,253708$ & & & & \\
Q 8 final & 0,666667 & $\pm 0,479463$ & 60 & 29 & 0,000 & $-0,786-(-0,413)$ \\
\hline
\end{tabular}

Análise do GE para a questão - Você mastiga de apenas um lado?

\begin{tabular}{lllllll}
\hline Variável & Média & Desvio Padrão & $\mathbf{N}$ & $\mathbf{d f}$ & $\mathbf{P}$ & IC (95\%) \\
\hline Q 9 & 0,533333 & $\pm 0,507416$ & & & & \\
Q 9 Final & 0,466667 & $\pm 0,507416$ & 60 & 29 & 0,572 & $-0,172-0,305$
\end{tabular}

As tabelas 23 a 26 faz referência a repercussão social e de relacionamento do hábito mastigatório.

Análise do GE para a questão - (Q10) Em relação às outras pessoas, você leva mais tempo pra mastigar os alimentos durante as refeições?

\begin{tabular}{lllllll}
\hline Variável & Média & Desvio Padrão & N & df & $\mathbf{p}$ & IC(95\%) \\
\hline Q 10 & 0,733333 & $\pm 0,449776$ & & & & \\
Q 10 final & 0,733333 & $\pm 0,449776$ & 60 & 29 & 1,000 & $-0,196-0,196$ \\
\hline
\end{tabular}


Análise do GE para a questão - Você está satisfeito com o tempo que leva pra mastigar durante as refeições?

\begin{tabular}{lllllll}
\hline Variável & Média & Desvio Padrão & N & df & $\mathbf{p}$ & IC(95\%) \\
\hline Q 11 & 0,500000 & $\pm 0,508548$ & & & & \\
Q 11 Final & 1,0000 & $\pm 0,00000$ & 60 & 29 & 0,000 & $-0,689-(-0,310)$ \\
\hline
\end{tabular}

Análise do GE para a questão - Você evita comer junto com outras pessoas?

\begin{tabular}{lllllll}
\hline Variável & Média & Desvio Padrão & N & df & p & IC(95\%) \\
\hline Q 12 & 0,400000 & $\pm 0,498273$ & & & & \\
Q 12 final & 0,100000 & $\pm 0,305129$ & 60 & 29 & 0,004 & $0,100-0,499$ \\
\hline
\end{tabular}

Análise do GE para a questão - Baseado nas respostas do teste, observando sua capacidade de mastigar vários alimentos, sejam macios ou duros, dê uma nota de 0 a 10 para sua capacidade de mastigatória.

\begin{tabular}{lllllll}
\hline Variavel & Média & Desvio Padrão & N & df & $\mathbf{p}$ & IC $(\mathbf{9 5 \%})$ \\
\hline Q 13 & 4,266667 & $\pm 3,117618$ & & & & \\
Q 13 final & 8,833333 & $\pm 1,147211$ & 60 & 29 & 0,000 & $-5,634-(-3,498)$ \\
\hline
\end{tabular}


APÊNDICE G. Comparação da Capacidade Mastigatória após reabilitação oral com o Capacidade Mastigatória do grupo controle

\begin{tabular}{|c|c|c|c|c|c|c|c|}
\hline \multirow[t]{2}{*}{ Variável 1 vs Variável2 } & Média & Média & $\mathbf{t}$ & df & $p$ & n (V1) & n (V2) \\
\hline & V1 & V2 & & & & & \\
\hline Q2 final vs Q 2 Controle & 0,200 & 0,000 & 1,8278 & 42 & 0,074 & 60 & 30 \\
\hline Q4 final vs Q 4 Controle & 0,200 & 0,000 & 1,8278 & 42 & 0,074 & 60 & 30 \\
\hline Q5A final vs $Q 5 A$ Controle & 0,733 & 1,000 & $-2,204$ & 42 & 0,033 & 60 & 30 \\
\hline Q5B final vs Q 5B Controle & 0,933 & 1,000 & $-0,977$ & 42 & 0,334 & 60 & 30 \\
\hline Q5C final vs Q 5C Controle & 0,933 & 1,000 & $-0,977$ & 42 & 0,334 & 60 & 30 \\
\hline Q5D final vs $Q$ 5D Controle & 0,933 & 1,000 & $-0,977$ & 42 & 0,334 & 60 & 30 \\
\hline Q5E final vs Q 5E Controle & 0,933 & 1,000 & $-0,977$ & 42 & 0,334 & 60 & 30 \\
\hline Q5F final vs Q 5F Controle & 0,933 & 1,000 & $-0,977$ & 42 & 0,334 & 60 & 30 \\
\hline Q5G final vs Q 5G Controle & 0,933 & 1,000 & $-0,977$ & 42 & 0,334 & 60 & 30 \\
\hline Q6 final vs Q 6 Controle & 0,933 & 1,000 & $-0,977$ & 42 & 0,334 & 60 & 30 \\
\hline Q7 final vs Q 7 Controle & 0,933 & 1,000 & $-0,977$ & 42 & 0,334 & 60 & 30 \\
\hline Q8 final vs Q 8 Controle & 0,666 & 0,000 & 5,1698 & 42 & 0,000 & 60 & 30 \\
\hline Q9 final vs $Q 9$ Controle & 0,466 & 0,000 & 3,4195 & 42 & 0,001 & 60 & 30 \\
\hline Q10 final vs Q10 Controle & 0,733 & 0,577 & 1,0633 & 42 & 0,293 & 60 & 30 \\
\hline Q11 final vs Q 11 Controle & 0,100 & 0,000 & 1,2185 & 42 & 0,229 & 60 & 30 \\
\hline Q12 final vs $Q 12$ Controle & 0,100 & 0,000 & 1,2185 & 42 & 0,229 & 60 & 30 \\
\hline Q13 final vs $Q 13$ Controle & 8,833 & 8,571 & 0,8131 & 42 & 0,420 & 60 & 30 \\
\hline
\end{tabular}




Anexos 


ANEXO A - Aprovação do Comitê de Ética em Pesquisa em Seres Humanos, FOB/USP

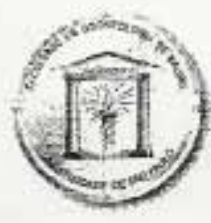

Processo ne 014/2011

Bauru, 30 de març de 2011

\section{Universidade de São Paulo Faculdade de Odontologia de Bauru}

Al. Dr. Octavio Pinheiro Brísolla, 9-75-Bainu-SP-CEP.17012-901 - C.P. 73 PABX (0XX14)3235-8000 - FAX (0XX14)3223-4679

Comite de Etica em Qesquisa (14)3235 8356

miferrari(Mfob.usp.br

Senhora Professora,

Informanus que após o envio da documenteçio solicitada, o projeto de pésqulsa encaminhado a este

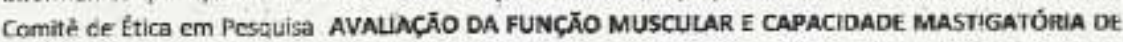
PACIENTES OBESOS COM INDICAÇÂQ PARA CIRURGIA BARIÁTRICA, de autoria de FrancisCo Julihermie Pires de Andräde, sob sua orientaçäo, foi novamente analisado e considerado AProvaDO por este Colerpiado, em reuniáo realizada no dia 30 de março de 2011.

Solicitamos que ao término do trabalho, seja envisdo a este Comitê um relatóric final para nowo parecer, a qual será utilizado para publicação cientifica.

Atenciosamente.

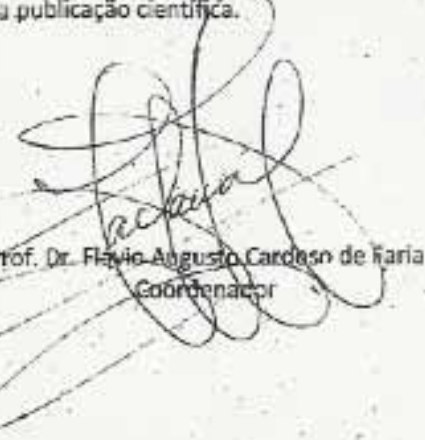

Profi Dril Silvia Helena de Carvalho Sales Peres

Docente do Deparamento de Ocontupediatria, Ortodontia e Saúde Coletiva 
ANEXO B - Aprovação do Comitê de Ética em Pesquisa em Seres Humanos, Hospital Amaral Carvalho/Jaú/SP

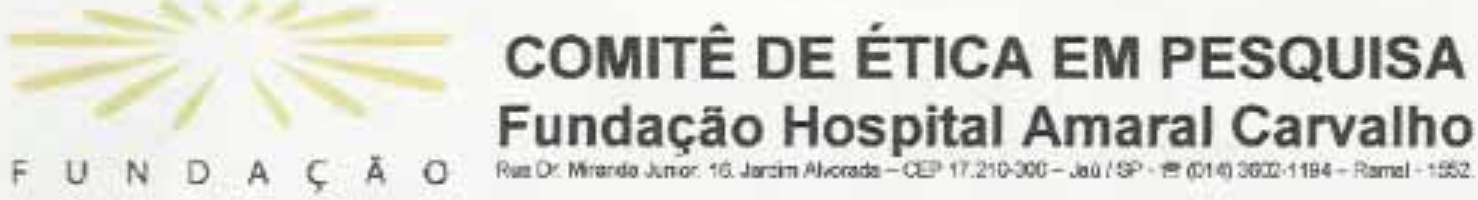

Parecer CEPFHAC - $111 / 11$ - Recurso.

Projeto de Pesquisa:

Avaliaçẵo da Funçảa Muscular e Capacidade Mastigatória de Pacientes Obesos com Indicação á Cirurgia Bariátrice

Documentos Analisados:

$\checkmark$ Oficio de Encaminhamento, datado de 17 de novembro de 2011;

$\checkmark$ Termo de Confidencialidade, datado de 17 de novembro de 2011;

$\checkmark$ Novo Termo de Consentimento Live e Esclarecido, recebido em 21 de novembro de 2011

Responsável pelo Estudo:

Autor: Francisco Juliherme Pires de Andrade - Círurgiä́o Dentista - Aluno da pós graduaçăo do programa de Odontologia cm Saúde Colotiva da Faculdade de Odontologia da USP - Bauru/SP

Orientadora: Silvia Helena de Carvalho Sales-Peres - Cirurgiā Dentista - Professora Associada da Faculdade de Odontologia da USP - Bauru'SP

Trata-se de recurso ao Parecer CEPFHAC $\mathrm{n}^{\mathrm{e}}$. 111/11, datado de 28 de outubro de 2011, onde os documentos avaliados foram considerados aprovados com recomendação, sendo esta a envio do Temmo de Confidencialidade e a inclusăo no Termo de Consenfimento Livre e Esclarecido da informaçấo de que năo haverá custos para o paciente se o mesmo acertar em participar da pesquisa.

O pesquisador apresentou um Termo de Confidencialidade e um novo Termo de Consentimento Livre e Esclarecido. com a referida recomendaçāo.

Não há qualquer outro entrave ético que possa impossibilitar o inicio da pesquisa.

Diante do exposto, manifestamo-nos pela aprovaçāo sem restriçðes dos documentos avaliadas.

Informamos que os referidos documentos são rubricados pelo colaborador do CEPFHAC, Ricardo Augusto Sartori, e que nenhum dos pesquisadores envolvidos no estudo participou da wolaçăo.

Aproveito para recordar-lhe do compromisso de enviar relatónios semestrais referentes à ovolução do estudo.

Jaú, 21 de novembro de 2011.

$$
\text { Edeno R.b sutle }
$$

Dr. Éderson Roberto de Mattos Coordenador do Comitè de Ética em Pesquisa Fundaçảo Hospital Amaral Carvalho 